\title{
Syntheses and transformations of
}

\section{carbamatoalkylnaphthols prepared via modified Mannich reactions}

Ph.D. Thesis

Renáta Csütörtöki

Supervisor:

Prof. Dr. Ferenc Fülöp

Institute of Pharmaceutical Chemistry

University of Szeged 
"We learn wisdom from failure much more than from success. We often discover what will do, by finding out what will not do; and probably he who never made a mistake never made a discovery."

(Samuel Smiles) 


\section{CONTENTS}

CONTENTS ii

PUBLICATIONS. .iii

List of abbreviations $\mathrm{V}$

1. INTRODUCTION AND AIMS 1

\section{LITERATURE BACKGROUND}

Syntheses of amido-, carbamido- and carbamatoalkylnaphthols...................................................... 3

2.1. Syntheses of amidoalkylnaphthols ......................................................................................... 4

2.1.1. Syntheses of amidoalkylnaphthols from nitriles........................................................... 4

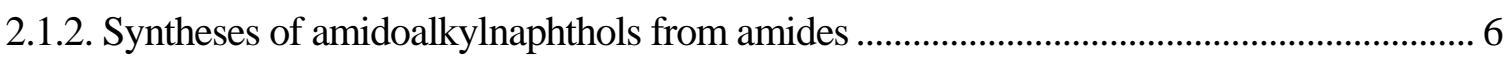

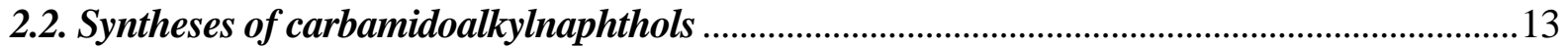

2.3. Syntheses of thioamido- and thiocarbamidoalkylnaphthols ..................................................19

2.3.1. Syntheses of thioamidoalkylnaphthols................................................................................ 19

2.3.2. Syntheses of thiocarbamidoalkylnaphthols..................................................................... 19

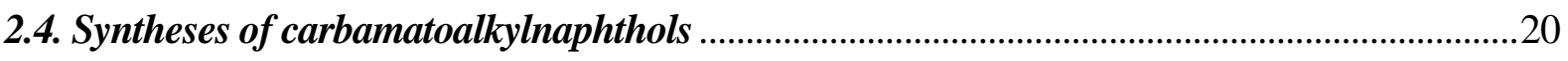

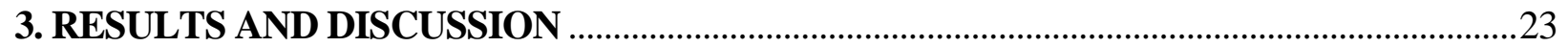

3.1. Syntheses of hydroxynaphthyl-substituted $\alpha$-amino acid derivatives......................................23

3.2. Syntheses and conformational analyses of naphthoxazine-fused quinazoline derivatives ....27

3.2.1. Syntheses of naphthoxazinoquinazoline derivatives ..........................................................2

3.2.2. Conformational study of naphthoxazinoquinazoline derivatives .......................................37

3.2.2.1. Conformational analysis of naphth[1,2-e][1,3] oxazino[3,4-c]quinazolines ........37

3.2.2.2. Conformational analysis of naphth[1,2-e][1,3] oxazino[3,2-c]quinazolinones ...39

3.2.2.3. Conformational analysis of piperidine-fused quinazolino- and benzoxazinonaphthoxazines 


\section{PUBLICATIONS}

\section{Papers related to the thesis}

I. Renáta Csütörtöki, István Szatmári, Attila Mándi, Tibor Kurtán, Ferenc Fülöp

Synthesis of hydroxynaphthyl-substituted $\alpha$-amino acid derivatives via a modified Mannich reaction

Synlett 2011, 1940-1946.

II. Renáta Csütörtöki, István Szatmári, Andreas Koch, Matthias Heydenreich, Erich Kleinpeter, Ferenc Fülöp

Synthesis and conformational analysis of new naphth[1,2-e][1,3]oxazino[3,4-c]quinazoline derivatives

Tetrahedron 2011, 67, 8564-8571.

IF: 3.011

III. Renáta Csütörtöki, István Szatmári, Andreas Koch, Matthias Heydenreich, Erich Kleinpeter, Ferenc Fülöp

Syntheses and conformational analyses of new naphth[1,2-e][1,3]oxazino[3,2-c]quinazolin-13ones

Tetrahedron 2012, 68, 4600-4608.

IF: 3.011

IV. Renáta Csütörtöki, István Szatmári, Matthias Heydenreich, Andreas Koch, Ines Starke, Ferenc Fülöp, Erich Kleinpeter

Novel piperidine-fused benzoxazino- and quinazolinonaphthoxazines - synthesis and conformational study

Tetrahedron 2012, 68, 6284-6288.

IF: 3.011

V. Renáta Csütörtöki, István Szatmári, Ferenc Fülöp

Syntheses of amido-, carbamido- and carbamatoalkylnaphthols

Current Organic Synthesis, submitted. 


\section{Conference lectures}

\section{Csütörtöki Renáta}

Módosított Mannich-reakció alkalmazása új funkcionalizált aminonaftol-származékok szintézisére

XXXII. Kémiai Előadói Napok

Szeged, 2009. október 26-28. Absztr.: 105.

\section{Csütörtöki Renáta}

Módosított Mannich-reakció alkalmazása $\alpha$-aminosav-származékok szintézisére

A Szegedi Ifjú Szerves Kémikusok Támogatásáért Alapitvány 10. tudományos elöadóülése Szeged, 2010. május 5.

VIII. István Szatmári, Renáta Csütörtöki, Andreas Koch, Matthias Heydenreich, Erich Kleinpeter, Ferenc Fülöp

Synthesis and conformational analysis of new naphth[1,2-e][1,3]oxazino[3,4-c]quinazoline derivatives

$X I V^{\text {th }}$ Conference on Heterocycles in Bio-organic Chemistry

Brno, Czech Republic, September 4-8, 2011. Abstr.: P-30.

IX. Ines Starke, Renáta Csütörtöki, Andreas Koch, Erich Kleinpeter, István Szatmári, Ferenc Fülöp

Mass spectrometric behaviour of new naphth[1,2-e][1,3]oxazino[3,2-c]quinazolin-13-ones Joint Conference of Polish Mass Spectrometry Society and German Mass Spectrometry Society Poznań, Poland, March 4-7, 2012. Abstr.: P-90.

X. Renáta Csütörtöki, István Szatmári, Andreas Koch, Matthias Heydenreich, Erich Kleinpeter, Ferenc Fülöp

Synthesis and conformational analysis of naphth[1,2-e][1,3]oxazino[3,2-c]quinazolin-13-ones

$X_{\text {XI }}^{\text {th }}$ Eurasia Conference on Chemical Sciences

Corfu, Greece, April 16-21, 2012. Abstr.: S3-PP5.

XI. Csütörtöki Renáta, Szatmári István, Fülöp Ferenc

Naftoxazinnal kondenzált kinazolin-származékok szintézise és konformáció-analízise

Heterociklusos és Elemorganikus Kémiai Munkabizottság ülése

Balatonszemes, 2012. június 6-8. 


\section{List of abbreviations}

\begin{tabular}{|c|c|c|}
\hline$[\mathrm{Bmim}] \mathrm{HSO}_{4}$ & $=$ & 1-Butyl-3-methylimidazolium hydrogensulfate \\
\hline$[\mathrm{Bmim}] \mathrm{Br}$ & $=$ & 1-Butyl-3-methylimidazolium bromide \\
\hline DAIL & $=$ & Dicationic acidic ionic liquid \\
\hline DCE & $=$ & 1,2-Dichloroethane \\
\hline$[\mathrm{Dsim}] \mathrm{Cl}$ & $=$ & 1,3-Disulfonic acid imidazolium chloride \\
\hline [FemSILP] & $=$ & Ferrocene labelled-supported ionic liquid phase \\
\hline $\mathrm{Hf}\left(\mathrm{NPf}_{2}\right)_{4}$ & $=$ & Hafnium(IV) bis(perfluorooctanesulfonyl)imide \\
\hline HMDS & $=$ & Hexamethyldisiloxane \\
\hline$[\mathrm{Hmim}] \mathrm{HSO}_{4}$ & $=$ & Methylimidazolium hydrogensulfate \\
\hline $\mathrm{IL}$ & $=$ & Ionic liquid \\
\hline$[\mathrm{MIMPS}]\left[\mathrm{HSO}_{4}\right]$ & $=$ & 1-Methyl-3-propanesulfonic acid imidazolium hydrogensulfate \\
\hline $\mathrm{mMR}$ & $=$ & Modified Mannich reaction \\
\hline$[\mathrm{Msim}] \mathrm{AlCl}_{4}$ & $=$ & 3-Methyl-1-sulfonic acid imidazolium tetrachloroaluminate \\
\hline$[\mathrm{Msim}] \mathrm{Cl}$ & $=$ & 3-Methyl-1-sulfonic acid imidazolium chloride \\
\hline$[\mathrm{NMP}]^{+} \mathrm{HSO}_{4}^{-}$ & $=$ & $N$-Methyl-2-pyrrolidone hydrogensulfate \\
\hline $\mathrm{Nph}$ & $=$ & Naphthyl \\
\hline PEG & $=$ & Poly(ethylene glycol) \\
\hline $\mathrm{Ph}$ & $=$ & Phenyl \\
\hline $\mathrm{PPA} / \mathrm{SiO}_{2}$ & $=$ & Silica-supported polyphosphoric acid \\
\hline PS & $=$ & Polystyrene \\
\hline TCT & $=$ & 2,4,6-Trichloro-1,3,5-triazine \\
\hline$[\mathrm{TEBSA}]\left[\mathrm{HSO}_{4}\right]$ & $=$ & $N$-(4-Sulfonic acid)butyl-triethylammonium hydrogensulfate \\
\hline TFA & $=$ & Trifluoroacetic acid \\
\hline THF & $=$ & Tetrahydrofuran \\
\hline TMSCl & $=$ & Chlorotrimethylsilane \\
\hline$p$-TSA & $=$ & para-Toluenesulfonic acid \\
\hline
\end{tabular}




\section{INTRODUCTION AND AIMS}

More than one hundred years ago, Mario Betti reported a straightforward synthesis of 1-( $\alpha$-aminobenzyl)-2-naphthol (the Betti base), ${ }^{1-5}$ starting from 2-naphthol, benzaldehyde and $\mathrm{NH}_{3}$. The Betti procedure can be interpreted as a modified Mannich reaction (mMR). The formaldehyde in the formal Mannich procedure is replaced by an aromatic aldehyde, the secondary amine by $\mathrm{NH}_{3}$ and the $\mathrm{C}-\mathrm{H}$ acid by an electron-rich aromatic compound such as 2-naphthol. Thanks to the variability of this reaction through the use of different electron-rich aromatic compounds (2- or 1-naphthol, quinolinols, isoquinolinols, etc.), aldehydes and a number of nitrogen sources ( $\mathrm{NH}_{3}$ or amines), it has become a hot topic in organic chemistry. The reaction conditions and the method for the isolation of the synthetized Mannich products are determined to a considerable extent by the character of the nitrogen source used $\left(\mathrm{NH}_{3}\right.$ or amine). ${ }^{6}$

Since one of the most important areas of application of aminonaphthols prepared via mMRs is the synthesis of new heterocycles, ${ }^{7}$ my Ph.D. work focused on the synthesis of novel trifunctional aminonaphthol derivatives. I therefore set out to prepare hydroxynaphthyl-substituted glycines (I and II) as new $\alpha$-amino acid derivatives by starting from 1- or 2-naphthol. As aminononaphthol derivatives I and II contain one chiral centre, the separation of their enantiomers by a chiral HPLC technique was a further aim.
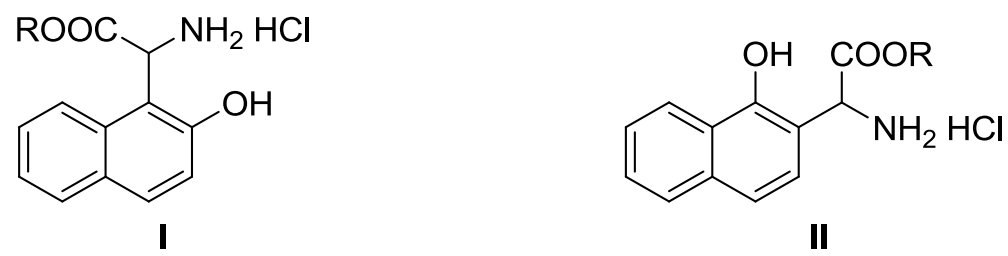

In previous studies, naphth[1,2-e][1,3] oxazino[1,3]benzoxazines were prepared through the ring closure of hydroxylated aminonaphthol or naphthoxazine derivatives with oxo compounds. $^{8,9}$ The syntheses of naphth[1,2-e][1,3] oxazinoisoquinolines were achieved via the cyclization of 1-( $\beta$-hydroxynaphthyl)-1,2,3,4-tetrahydroisoquinoline or through the unexpected reactions between 1-aminobenzyl-2-naphthols and 3,4-dihydroisoquinolines. ${ }^{10,11}$

In order to extend the series of naphthoxazino-fused heterocyclic ring systems during my Ph.D. work, the syntheses of naphth[1,2-e][1,3] oxazino[3,4-c]quinazoline derivatives (IV) via the ring closure of diaminonaphthol III were planned. 
<smiles>Nc1ccccc1C(N)c1c(O)ccc2ccccc12</smiles>

III

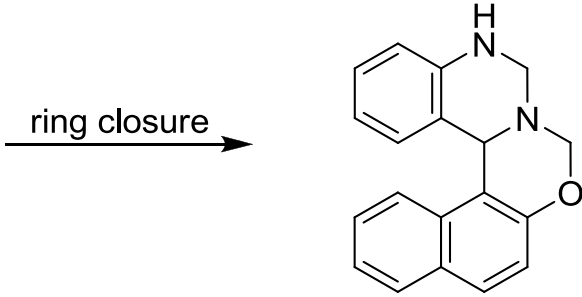

IV

In order to compare the naphthoxazine-fused quinazolines from the aspect of their conformational behaviour, I additionally set out to prepare naphth[1,2-e][1,3] oxazino[3,2-c]quinazolines (VI) through the cyclization of anilinonaphthoxazine $\mathbf{V}$ with oxo compounds.<smiles>Nc1ccccc1C1NCc2c(ccc3ccccc23)O1</smiles><smiles>[GeH3]C[GeH3]</smiles><smiles>C1=Cc2ccc3c4c2-c2ccccc2CN(CNC4=C1)O3</smiles>

Another goal was the conformational analysis of the newly prepared naphth[1,2-e][1,3]oxazinoquinazolines (IV and VI) by means of NMR spectroscopy and accompanying molecular modelling.

In order to capitalize on all three functional groups in 1-(amino(2-aminophenyl)methyl)-2naphthol and 1-(amino(2-hydroxyphenyl)methyl)-2-naphthol ${ }^{9}$ at the same time, it was decided to investigate their reactions with dialdehydes, with a view to obtaining new hetero- and polycyclic compounds (VII and VIII). The heterocyclic moieties in VII and VIII are flexible, and their detailed conformational analysis by NMR spectroscopy and accompanying molecular modelling therefore appeared necessary.<smiles></smiles>

VII<smiles></smiles>

$\mathrm{n}=1,2,3$

VIII 


\section{LITERATURE BACKGROUND}

\section{Syntheses of amido-, carbamido- and carbamatoalkylnaphthols}

The application of amides or their derivatives instead of $\mathrm{NH}_{3}$ or amines in the $\mathrm{mMR}$ can be interpreted as a special alteration. The research group of Möhrle successfully introduced the use of amides to synthetize 2-acetamidoalkyl-1-naphthol ${ }^{12}$ and 7-benzamidoalkyl-8-quinolinol. ${ }^{13}$ The desired products were isolated in low yields (7\% and 48\%) and it was found that an indirect synthetic pathway (the aminoalkylation of 8-quinolinol with benzaldehyde in the presence of $\mathrm{NH}_{3}$, followed by acylation of the intermediate Schiff base with benzoyl chloride) was more efficient for the synthesis of 7-benzamidoalkyl-8-quinolinol, e.g. milder conditions were needed and the yields could be improved. ${ }^{13}$

Since 2006, attention has again focused on the preparation of amido-, carbamido- and carbamatoalkylnaphthol derivatives, since the reaction can be accelerated dramatically by the use of various heterogeneous Lewis and Brønsted acid catalysts. ${ }^{14-16}$

The importance of these compounds is that they can easily be converted by hydrolysis of the amide and carbamide moieties to aminoalkylnaphthols with potential hypotensive and bradycardiac properties, ${ }^{17}$ they can also be transformed to 1,3-oxazine derivatives, and at higher temperatures they yield 1,3-oxazine derivatives with potentially valuable biological activities, e.g. antibiotic, antitumour, analgesic, anticonvulsant, antipsychotic, antimalarial, antianginal, antihypertensive and antirheumatic activities. ${ }^{16}$ On the other hand, following deprotection, carbamatoalkylnaphthols can serve as important starting materials for the synthesis of new building blocks with potential pharmacological activities. ${ }^{18}$

The literature on the syntheses of amido-, carbamido- and carbamatoalkylnaphthol derivatives will be reviewed. With regard to the appreciable number of publications (over 110) that have appeared in the past 6 years, the various reactions will be classified according to the types of nitrogen sources used (nitriles, amides, thioamide, ureas, thioureas or carbamates). A detailed description of the processes reported in the literature can be found in the review submitted to Current Organic Synthesis. 


\subsection{Syntheses of amidoalkylnaphthols}

\subsubsection{Syntheses of amidoalkylnaphthols from nitriles}

The preparation of a 1-amidoalkyl-2-naphthol can be interpreted as a Ritter reaction. It is suggested that the aryl aldehyde first reacts with 2-naphthol to give 1-(hydroxy(aryl)methyl)-2naphthol, which then reacts with acetonitrile (MeCN; both reactant and solvent) to produce $N$-((2-hydroxynaphthalen-1-yl)(aryl)methyl)ethanaminium as intermediate, hydrolysis of which gives the desired 1-amidoalkyl-2-naphthol.

Shaterian et al. reported the syntheses of a series of amidoalkylnaphthols from 2-naphthol, aryl aldehydes and $\mathrm{MeCN}$, successfully applying different heterogeneous acid catalysts. For example, with $\mathrm{Fe}\left(\mathrm{HSO}_{4}\right)_{3}$ as catalyst at $85{ }^{\circ} \mathrm{C}$, amidonaphthols $\mathbf{2 a - q}$ were isolated in moderate yields (47-74\%) after $20 \mathrm{~h},{ }^{17}$ while in the presence of $\mathrm{SiO}_{2}$-supported $\mathrm{FeCl}_{3}\left(\mathrm{FeCl}_{3} / \mathrm{SiO}_{2}\right),{ }^{19} \mathrm{HClO}_{4} / \mathrm{SiO}_{2}{ }^{20}$ or $\mathrm{NaHSO}_{4} \cdot \mathrm{H}_{2} \mathrm{O}^{21}$ under the same conditions, the yields were improved (60-88\%). Furthermore, they achieved the syntheses of 2a-l and 2n-r by using $\mathrm{Al}_{2} \mathrm{O}_{3}$-supported sulfonic acid $\left(\mathrm{HSO}_{3} / \mathrm{Al}_{2} \mathrm{O}_{3}\right)$ as a solid heterogeneous acid catalyst; $\mathbf{2 h}, \mathbf{q}, \mathbf{r}$, aromatic aldehydes bearing electron-donating groups, were obtained in relatively low yields (25-33\%) (Scheme 1$){ }^{22}$<smiles>Oc1ccc2ccccc2c1</smiles>

1

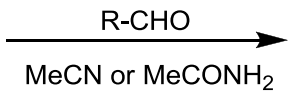<smiles>[R]C(NC(C)=O)c1c(O)ccc2ccccc12</smiles>

2a-aw

$\mathrm{R}=\mathrm{Ph}: \mathbf{a} ; 4$-F-Ph: b; 4-Cl-Ph: c; 4-Br-Ph: d; 4-NO $\mathrm{N}_{2}-\mathrm{Ph}: \mathbf{e}$; 4-Me-Ph: f; 4-OMe-Ph: $\mathbf{g}$ 4-NMe $-\mathrm{Ph}: \mathbf{h}$; 3-F-Ph: i; 3-NO ${ }_{2}-\mathrm{Ph}$ : j; 3-OMe-Ph: k; 2-Cl-Ph: I; 2-NO $-\mathrm{Ph}: \mathbf{m}$; 2-Me-Ph: $\mathbf{n}$ 2,4-Cl $2-\mathrm{Ph}: \mathbf{0} ; 2,5-(\mathrm{OMe})_{2}-\mathrm{Ph}: \mathbf{p} ; 3,4-(\mathrm{OMe})_{2}-\mathrm{Ph}: \mathbf{q} ; 3,4,5-(\mathrm{OMe})_{3}-\mathrm{Ph}: \mathbf{r}$; 4-OH-Ph: s; 2-OMe-Ph: t; 2-OH-Ph: u; 2-Br-Ph: v; 1-Nph: w; 2-Nph: $\mathbf{x}$; Et: y; 4-CN-Ph: z; 2-furyl: aa; styryl: ab; 3,4-( $\left.\mathrm{OCH}_{2} \mathrm{O}\right)-\mathrm{Ph}$ : ac; $2-\mathrm{NO}_{2}, 4,5-(\mathrm{OMe})_{2}-\mathrm{Ph}$ : ad; 2-pyrimidyl: ae; 3-Me,4-OH-Ph: af; 3,4-Cl2 $-\mathrm{Ph}$ : ag; 2-F-Ph: ah; 9-phenanthryl: ai; 2-pyrrolyl: aj; 3-Cl-Ph: ak; 2-pyridyl: al; Et: am; iPr: an; $n$-pentyl: ao; undecyl: ap; $n$ Pr: aq; $n \mathrm{Bu}$ : ar; iBu: as; cyclohexyl: at; 2,6- $\mathrm{Cl}_{2}-\mathrm{Ph}$ : au; 4-COOMe-Ph: av; 3-Br-Ph: aw

\section{Scheme 1}

A series of 1-(acetylamino(aryl)methyl)-2-naphthols were synthetized in excellent yields in the presence of $\mathrm{HSO}_{3} \mathrm{Cl}^{23}$

$\mathrm{SiO}_{2}$-supported Preyssler nanoparticles were found to be an effective catalyst for the preparation of acetamidonaphthols $\mathbf{2 a - c , e - g , j , m ~}(86-92 \%)$ in a short reaction time $(3-8 \mathrm{~min}){ }^{24}$ Liu et al. reported

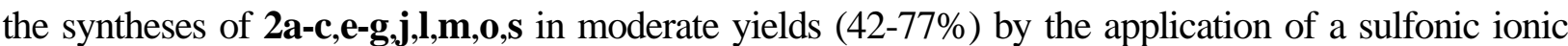
liquid (IL), methylimidazolium hydrogensulfate ([MIMPS][HSO $\left.{ }_{4}\right]$ ), in a reaction time of $25 \mathrm{~h},{ }^{25}$ while 
Zolfigol et al. described a highly efficient and simple procedure for the preparation of $\mathbf{2 a - h}, \mathbf{j}-\mathbf{0}, \mathbf{q}$ in the presence of a catalytic amount of trityl chloride $\left(\mathrm{Ph}_{3} \mathrm{CCl}\right)$ at room temperature (r.t.; Scheme 1); the reactions proceeded with high yields (83-94\%) and in relatively short reaction times $(0.75-3.5 \mathrm{~h}){ }^{26}$

The research group of Anary-Abbasinejad carried out the syntheses of acetamidonaphthols 2a-d,f,j-l,n,t at r.t. in $\mathrm{MeCN}$, induced by a mixture of $\mathrm{P}_{2} \mathrm{O}_{5}$ and hexamethyldisiloxane (HMDS; Scheme 1). To develop the above method, they also conducted the reaction with other 2-naphthol analogues, such as 3-hydroxy-2-naphthoic acid (3), aryl aldehydes and $\mathrm{MeCN}$, which afforded the corresponding 4-(acetamido(aryl)methyl)-3-hydroxy-2-naphthoic acids (4a-i, Scheme 2) in excellent yields $(90-97 \%){ }^{27}$<smiles>O=C(O)c1cc2ccccc2cc1O</smiles>

3<smiles>[X]c1cccc(C=O)c1</smiles><smiles>[X]c1ccc(C(NC(C)=O)c2c(O)c(C(=O)O)cc3ccccc23)cc1</smiles>

4a-i

$\mathrm{X}=4-\mathrm{Cl}-\mathrm{Ph}: \mathbf{a} ; 3-\mathrm{Cl}-\mathrm{Ph}: \mathbf{b} ; 2-\mathrm{Cl}-\mathrm{Ph}: \mathbf{c} ; 4-\mathrm{Me}-\mathrm{Ph}: \mathbf{d} ; 4-\mathrm{NO}_{2}-\mathrm{Ph}: \mathbf{e}$; 3-Cl-Ph: f; 4-Br-Ph: g; 3-OMe-Ph: h; 2-OMe-Ph: i

\section{Scheme 2}

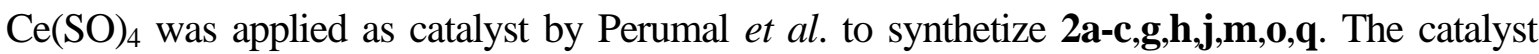
proved to be efficient enough to extend the series of aldehydes to aliphatic aldehydes and naphthaldehydes, leading to $\mathbf{2 w}, \mathbf{y}$ in moderate yields $(42-74 \%){ }^{14}$ The process was later optimized for 2a-c, $\mathbf{g}, \mathbf{h}, \mathbf{j}, \mathbf{m}, \mathbf{o}, \mathbf{q}, \mathbf{u}, \mathbf{w}, \mathbf{y}$, when, instead of heating of the reaction in $\mathrm{MeCN}$, a mixture of acetyl chloride and $4 \mathrm{~mol} \% \mathrm{I}_{2}$ was applied as catalyst (Scheme 1). ${ }^{28}$

To demonstrate the versatility of this reaction procedure, they examined the reactions with $\alpha$-substituted nitriles (2-phenylacetonitrile and valeronitrile) and substituted aldehydes, obtaining the corresponding amidoalkylnaphthols 5a-i (Scheme 3) in yields of $45-70 \%$ within 8-14 h. ${ }^{28}$

The research group of Tammadon found that $\mathrm{ZnCl}_{2} / \mathrm{SiO}_{2}$ is an efficient catalyst for the synthesis of $N$-tert-butyl amides via the Ritter reaction, and as an extension of their study they synthetized $\mathrm{N}$-((2-hydroxynaphthalen-1-yl)(phenyl)methyl)benzamide (5j, Scheme 3) from $\mathbf{1}$, benzonitrile and benzaldehyde. ${ }^{29}$ They additionally accomplished the syntheses of $\mathbf{5 j - q}$ in good yields $(84-91 \%)$ in the presence of $\left[\mathrm{MeC}(\mathrm{OH})_{2}\right]^{+} \mathrm{ClO}_{4}{ }^{-}$as a super-acidic IL (Scheme 3). ${ }^{30}$ 


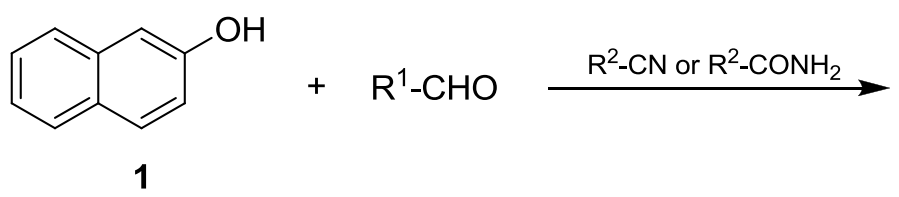<smiles>[R]C(=O)NC([R1])c1c(O)ccc2ccccc12</smiles>

$\mathrm{R}^{1} / \mathrm{R}^{2}=2,4-\mathrm{Cl}-\mathrm{Ph}, \mathrm{Bn}: \mathbf{a}$; 4-Cl-Ph, Bn: b; 3-NO $-\mathrm{Ph}, \mathrm{Bn}: \mathbf{c}$; 4-NO ${ }_{2}-\mathrm{Ph}, \mathrm{Bn}: \mathbf{d} ; 2,4-\mathrm{Cl}_{2}-\mathrm{Ph}, n \mathrm{Bu}: \mathbf{e}$;

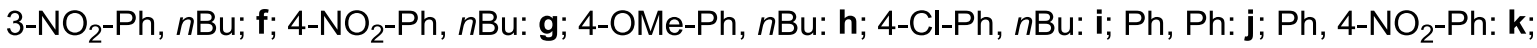
$\mathrm{Ph}, 4-\mathrm{Me}-\mathrm{Ph}: \mathrm{I} ; 4-\mathrm{Br}-\mathrm{Ph}, \mathrm{Ph}: \mathbf{m}$; 4-Br-Ph, 4-NO ${ }_{2} \mathrm{Ph}: \mathbf{n}$; 4-Cl-Ph, $\mathrm{Ph}: \mathbf{0} ; \mathrm{Ph}, n \mathrm{Pr}: \mathbf{p}$; 4-Br-Ph, 2-furyl: q;

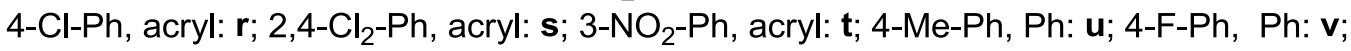
3-OMe-Ph, $\mathrm{Ph}: \mathbf{w}$; 3-NO $2-\mathrm{Ph}, \mathrm{Ph}: \mathbf{x} ; 3,4,5-(\mathrm{OMe})_{3}-\mathrm{Ph}, \mathrm{Ph}: \mathbf{y}$; 4-CN-Ph, $\mathrm{Ph}: \mathbf{z}$; 4-NO ${ }_{2}-\mathrm{Ph}, \mathrm{Ph}:$ aa; 4-OMe-Ph, $\mathrm{Ph}$ : ab; $2,5-(\mathrm{OMe})_{2}-\mathrm{Ph}, \mathrm{Ph}: \mathbf{a c} ; 4-\mathrm{NMe}_{2}-\mathrm{Ph}, \mathrm{Ph}$ : ad; 3-OMe,4-OH-Ph, $\mathrm{Ph}$ : ae; 2-Cl-Ph, $\mathrm{Ph}$ : af; 2-Br-Ph, $\mathrm{C}_{6} \mathrm{H}_{5}$ : ag; 4-Cl-Ph, 3-pyridyl: ah; $\mathrm{Ph}$, acryl: ai; 4-OMe-Ph, acryl: aj; 4-Me-Ph, acryl: ak; 3-Br-Ph, acryl: al; 2-F-Ph, $\mathrm{Ph}$ : am; 2-F-Ph, acryl: an; 2-NO ${ }_{2}-\mathrm{Ph}, \mathrm{Ph}$ : ao;

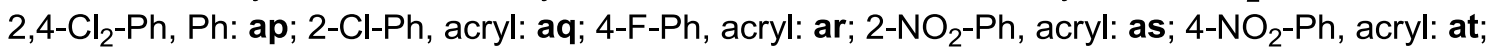
4-OH-Ph, acryl: au; 2-OMe-Ph, $\mathrm{Ph}$ : av; 4- $\mathrm{NO}_{2}-\mathrm{Ph}, \mathrm{CH}_{2} \mathrm{Cl}$ : aw; 4-Cl-Ph, $\mathrm{CH}_{2} \mathrm{Cl}$ : ax;

4-Me-Ph, $\mathrm{CH}_{2} \mathrm{Cl}$ : ay; 4-OMe-Ph, $\mathrm{CH}_{2} \mathrm{Cl}$ : az; $\mathrm{Ph}, \mathrm{CH}_{2} \mathrm{Cl}$ : ba; 1-Nph, $\mathrm{Ph}$ : bb; 4-iPr-Ph, Ph: bc; 2-Nph, Ph: bd; 9-phenanthryl, Ph: be; 1-pyrenyl, Ph: bf; styryl, Ph: bg; Et, Ph: bh; undecyl, Ph: bi; $\mathrm{Ph}, 4-\mathrm{Br}-\mathrm{Ph}: \mathbf{b j}$; 4-NO $\mathrm{N}_{2} \mathrm{Ph}, 4-\mathrm{Br}-\mathrm{Ph}$ : bk; 2-furyl, $\mathrm{Ph}: \mathbf{b l}$; 2-pyrrolyl, $\mathrm{Ph}: \mathbf{b m}$; $n \mathrm{Pr}, \mathrm{Ph}: \mathbf{b n}$; 4-Br-Ph: acryl: bo; $n \mathrm{Pr}$, acryl: bp; $i \mathrm{Pr}, \mathrm{Ph}$ : bq; 4-pyridyl, $\mathrm{Ph}$ : br

\section{Scheme 3}

Das et al. achieved the three-component condensation of $\mathbf{1}$, aryl aldehydes and alkyl nitriles in the presence of triflic acid (TfOH) at $85{ }^{\circ} \mathrm{C}$ to obtain the corresponding amidoalkylnaphthols 2a,c,e, $, \mathbf{g}, \mathbf{j}, \mathbf{o}, \mathbf{s}, \mathbf{v}, \mathbf{x}$ and 5r-t (Schemes 1 and 3). It should be mentioned that, when MeCN was used, the reaction was complete within 1.5-5 h and the yields were good to excellent (50-91\%), while with acrylonitrile the reaction time was somewhat longer $(4.5-6 \mathrm{~h})$ and the yield somewhat lower $(60-67 \%){ }^{15}$

\subsubsection{Syntheses of amidoalkylnaphthols from amides}

The syntheses of acetamidoalkylnaphthols can also be achieved by the reaction of 2-naphthol, aryl aldehydes and acetamide. In the presence of $\mathrm{Fe}\left(\mathrm{HSO}_{4}\right)_{3},{ }^{17} \mathrm{HClO}_{4} / \mathrm{SiO}_{2}{ }^{20}$ or $\mathrm{NaHSO}_{4} \cdot \mathrm{H}_{2} \mathrm{O}^{21}$ as catalyst under thermal $\left(85 / 110 / 120^{\circ} \mathrm{C}\right)$ solvent-free conditions, $2 \mathbf{2 a - q}$ were formed in good yields (73-97\%) within a short reaction time $(7-80 \mathrm{~min})$. Under microwave $(450 / 800 \mathrm{~W})$ solvent-free conditions, the yields of the synthetized compounds were higher (84-97\%) within very short reaction times (3-20 min). In the presence of $\mathrm{HSO}_{3} / \mathrm{Al}_{2} \mathrm{O}_{3}, \mathbf{2 a - 1 , n - r}$ (Scheme 1) were successfully prepared, but in the case of aryl aldehydes bearing electron-donating groups, the yields were moderate, even under microwave agitation $(37-41 \%){ }^{22}$ 
$\mathrm{FeCl}_{3} / \mathrm{SiO}_{2}{ }^{19}$ and $\mathrm{NaHSO}_{4}{ }^{31}$ were used as catalysts only under thermal $\left(120\right.$ or $\left.125^{\circ} \mathrm{C}\right)$ solvent-

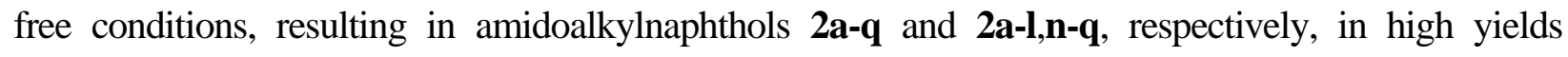
(73-94\%) within 7-40 min (Scheme 1). The series of catalysts was extended by using $\mathrm{Sr}(\mathrm{OTf})_{2}, \mathrm{LiBr}$ and $\mathrm{POCl}_{3} / \mathrm{Na}_{2} \mathrm{~B}_{4} \mathrm{O}_{7}{ }^{32-34}$

1,3-Dibromo-5,5-dimethylhydantoin was used as catalyst in the absence of organic solvent under thermal conditions $\left(100^{\circ} \mathrm{C}\right)$ or with microwave irradiation $(160 \mathrm{~W})$, affording $\mathbf{2 a - h}, \mathbf{j}-\mathbf{o}, \mathbf{q}$ in good yields $(89-96 \%)$ in reaction times of 17-28 min and 4-9 min, respectively (Scheme 1). ${ }^{35}$

The research group of Heravi applied $\mathrm{SiO}_{2}$-supported Preyssler nanoparticles under thermal $\left(90^{\circ} \mathrm{C}\right.$ ) solvent-free conditions for the preparation of acetamidonaphthols $\mathbf{2 a - c , e - g , j , m}$. The desired compounds were formed in high yields (84-96\%) after a very short reaction time (3-8 min). ${ }^{24}$ This group later investigated the efficiency of Brønsted acidic ILs in the one-pot three-component synthesis of acetamidonaphthols, both in $\mathrm{CH}_{2} \mathrm{Cl}_{2}$ and under neat conditions $\left(90{ }^{\circ} \mathrm{C}\right)$. Aromatic aldehydes underwent facile conversions (76-97\%), yielding 2a,c-g,j,.l, but aliphatic aldehydes (ethanal and $n$-octanal) afforded the products in very poor yields (traces, Scheme 1). ${ }^{36}$

The Amberlite IR-120-catalysed syntheses of $\mathbf{2 a - h , j - o , q ~ ( S c h e m e ~ 1 ) ~ w e r e ~ f o u n d ~ t o ~ p r o c e e d ~}$ efficiently within 3-6 min in the absence of any organic solvent under microwave irradiation. ${ }^{37}$

Zare et al. reported an efficient and simple new method for the preparation of 1-amidoalkyl-2naphthols as biologically interesting compounds. The one-pot multicomponent condensation of $\mathbf{1}$, aromatic aldehydes and acetamide in the IL 1-butyl-3-methylimidazolium bromide ([Bmim]Br) under microwave and catalyst-free conditions afforded 2a-f,j,l,n,o in high yields (78-94\%) and in short reaction times (25-35 min). ${ }^{38}$ They subsequently developed a clean and efficient solvent-free method

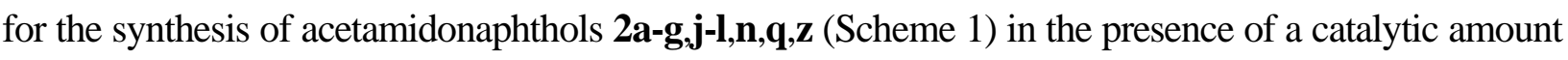
of silphox $\left[\mathrm{POCl}_{3-\mathrm{n}}\left(\mathrm{SiO}_{2}\right)_{\mathrm{n}}\right]$ or silphos $\left[\mathrm{PCl}_{3-\mathrm{n}}\left(\mathrm{SiO}_{2}\right)_{\mathrm{n}}\right]$ as inexpensive, green and heterogeneous $\mathrm{SiO}_{2}$-supported P-containing reagents. ${ }^{39}$

Nano-sulfated $\mathrm{ZrO}_{2}$ at $120^{\circ} \mathrm{C}$ under neat conditions proved to be an efficient, recyclable and

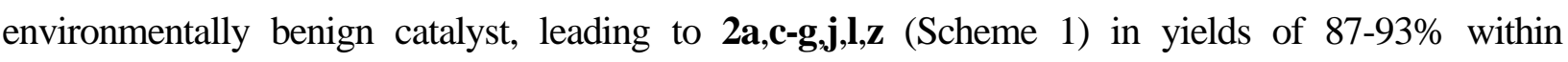
30-90 min. ${ }^{40}$

Montazeri et. al investigated the effect of a $\mathrm{SiO}_{2}$-supported Caro's acid $\left(\mathrm{H}_{2} \mathrm{SO}_{5} / \mathrm{SiO}_{2}\right)$ as catalyst under thermal $\left(140^{\circ} \mathrm{C}\right)$ and solvent-free conditions: $\mathbf{2 a}, \mathbf{c}, \mathbf{e}-\mathbf{g}, \mathbf{j}, \mathbf{l , n}$ (Scheme 1) were formed in yields of 85-95\% within 2-4 min. ${ }^{41}$

It is interesting that the syntheses of amidoalkylnaphthols 2a-g,j-l,aa (Scheme 1) in the presence of $\mathrm{KHSO}_{4}$ at $100{ }^{\circ} \mathrm{C}$ under neat conditions were reported in three different publications ${ }^{42-44}$ and the yields of the products were the same. 
Amidoalkylnaphthols 2a,c-g,j (Scheme 1) were prepared in the presence of mixed-addenda vanadium(V)-substituted polyoxomolybdates, including the heteropolyacids $\mathrm{H}_{3+\mathrm{x}} \mathrm{PMo}_{12-\mathrm{x}} \mathrm{V}_{\mathrm{x}} \mathrm{O}_{40}$ $(\mathrm{x}=1-3)$ as recyclable catalysts under solvent-free conditions. In all cases, the heteropolyacid with $\mathrm{x}=3$ gave the highest yield (84-92\%) under solvent-free conditions at $130{ }^{\circ} \mathrm{C} .{ }^{45}$

12-Tungstophosphoric acid $\left(\mathrm{H}_{3} \mathrm{PW}_{12} \mathrm{O}_{40}\right)$ was successfully applied as a heterogeneous catalyst for the syntheses of $\mathbf{2 a}, \mathbf{c}, \mathbf{e}, \mathbf{f}, \mathbf{j}, \mathbf{l}, \mathbf{n}, \mathbf{0}$ (Scheme 1). The reaction mixture was heated to $100{ }^{\circ} \mathrm{C}$ in the presence of $2 \mathrm{~mol} \%$ of catalyst for $80 \mathrm{~min}$ in 1 equivalent of molten $\mathrm{Et}_{4} \mathrm{NCl}$, furnishing the desired compounds in yields of $65-95 \%{ }^{46}$

The research group of Maheria successfully applied zeolite H-Beta as catalyst in refluxing toluene or under solvent-free conditions $\left(120^{\circ} \mathrm{C}\right)$. The reactions starting from aryl aldehydes led efficiently to the formation of $\mathbf{2 a}-\mathbf{h}, \mathbf{k}-\mathbf{m}, \mathbf{o}, \mathbf{a b}$ (Scheme 1). ${ }^{47}$

$\mathrm{InCl}_{3}$ was found to be a very efficient catalyst for the synthesis of amidoalkylnaphthols

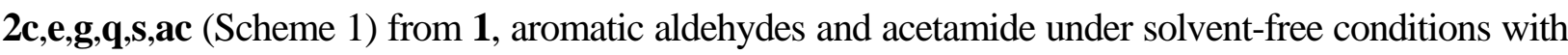
the use of microwave irradiation $(800 \mathrm{~W}) .^{48}$

Shingare et al. extended the series of aldehydes to heteroaromatic and aliphatic aldehydes. The reaction conditions were solvent-free heating at $60{ }^{\circ} \mathrm{C}$ in the presence of $[\mathrm{Bmim}] \mathrm{HSO}_{4}$, leading to

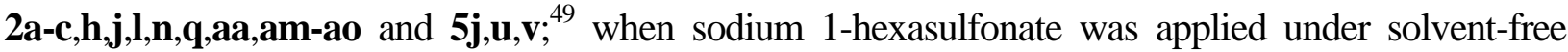
heating and microwave irradiation, ${ }^{50} \mathbf{2 a}, \mathbf{c}, \mathbf{d}, \mathbf{a m}$ and $\mathbf{5 j} \mathbf{j}, \mathbf{o , v}$ were obtained (Schemes 1 and 3 ).

Potassium dodecatungstocobaltate trihydrate $\left(\mathrm{K}_{5} \mathrm{CoW}_{12} \mathrm{O}_{40} \cdot 3 \mathrm{H}_{2} \mathrm{O}\right)$ was found to be an efficient heterogeneous catalyst for the syntheses of $\mathbf{2 a}, \mathbf{c}, \mathbf{d}, \mathbf{j}-\mathbf{l}, \mathbf{0}$ and $\mathbf{5 j}, \mathbf{o}, \mathbf{u}, \mathbf{w}$ (Schemes 1 and 3), both at r.t. in 1,2-dichloroethane (DCE) and under neat conditions at $125^{\circ} \mathrm{C}$. Aryl aldehydes underwent facile conversions (86-92\%), but aliphatic aldehydes afforded 2am,an (Scheme 1) in only trace amounts. ${ }^{51}$

The montmorillonite K10-catalysed preparation of 1-amidoalkyl-2-naphthols $\mathbf{2 a , d , j , k , o , q , r , a d ~}$ and $\mathbf{5 j}, \mathbf{x}, \mathbf{y}$ (Schemes 1 and 3) was carried out under neat conditions at $125^{\circ} \mathrm{C}$ to furnish good yields $(65-96 \%)$ within $0.5-2 \mathrm{~h}^{52}$

The research group of Mahdavinia applied $\mathrm{HClO}_{4} / \mathrm{SiO}_{2}$ at reflux temperature in DCE and under solvent-free conditions at $125{ }^{\circ} \mathrm{C},{ }^{53}$ or used wet cyanuric chloride at $100{ }^{\circ} \mathrm{C}^{54}$ to synthetize $\mathbf{2 a - d}, \mathbf{j}-\mathbf{l}, \mathbf{z}$ and $\mathbf{5 j}, \mathbf{o}, \mathbf{u}, \mathbf{v}, \mathbf{z}$ (Schemes 1 and 3). The conversions were high (85-96\%) and reaction times of 6-14 h were usually needed.

Shinde et al. achieved the synthesis of $\mathbf{2} \mathbf{j}$ and $\mathbf{5 x}$ in the presence of $\mathrm{ZrOCl}_{2},{ }^{55} \mathrm{H}_{3} \mathrm{NSO}_{3}$ (sulfamic acid) ${ }^{56}$ and $\mathrm{I}_{2}{ }^{57}$ at r.t. in DCE: $\mathrm{I}_{2}$ was found to be the most effective. They also investigated oxalic acid as catalyst at $125^{\circ} \mathrm{C}$ under solvent-free conditions in order to prepare amidoalkylnaphthols $\mathbf{2 a}, \mathbf{c}, \mathbf{e}-\mathbf{h}, \mathbf{p}, \mathbf{q}$ and $\mathbf{5 j}, \mathbf{o}, \mathbf{u}, \mathbf{a a},{ }^{58}$ while the catalytic activity of $\mathrm{H}_{3} \mathrm{PMo}_{12} \mathrm{O}_{40}$ (phosphomolybdic acid) in $\mathrm{CCl}_{4}$ at reflux 
temperature proved to be appropriate for the preparation of $\mathbf{2 a}, \mathbf{c}, \mathbf{f}, \mathbf{g}, \mathbf{j}, \mathbf{a e}$ and $\mathbf{5 j}, \mathbf{m}, \mathbf{u}, \mathbf{x}, \mathbf{a b}$ (Schemes 1 and 3). ${ }^{59}$

Shaterian et al. applied $\mathrm{Al}\left(\mathrm{H}_{2} \mathrm{PO}_{4}\right)_{3}$ as catalyst under solvent-free conditions by using classical

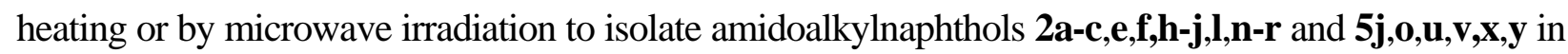
yields of $63-93 \% .{ }^{60} \mathrm{HClO}_{4} / \mathrm{Al}_{2} \mathrm{O}_{3}$ as catalyst under neat conditions at $125{ }^{\circ} \mathrm{C}$ resulted in $\mathbf{2 a - c , e , f , h - l , n - r}$ and $\mathbf{5 j}, \mathbf{o}, \mathbf{u}, \mathbf{v}, \mathbf{x}, \mathbf{y}$ in from moderate to good yields (Schemes 1 and 3). ${ }^{61}$ On $\mathrm{SiO}_{2}$-supported

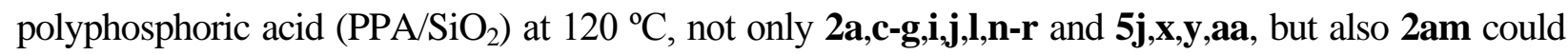
be obtained, in a yield of $49 \%$ (Schemes 1 and 3). ${ }^{62}$

A series of 1-amidoalkyl-2-naphthols $\mathbf{2 a}, \mathbf{c}, \mathbf{e}-\mathbf{g}, \mathbf{j}, \mathbf{l}, \mathbf{n}, \mathbf{o}$ and $\mathbf{5 j}, \mathbf{0}, \mathbf{u}, \mathbf{x}$ were synthetized in the presence of $\mathrm{Cu}$-exchanged heteropolyacids $\mathrm{Cu}_{1-5} \mathrm{PMo}_{12} \mathrm{O}_{40}$ and $\mathrm{Cu}_{1-5} \mathrm{PW}_{12} \mathrm{O}_{40}$ in molten $\mathrm{Bu}_{4} \mathrm{NBr}$ as an $\mathrm{IL}$ (Schemes 1 and 3). ${ }^{63}$

A Ferrocene labelled-supported ionic liquid phase ([FemSILP]) catalyst containing $L$-prolinate

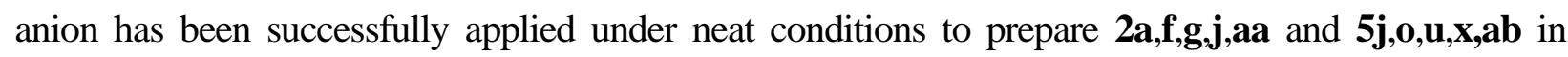
moderate yields (62-87\%; Schemes 1 and 3$){ }^{64}$

Gokavi et al. prepared amidoalkylnaphthols $\mathbf{2 a}, \mathbf{e}, \mathbf{g}, \mathbf{j}, \mathbf{k}$ and $\mathbf{5 j} \mathbf{j}, \mathbf{w}, \mathbf{x}, \mathbf{a a}, \mathbf{a b}$ (Schemes 1 and 3) in the presence of silicotungstic acid $\left(\mathrm{H}_{4} \mathrm{SiW}_{12} \mathrm{O}_{40}\right)$ under solvent-free conditions at $110{ }^{\circ} \mathrm{C}$ in high yields (80-95\%) within a short reaction time (15-40 $\mathrm{min}){ }^{65}$

The combination of glycerol (solvent) and a polystyrene-poly(ethylene glycol) (PS-PEG) resinsupported sulfonic acid (catalyst) was found to be an environmentally friendly system with which to obtain 2a,c,e-g and 5u,x in yields of $80-89 \%$ within $6 \mathrm{~h}$ at $100{ }^{\circ} \mathrm{C}$ (Schemes 1 and 3). ${ }^{66}$

Methylimidazolium hydrogensulfate $\left([\mathrm{Hmim}] \mathrm{HSO}_{4}\right)$ as a Brønsted acidic IL was efficiently employed as catalyst for the syntheses of $\mathbf{2 a}, \mathbf{c}-\mathbf{g}, \mathbf{j}-\mathbf{l}, \mathbf{p}, \mathbf{t}, \mathbf{z}, \mathbf{a u}, \mathbf{a v}$ and $\mathbf{5 j}, \mathbf{m}, \mathbf{o}, \mathbf{u}, \mathbf{w}, \mathbf{x}, \mathbf{a c}$ within 15 min under solvent-free conditions at $115{ }^{\circ} \mathrm{C},{ }^{67}$ while the research group of Pasha prepared 2a,c,e,g,h,j-l,o,qs,af and $\mathbf{5 j} \mathbf{j}, \mathbf{o}, \mathbf{w}-\mathbf{y}, \mathbf{a a}, \mathbf{a b}, \mathbf{a d}, \mathbf{a e}$ in excellent yields (90-98\%) within 9-36 $\mathrm{min}$ in the presence of $\mathrm{SiO}_{2} \mathrm{Cl}$, accelerated by ultrasound at r.t. (Schemes 1 and 3). ${ }^{68}$

The research group of Cai used the complex hafnium(IV) bis(perfluorooctanesulfonyl)imide

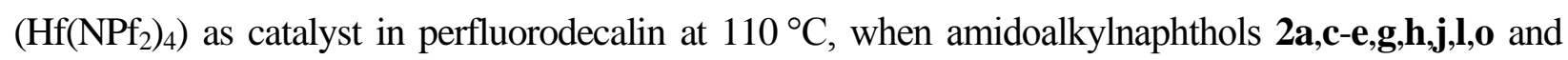
$\mathbf{5 j}, \mathbf{o}, \mathbf{a b}$ were formed in 75-95\% yields within $4-8 \mathrm{~h}$ (Schemes 1 and 3). ${ }^{69}$

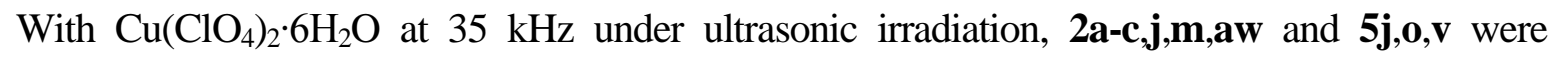
formed in high yields (84-90\%) within 30-75 min (Schemes 1 and 3). ${ }^{70}$

Srivastava et al. applied seven different Brønsted acidic ILs functionalized with imidazole and benzimidazole-based sulfonic acid groups at r.t. in DCE as catalysts for the synthesis of $N$-((2-hydroxynaphthalen-1-yl)(phenyl)methyl)benzamide (5j).$^{71}$ They later described the synthesis of $\mathbf{5 j}$ in the presence of dual metal $\left(\mathrm{Zn}^{2+}, \mathrm{Mn}^{2+}, \mathrm{Ni}^{2+}, \mathrm{Co}^{2+}\right.$ and $\left.\mathrm{Fe}^{2+}\right)$ cyanide catalysts, of which 
Fe-Fe-PEG at $80{ }^{\circ} \mathrm{C}$ in DCE was found to be the most efficient, and was therefore utilized for the synthesis of $\mathbf{5 o , u}$ (Scheme 3). ${ }^{72}$

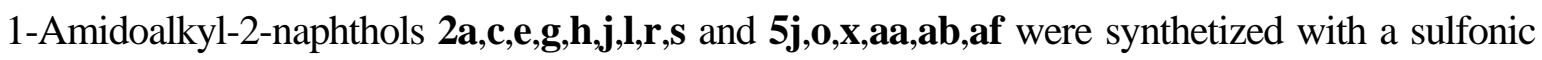
acid-functionalized benzimidazolium-based supported IL catalyst as a mild and effective catalyst under solvent-free conditions, ${ }^{73}$ while Bhanage et al. described the syntheses of $\mathbf{2 a , c , e , f , l - n}$ and $\mathbf{5 j}, \mathbf{u}, \mathbf{x}, \mathbf{a g}$ under solvent-free conditions, $N$-methyl-2-pyrrolidone hydrogensulfate ([NMP] ${ }^{+} \mathrm{HSO}_{4}{ }^{-}$) being used as Brønsted acidic IL. This methodology has several advantages: good yields (82-94\%, except for $\mathbf{2 m}$ 68\%), short reaction times (4-22 $\mathrm{min}$ ), easy work-up procedures, and a reusable catalyst (Schemes 1 and 3). ${ }^{74}$

The research group of Hajipour developed a facile, convenient and solvent-free method to obtain $\mathbf{2 a}, \mathbf{c - f}, \mathbf{j}-\mathbf{l}, \mathbf{p}, \mathbf{z}, \mathbf{a u}, \mathbf{a v}$ and $\mathbf{5 j}, \mathbf{m}, \mathbf{o}, \mathbf{u}, \mathbf{w}, \mathbf{x}, \mathbf{a c}$ (Schemes 1 and 3) by coupling various aromatic aldehydes with amides and 2-naphthol, using $N$-(4-sulfonic acid)butyl-triethylammonium hydrogensulfate ([TEBSA] $\left[\mathrm{HSO}_{4}\right]$ ) as catalyst, ${ }^{75}$ while $\mathrm{MoO}_{3}-\mathrm{ZrO}_{2}$ served as an efficient catalyst for the synthesis of $\mathbf{5 j}$,aa,ab,af (Scheme 3) under solvent-free conditions with conventional or microwave heating. ${ }^{76}$

Compounds 2a-f,j-1,n,q and 5j,o,u,x,ag,ah (Schemes 1 and 3) were produced in excellent yields (81-96\%) by Zolfigol et al. through the use of different sulfonic acid-functionalized imidazolium salts, including 3-methyl-1-sulfonic acid imidazolium chloride ([Msim] Cl), 1,3-disulfonic acid imidazolium chloride $([\mathrm{Dsim}] \mathrm{Cl})$ and 3-methyl-1-sulfonic acid imidazolium tetrachloroaluminate ([Msim] $\left.\mathrm{AlCl}_{4}\right)$ under solvent-free conditions $\left(120{ }^{\circ} \mathrm{C}\right) .^{77}$ Furthermore, in the presence of a catalytic amount of $\mathrm{H}_{3} \mathrm{PMo}_{12} \mathrm{O}_{40} \cdot \mathrm{H}_{2} \mathrm{O} / \mathrm{SiO}_{2}$ under neat conditions at $120{ }^{\circ} \mathrm{C}, \mathbf{2 a - g , j}-\mathbf{n}, \mathbf{q}$ and $\mathbf{5 j}, \mathbf{x}, \mathbf{a h}$ (Schemes 1 and 3) were produced in high to excellent yields. ${ }^{78}$

A series of amidoalkylnaphthols 2a-g,j,l,m,o,ag,aw and 5j,o,r,t-v,x,ai,aj (Schemes 1 and 3) were successfully prepared by the condensation of $\mathbf{1}$, amides (acetamide, benzamide and acrylamide) and aldehydes, with 2,4,6-trichloro-1,3,5-triazine (TCT) as catalyst. ${ }^{79}$

In the presence of para-toluenesulfonic acid (p-TSA) the syntheses of $\mathbf{2 a}, \mathbf{c}, \mathbf{j}$ and $\mathbf{5 j}, \mathbf{0}, \mathbf{r}, \mathbf{t}, \mathbf{u}, \mathbf{x}$ (Schemes 1 and 3) were performed both in DCE at r.t. and under solvent-free conditions at $125^{\circ} \mathrm{C}$. The yield of the reaction was found to depend on the nature of the starting aldehyde (e.g. $65 \%$ for $2 \mathrm{I}$ and $20 \%$ for $2 \mathbf{a a}){ }^{80}$

Das et al. successfully prepared $\mathbf{2 a}, \mathbf{c}, \mathbf{j}$ and 5o,r,t,u,ak (Schemes 1 and 3) by applying $\mathrm{I}_{2}$ as catalyst at r.t. in DCE, and also under neat conditions at $125^{\circ} \mathrm{C} .{ }^{81}$

The research group of Samant achieved the syntheses of $\mathbf{2 a - c , j , l , n , a a ~ a n d ~} \mathbf{5 j}, \mathbf{j}, \mathbf{0}, \mathbf{r}, \mathbf{t}, \mathbf{u}, \mathbf{v}, \mathbf{x}, \mathbf{a g}, \mathbf{a l}$ (Schemes 1 and 3) in the presence of $\mathrm{H}_{3} \mathrm{NSO}_{3}$, accelerated by ultrasound at r.t. ${ }^{82}$ These products were resynthetized by applying different cation-exchange resins, of which Indion-130 was the best under neat conditions at $110^{\circ} \mathrm{C}$. $^{83}$ 
$\mathrm{H}_{3} \mathrm{PMo}_{12} \mathrm{O}_{40}$ catalysed the formation of $\mathbf{2 a}, \mathbf{f}, \mathbf{g}, \mathbf{a b}, \mathbf{a h}$ and $\mathbf{5 j}, \mathbf{0}, \mathbf{a b}, \mathbf{a i}, \mathbf{a j}, \mathbf{a k}, \mathbf{a m}, \mathbf{a n}$ via the threecomponent condensation of $\mathbf{1}$, aldehydes and amides in EtOAc at $65^{\circ} \mathrm{C}$ (Schemes 1 and 3). ${ }^{84}$

Polymer-supported sulfonic acid NKC-9 was investigated as catalyst under reflux conditions in $\mathrm{CHCl}_{3}$. Compounds $\mathbf{2 a}, \mathbf{f}, \mathbf{a b}$ and $\mathbf{5 j}, \mathbf{0}, \mathbf{v}, \mathbf{x}, \mathbf{a a}, \mathbf{a b}, \mathbf{a i}$ were obtained in good yields, except from formamide, which did not lead to any product, even after $10 \mathrm{~h}$ (Schemes 1 and 3). ${ }^{85}$

The syntheses of 1-amidoalkyl-2-naphthol derivatives $\mathbf{2 a - c , e - g , j , l , m , o , s ~ a n d ~ 5 j , ~} \mathbf{0}, \mathbf{r}, \mathbf{s}, \mathbf{t}, \mathbf{v}, \mathbf{x}, \mathbf{a a}, \mathbf{a b}$, af,ai-ak,ao-au were promoted by $[\mathrm{MIMPS}]\left[\mathrm{HSO}_{4}\right]$ under neat conditions at $125^{\circ} \mathrm{C}$. The expected products were formed in excellent yields (86-97\%) within 5-40 min (Schemes 1 and 3). ${ }^{25}$

The amidoalkylation of 1 with aldehyde and amide, with $\mathrm{P}_{2} \mathrm{O}_{5}$ as catalyst at $60{ }^{\circ} \mathrm{C}$, resulted in $\mathbf{2 c}, \mathbf{e}-\mathbf{g}, \mathbf{j}, \mathbf{l}, \mathbf{m}, \mathbf{t}$ and $\mathbf{5 j} \mathbf{j}, \mathbf{o}, \mathbf{u}, \mathbf{x}, \mathbf{a a}, \mathbf{a b}, \mathbf{a d}, \mathbf{a f}, \mathbf{a o}, \mathbf{a p}, \mathbf{a v}, \mathbf{a w}-\mathbf{b a}$ in high yields (84-97\%) within 5-15 min, ${ }^{86}$ while in the presence of $\mathrm{HClO}_{4} / \mathrm{SiO}_{2}$ under thermal $\left(100{ }^{\circ} \mathrm{C}\right)$ solvent-free conditions, $\mathbf{2 a}, \mathbf{s}$ and

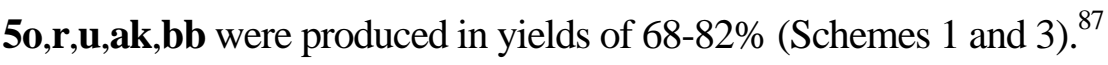

Sardarian et al. reported a convenient, mild and efficient procedure for the syntheses of $\mathbf{2 a}, \mathbf{v}, \mathbf{a b}, \mathbf{a i}, \mathbf{a p}$ and $\mathbf{5 j}, \mathbf{x}, \mathbf{a a}, \mathbf{a b}, \mathbf{a g}, \mathbf{b c}, \mathbf{b d}-\mathbf{b i}$ (Schemes 1 and 3) from various aryl and alkyl aldehydes, 2-naphthol (1) and different amides in the presence of dodecylphosphonic acid under solvent-free conditions at $90^{\circ} \mathrm{C}$. It was noteworthy that hindered aromatic aldehydes such as 2-naphthaldehyde, phenantherene-9-carbaldehyde and pyrene-1-carbaldehyde also gave the corresponding products in good yields $(81-90 \%){ }^{88}$

A super-acidic IL $\left(\left[\mathrm{MeC}(\mathrm{OH})_{2}\right]^{+} \mathrm{ClO}_{4}^{-}\right)$proved to be a new and highly efficient catalyst in the syntheses of $\mathbf{2 a}, \mathbf{a j}, \mathbf{a q}$ and $\mathbf{5 j}, \mathbf{u}, \mathbf{a a}, \mathbf{b j}$-bn via the condensation of $\mathbf{1}$, aldehydes (aryl, heteroaryl or alkyl) and amides at r.t. or at $80{ }^{\circ} \mathrm{C}$ under-solvent free conditions (Schemes 1 and 3). ${ }^{30}$

An eco-friendly procedure for the syntheses of $\mathbf{2 a}, \mathbf{c}-\mathbf{g}, \mathbf{j}, \mathbf{k}, \mathbf{0}, \mathbf{a q}$ and $\mathbf{5 j}, \mathbf{m}, \mathbf{0}, \mathbf{u}, \mathbf{x}, \mathbf{a b}, \mathbf{a c}, \mathbf{b n}$ in the presence of silica gel-supported dual acidic IL at $85{ }^{\circ} \mathrm{C}$ in yields of $85-94 \%$ within $5-15$ min (Schemes 1 and 3) was reported by the research group of Zhang. ${ }^{89}$ They later investigated the efficiency of PEG-based dicationic acidic ionic liquid (DAIL) under thermal $\left(80{ }^{\circ} \mathrm{C}\right)$ solvent-free conditions. This procedure was uniformly effective for both aliphatic and aromatic aldehydes, yielding

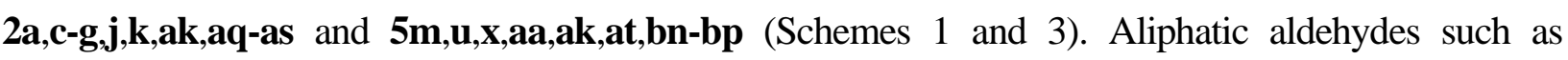
$n$-butyraldehyde, valeraldehyde, and isovaleraldehyde were all converted to the corresponding products in yields of $80-98 \% .^{90}$

The research team of Kumar prepared 2a,c,e,f,j,k,ak (Scheme 1) by using $\mathrm{Yb}(\mathrm{OTf})_{3}$ as a mild Lewis acid catalyst in the IL $[\mathrm{Bmim}]\left[\mathrm{BF}_{4}\right]$ at $80{ }^{\circ} \mathrm{C}$. When acetamide was replaced by benzamide, $\mathbf{5 j}$ was isolated in a yield of only $35 \%$ (Scheme 3). When their method was applied to 7-methoxynaphthalen-2-ol (6), 7a-h were produced in yields of 85-90\% (Scheme 4). The reaction from $\mathrm{N}$-methylacetamide under the same conditions also took place, but the transformation was slower than 
that from acetamide, and $\mathbf{7 i}$ was obtained in a yield of only $61 \%$ after $12 \mathrm{~h}$ (Scheme 4). ${ }^{91}$ Murthy et al. applied $\mathrm{H}_{2} \mathrm{SO}_{4} / \mathrm{SiO}_{2}$ successfully to obtain $\mathbf{2 a}, \mathbf{c}, \mathbf{a b}, \mathbf{a l}-\mathbf{a o}$,at and $\mathbf{5 w}, \mathbf{b h}, \mathbf{b q}, \mathbf{b r}$ (Schemes 1 and 3) in high yields $(84-92 \%) .^{92}$

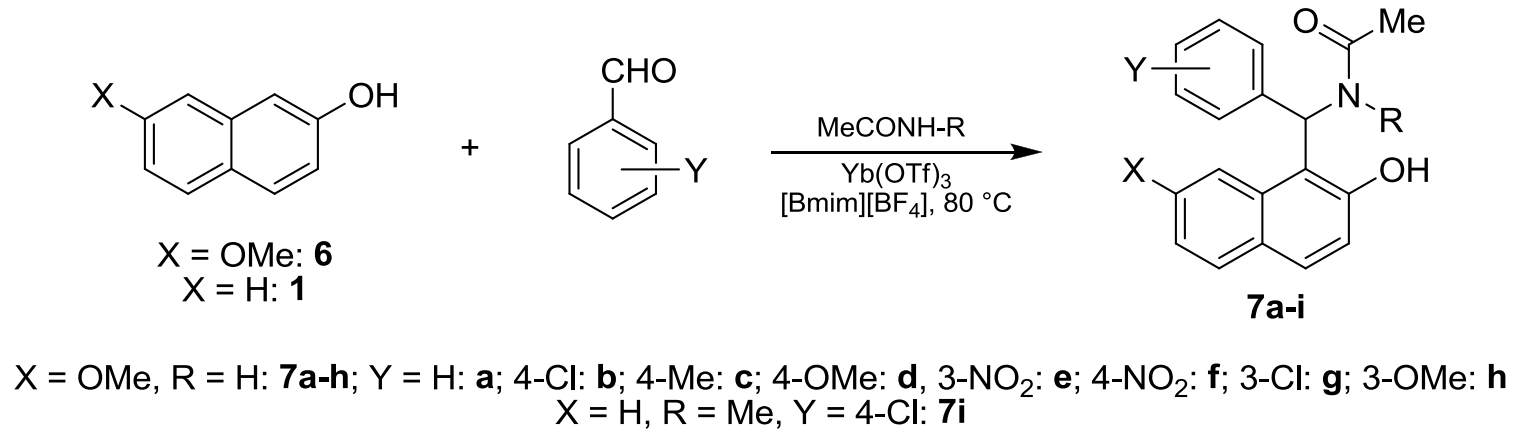

\section{Scheme 4}

1-Amidoalkyl-2-naphthols $\mathbf{2 a , c , e , g , p}$ and $\mathbf{5 j}$,o,aa,ab were prepared in high yields (85-94\%) within surprisingly short reaction times (1-2 min) in the presence of $\mathrm{MeSO}_{3} \mathrm{H}$ at r.t. In the case of furfural, the desired $\mathbf{5 b l}$ could be isolated in a yield of only $60 \%$ after a reaction time of $5 \mathrm{~min}$ (Schemes 1 and 3). ${ }^{93}$

When $\mathrm{Cu} p$-toluenesulfonate was applied under thermal $\left(80^{\circ} \mathrm{C}\right)$ solvent-free conditions, the corresponding products $\mathbf{2 a}, \mathbf{c}, \mathbf{j}, \mathbf{l}$ and $\mathbf{5 j} \mathbf{j}, \mathbf{o}, \mathbf{u}, \mathbf{x}, \mathbf{a a}, \mathbf{a b}, \mathbf{a f}, \mathbf{a o}, \mathbf{a p}, \mathbf{b h}, \mathbf{b n}$ (Schemes 1 and 3) were formed in good yields (72-96\%). Aromatic aldehydes bearing electron-donating groups reacted more slowly (2f,g and 5ad) and the yields were lower (65, 16 and 31\%). It should be mentioned that the reactions of aliphatic aldehydes (propionaldehyde and butyraldehyde) also led to the desired products (2am and 2aq, Scheme 1) in moderate to good yields. ${ }^{94}$ In the presence of $\mathrm{Cu} o$-tolunesulfonate, the amidoalkylation of $\mathbf{1}$ with alkyl or aryl aldehydes and benzamide led to the formation of

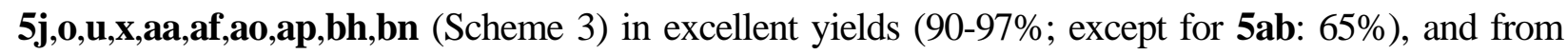
acetamide compounds, $\mathbf{2 a}, \mathbf{c}, \mathbf{f}, \mathbf{j}, \mathbf{l}, \mathbf{a m}, \mathbf{a q}$ (Scheme 1) were isolated in yields of 51-76\%. ${ }^{95}$

The research group of Wang used $\mathrm{MeSO}_{3} \mathrm{H} / \mathrm{SiO}_{2}$ under solvent-free conditions at $80{ }^{\circ} \mathrm{C}$ for the synthesis of 2a,c,e-g,j,l,m,o and $\mathbf{5 j}, \mathbf{j}, \mathbf{o}, \mathbf{u}, \mathbf{x}, \mathbf{a b}, \mathbf{a f}, \mathbf{a o}, \mathbf{a p}, \mathbf{b h}, \mathbf{b n}$ (Schemes 1 and 3), this method affording the corresponding products in from moderate to good yields (70-96\%). Aromatic aldehydes containing a strong electron-donating group, such as 4-dimethylaminobenzaldehyde, generally failed to yield any product, and $2 \mathrm{am}$ was isolated in a yield of only $34 \%$ (Scheme 1). ${ }^{96}$ The efficiency of $\mathrm{Bi}\left(\mathrm{NO}_{3}\right)_{3} \cdot 5 \mathrm{H}_{2} \mathrm{O}$ in the preparation of $\mathbf{2} \mathbf{a}-\mathbf{e}, \mathbf{g}, \mathbf{j}, \mathbf{a m}, \mathbf{a q}$ and $\mathbf{5 j}, \mathbf{o}, \mathbf{u}, \mathbf{x}, \mathbf{a a}, \mathbf{a b}, \mathbf{a f}, \mathbf{a o}, \mathbf{a p}, \mathbf{b h}, \mathbf{b n}$ was investigated under the same conditions (Schemes 1 and 3). ${ }^{97}$ 
A zwitterionic-type molten salt was successfully applied as mild organocatalyst under neat conditions at $80{ }^{\circ} \mathrm{C}$ to furnish $\mathbf{2 a - e , g , j , a q , a r}$ and $\mathbf{5 j}, \mathbf{o , u}, \mathbf{u}, \mathbf{b q}$ (Schemes 1 and 3) in yields of 74-90\%, even from aliphatic aldehydes such as $n$-butyraldehyde, isobutyraldehyde, and valeraldehyde. ${ }^{98}$

The application of thiamine hydrochloride as catalyst in the condensations of $\mathbf{1}$ and acetamide/acrylamide/benzamide with aromatic aldehydes gave the desired products $(\mathbf{2 a}, \mathbf{f}, \mathbf{j}$ and $\mathbf{5 j}, \mathbf{u}, \mathbf{x}, \mathbf{a b}, \mathbf{a i}-\mathbf{a k}, \mathbf{a s} ;$ Schemes 1 and 3) in excellent yields (88-93\%). It was reported that this methodology failed when $N$-methylbenzamide and caprolactam were utilized as nitrogen sources. ${ }^{99}$

The research team of Murthy investigated the use of 1-naphthol (8) to afford amidoalkylated products. As catalyst, $\mathrm{H}_{2} \mathrm{SO}_{4} / \mathrm{SiO}_{2}$ was used and the reaction was carried out at r.t. under solvent-free conditions, during which mixtures of regioisomers 9a-c (30-32\%) and 10a-c (38-42\%) were formed (Scheme 5). ${ }^{92}$

The catalytic activity of $\mathrm{Hf}\left(\mathrm{NPf}_{2}\right)_{4}$ was studied in the three-component condensation of 1-naphthol, benzaldehyde and acetamide at $110{ }^{\circ} \mathrm{C}$ in perfluorodecalin, yielding $9 \mathbf{c}$ and 10c in yields of $41 \%$ and $59 \%$, respectively (Scheme 5). ${ }^{69}$<smiles>Oc1cccc2ccccc12</smiles>

8

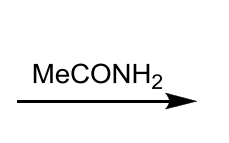<smiles>[R]C(NC(C)=O)c1ccc2ccccc2c1O</smiles>

$\mathrm{R}=\mathrm{Et}: \mathbf{a} ; \boldsymbol{i P r}: \mathbf{b} ; \mathrm{Ph}: \mathbf{c}$<smiles>[R]C(NC(C)=O)c1ccc(O)c2ccccc12</smiles>

$10 \mathrm{a}-\mathrm{c}$

Scheme 5

\subsection{Syntheses of carbamidoalkylnaphthols}

1-Carbamidoalkyl-2-naphthols can be prepared successfully through the condensation of 2-naphthol (1), aromatic aldehydes and urea in the presence of various catalysts.

Mahdavinia et al. produced 11a-e (Scheme 6) in the presence of $\mathrm{HClO}_{4} / \mathrm{SiO}_{2}{ }^{53}$ under both thermal (refluxing in DCE) and neat conditions $\left(125^{\circ} \mathrm{C}\right)$, and also with wet cyanuric chloride $\left(100{ }^{\circ} \mathrm{C}\right) .{ }^{54}$

11a,e-g (Scheme 6) were synthetized in good yields when either conventional heating in DCE or microwave irradiation $\left(125^{\circ} \mathrm{C}\right)$ was utilized in the presence of $\mathrm{K}_{5} \mathrm{CoW}_{12} \mathrm{O}_{40} \cdot 3 \mathrm{H}_{2} \mathrm{O}$ as catalyst. ${ }^{51}$

Montmorillonite K10 effectively catalysed the formation of 11a,g-i under neat conditions $\left(125^{\circ} \mathrm{C}\right)$ within $1.5 \mathrm{~h},{ }^{52}$ while the syntheses of $\mathbf{1 1 b}, \mathbf{e}, \mathbf{j}$ could be carried out with TCT as catalyst under solvent-free conditions at $100{ }^{\circ} \mathrm{C}($ Scheme 6$) .{ }^{79}$ 
When thiamine hydrochloride ${ }^{99}$ at $80{ }^{\circ} \mathrm{C}$ in $\mathrm{EtOH}$ and Brønsted acidic IL $\left[\right.$ TEBSA] $\left[\mathrm{HSO}_{4}\right]^{75}$ were employed as catalysts under thermal $\left(120^{\circ} \mathrm{C}\right)$ solvent-free conditions, 11a,e were formed in moderate yields (Scheme 6).

Khabazzadeh et al. applied $\mathrm{Cu}_{1-5} \mathrm{PMo}_{12} \mathrm{O}_{40}$ and $\mathrm{Cu}_{1-5} \mathrm{PW}_{12} \mathrm{O}_{40}$ as catalysts in molten $\mathrm{Bu}_{4} \mathrm{NBr}$ as an IL for the synthesis of 11a,b,e (Scheme 6). ${ }^{63}$

1-Carbamidoalkyl-2-naphthols 11a,j were produced in yields of $83 \%$ and $74 \%$ in the presence of [FemSILP] $L$-prolinate as catalyst at $100^{\circ} \mathrm{C}^{64}$ and Zhang et al. efficiently used silica gel-supported dual acidic IL as catalyst for the preparation of $\mathbf{1 2 a}, \mathbf{e}, \mathbf{g} .{ }^{89}$ They later tested PEG $_{1,000-D A I L}$ as catalyst at $80^{\circ} \mathrm{C}$, which resulted in 11a,b,e in yields of 80-84\% within 5-10 min (Scheme 6). ${ }^{90}$

1,2-Dihydro-1-(4-chlorophenyl)naphth[1,2-e][1,3]oxazin-3-one (12b) was prepared from 2-naphthol, 4-chlorobenzaldehyde, urea and $\mathrm{AcOH}$, and its structure was elucidated by means of X-ray diffraction (Scheme 6). ${ }^{100}$

$\mathrm{MeSO}_{3} \mathrm{H}$ was demonstrated to be an effective catalyst in water at r.t. for the synthesis of carbamidoalkylnaphthols $\mathbf{1 1 a}, \mathbf{b}, \mathbf{k}-\mathbf{m},{ }^{93}$ while the syntheses of 11e,f,l,n in yields of $85-89 \%$ were carried out by applying [MIMPS] $\left[\mathrm{HSO}_{4}\right]$ at $125^{\circ} \mathrm{C}$ (Scheme 6). ${ }^{25}$

Heravi et al. prepared 11a-c,e,f,j (Scheme 6) in the presence of two Brønsted acidic ILs, 3-methyl-1-(4-sulfonic acid)butylimidazolium hydrogensulfate $\left[\left(\mathrm{CH}_{2}\right)_{4} \mathrm{SO}_{3} \mathrm{HMIM}\right]\left[\mathrm{HSO}_{4}\right]\left(\mathrm{IL}_{1}\right)$ and $N$-(4-sulfonic acid)butylpyridinium hydrogensulfate $\left[\left(\mathrm{CH}_{2}\right)_{4} \mathrm{SO}_{3} \mathrm{HPY}\right]\left[\mathrm{HSO}_{4}\right]\left(\mathrm{IL}_{2}\right)$. The reactions promoted by $\mathrm{IL}_{2}$ gave higher yields of the products within shorter reaction times. ${ }^{36}$

The oxalic acid-catalysed solvent-free condensations of $\mathbf{1}$, aromatic aldehydes and urea afforded $\mathbf{1 1 a}, \mathbf{b}, \mathbf{e}, \mathbf{j}$ in yields of $88-98 \%$ within $8-24 \mathrm{~min},{ }^{58}$ and the group of Gokavi investigated the effectiveness of $\mathrm{H}_{4} \mathrm{SiW}_{12} \mathrm{O}_{40}$ as catalyst under thermal $\left(110^{\circ} \mathrm{C}\right)$ solvent-free conditions, obtaining 11a,e,g,k,l in good yields (Scheme 6). ${ }^{65}$

Hosseini et al. achieved the synthesis of $\mathbf{1 1 a}, \mathbf{b}, \mathbf{k}$ (Scheme 6) by using $\mathrm{H}_{3} \mathrm{PW}_{12} \mathrm{O}_{40}$ as catalyst, and their corrosion inhibition ability in $0.5 \mathrm{M} \mathrm{H}_{2} \mathrm{SO}_{4}$ solution was additionally investigated. ${ }^{101}$ These compounds were also prepared by Cai et al. in yields of $76-89 \%$, in the presence of $\left.\mathrm{Hf}_{(\mathrm{NPf}}\right)_{4}$ in perfluorodecalin at $110^{\circ} \mathrm{C}$.

When the combination chlorotrimethylsilane (TMSCl)/NaI was applied as catalyst in $\mathrm{MeCN}$ at r.t. the reactions of $\mathbf{1}$, aromatic aldehydes and urea gave the corresponding carbamidoalkylnaphthols (11a,b,j,k,o) in 78-81\% yields. When 11a was heated in DMF at $140{ }^{\circ} \mathrm{C}$ for $2 \mathrm{~h}$, cyclization occurred to produce the naphth[1,2-e][1,3] oxazinone (12a). The syntheses of naphth[1,2-e][1,3]oxazinones (12b-m) were achieved directly through the reactions of $\mathbf{1}$, aromatic aldehydes and urea. ${ }^{102}$ Compounds 12a,b,d-g,n were also prepared in excellent yields (90-96\%) within $5 \mathrm{~min}$ in the presence of $\mathrm{I}_{2}$ as catalyst at $80{ }^{\circ} \mathrm{C},{ }^{103}$ while Chaskar et al. accomplished the syntheses of 12a-d,h,n-r in the presence of 
$\mathrm{H}_{3} \mathrm{PMo}_{12} \mathrm{O}_{40}$ in DMF at $100{ }^{\circ} \mathrm{C}$ (Scheme 6). ${ }^{104}$ For the syntheses of 1-carbamidoalkyl-2-naphthols, $\mathrm{Sr}(\mathrm{OTf})_{2}$ and $\mathrm{POCl}_{3} / \mathrm{Na}_{2} \mathrm{~B}_{4} \mathrm{O}_{7}$ were also stated to be convenient and efficient catalysts. ${ }^{32,34}$

On the addition of aromatic aldehydes, 2-naphthol, urea and $\mathrm{ZnO}$ nanoparticles in an inappropriate sequence, a xanthene derivative was observed as major product and no naphthoxazinone derivative was formed. The correct sequential addition of aryl aldehydes, urea and catalyst followed by 1 played a crucial role and influenced the reaction in the direction of the desired naphthoxazinone 12b-d,f,s-x (Scheme 6). ${ }^{105}$

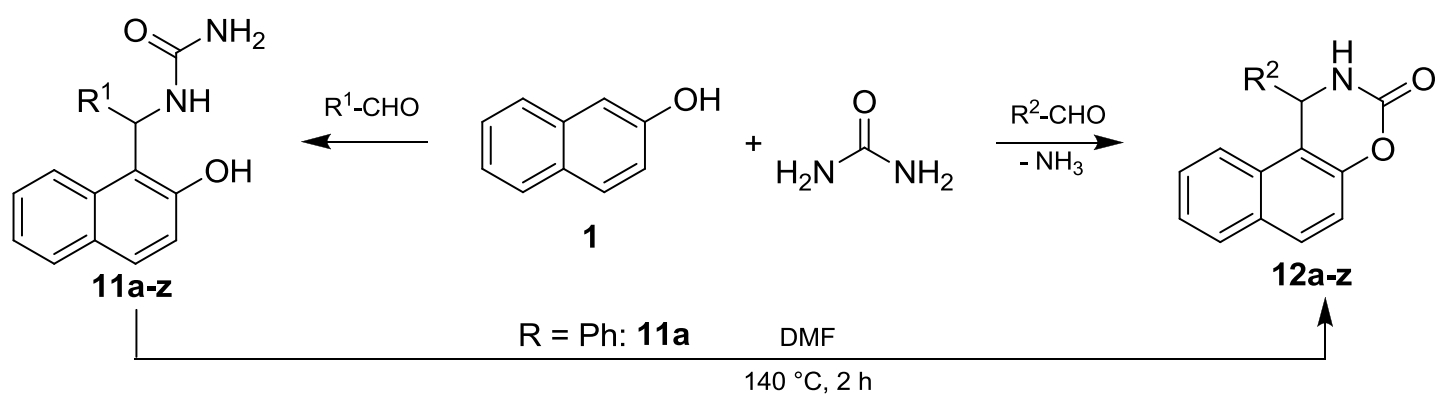

$\mathrm{R}^{1}=\mathrm{Ph}: \mathbf{a} ; 4-\mathrm{Cl}-\mathrm{Ph}: \mathbf{b} ; 4-\mathrm{Br}-\mathrm{Ph}: \mathbf{c} ; 4-\mathrm{CN}-\mathrm{Ph}: \mathbf{d}$; 3-NO $-\mathrm{Ph}: \mathbf{e}$; 2-Cl-Ph: f; 3-OMe-Ph: g; 3,4-(OMe) $)_{2}-\mathrm{Ph}: \mathbf{h} ; 3,4,5-(\mathrm{OMe})_{3}-\mathrm{Ph}: \mathbf{i} ; 4-\mathrm{Me}-\mathrm{Ph}$ : j;

4-OMe-Ph: k; 4-NO $\mathrm{N}_{2}-\mathrm{Ph}: \mathbf{I}$; 2,5-(OMe $)_{2}-\mathrm{Ph}: \mathbf{m}$; 2- $\mathrm{NO}_{2}-\mathrm{Ph}: \mathbf{n}$; 4-OH-Ph: o; 2-Br-Ph: p; 2,4-Cl $-\mathrm{Ph}: \mathbf{q}$; 1-Nph: r; Et: s; iBu: t; 2-pyridyl: u; 2-thienyl: v; 3-pyridyl: w; 2-furyl: x; 4-NMe ${ }_{2}-\mathrm{Ph}: \mathbf{y} ; 3,4-\left(\mathrm{OCH}_{2} \mathrm{O}\right)-\mathrm{Ph}: \mathbf{z}$
$\mathrm{R}^{2}=\mathrm{Ph}: \mathbf{a} ; 4-\mathrm{Cl}-\mathrm{Ph}: \mathbf{b}$; 4-Me-Ph: c; 4-OMe-Ph: d; 4-OH-Ph: e; 4-F-Ph: f; 4-Br-Ph: g; 2-Cl-Ph: h; 3-Br-Ph: i; 3-OMe-Ph: j; 3-OH-Ph: k; 4-iPr-Ph: I; 4-tBu-Ph: m; 3- $\mathrm{NO}_{2}-\mathrm{Ph}: \mathbf{n} ; 4-\mathrm{NO}_{2}-\mathrm{Ph}: \mathbf{o}$; 2-OH-Ph: p; 2,5-(OH) $2-\mathrm{Ph}: \mathbf{q}$; 2-OH,5-OMe-Ph: r; 3-F-Ph: s; 3-Cl-Ph: t; 4-OEt-Ph: u; 4-CF $3-\mathrm{Ph}$ : v; 4-OCF 3 -Ph: w; 4-tBu-Ph: $\mathbf{x}$; 3-OMe,4-OH-Ph: $\mathbf{y}$; 2-furyl: z; 3,4-( $\left.\mathrm{OCH}_{2} \mathrm{O}\right)-\mathrm{Ph}$ : aa

\section{Scheme 6}

The research group of Srivastava investigated the efficiency of different dual metal $\left(\mathrm{Zn}^{2+}, \mathrm{Mn}^{2+}\right.$, $\mathrm{Ni}^{2+}, \mathrm{Co}^{2+}$ and $\mathrm{Fe}^{2+}$ ) cyanide complexes at reaction temperatures of $25{ }^{\circ} \mathrm{C}, 50{ }^{\circ} \mathrm{C}$ and $80{ }^{\circ} \mathrm{C}$. Fe-Fe-PEG at $80{ }^{\circ} \mathrm{C}$ was found to be best for the synthesis of $\mathbf{1 1 a}, \mathbf{b}, \mathbf{k}$ (Scheme 6). ${ }^{72}$

Composite oxides $\mathrm{MoO}_{3}-\mathrm{ZrO}_{2}$ were successfully applied as catalysts for the preparation of 11a,b,e,f,k,l,o through conventional or microwave heating (Scheme 6). The products were formed in yields of 76-86\% within 3-6 min under microwave irradiation. ${ }^{76}$

The preparation of 11a,b,e (Scheme 6) proceeded satisfactorily in a very short reaction time (4-7 $\mathrm{min}$ ) in the presence of $[\mathrm{Hmim}] \mathrm{HSO}_{4}$ at $125^{\circ} \mathrm{C}^{67}$ or on the use of sodium 1-hexasulfonate under solvent-free and microwave irradiation. ${ }^{50}$

The formation of 11a,e through thermal $\left(80^{\circ} \mathrm{C}\right)$ solvent-free condensation in the presence of $\mathrm{Cu} p$-toluenesulfonate has been described. ${ }^{94}$ When $\mathrm{Cu} o$-toluenesulfonate was used as catalyst, 11a,e were formed in yields of $86 \%$, whereas that of $\mathbf{1 1 b}$ was only $59 \%{ }^{95}$ In the presence of $\mathrm{MeSO}_{3} \mathrm{H} / \mathrm{SiO}_{2}$, the yield of $\mathbf{1 1 a}$ was $77 \%$, and that of $\mathbf{1 1 e}$ was $30 \%$, while $\mathbf{1 1} \mathbf{j}$ was formed in merely trace amounts (Scheme 6). ${ }^{96}$ 
Compound 11a was prepared both in the presence of $\mathrm{Bi}\left(\mathrm{NO}_{3}\right)_{3} \cdot 5 \mathrm{H}_{2} \mathrm{O}$ at $80{ }^{\circ} \mathrm{C}^{97}$ and by using $\left[\mathrm{MeC}(\mathrm{OH})_{2}\right]^{+} \mathrm{ClO}_{4}{ }^{-}$as a super-acidic IL. ${ }^{30}$ When $\mathrm{Fe}\left(\mathrm{HSO}_{4}\right)_{3}$ was applied as catalyst in DCE at $60{ }^{\circ} \mathrm{C}$, carbamidoalkylnaphthols 11a,b,k,l were formed in yields of 84-94\% (Scheme 6). ${ }^{106}$

11a,b,e (Scheme 6) have been prepared independently by different research groups with the use of different catalysts as follows: [Bmim] $\mathrm{Br}$ under microwave irradiation; ${ }^{38}$ silphox and silphos at $120{ }^{\circ} \mathrm{C} ;{ }^{39}$ a sulfonic acid-functionalized benzimidazolium-based supported IL catalyst at $100{ }^{\circ} \mathrm{C} ;{ }^{73}$ $[\mathrm{NMP}]^{+} \mathrm{HSO}_{4}^{-}$as a reusable Brønsted acidic IL at $125{ }^{\circ} \mathrm{C} ;{ }^{74}$ and $\mathrm{Cu}\left(\mathrm{ClO}_{4}\right)_{2} \cdot 6 \mathrm{H}_{2} \mathrm{O}$ accelerated by ultrasound irradiation. ${ }^{70}$

11a,e were prepared in the presence of the imidazolium salts $[\mathrm{Msim}] \mathrm{Cl},[\mathrm{Dsim}] \mathrm{Cl}$ and $[\mathrm{Msim}] \mathrm{AlCl}_{4}$ as catalysts, ${ }^{77}$ while Das et al. isolated 11a,b,e,j,p,q,r in yields of $71-93 \%$ under solventfree conditions by using $\mathrm{HClO}_{4} / \mathrm{SiO}_{2}$ as heterogeneous catalyst. ${ }^{87}$ The series of compounds was extended by starting from propionaldehyde in the presence of $\mathrm{I}_{2}$ in DCE at r.t. and under solvent-free conditions at $125^{\circ} \mathrm{C}$ to lead to $11 \mathrm{~s}$ (Scheme 6). ${ }^{81}$

Under mild conditions $\left(60^{\circ} \mathrm{C}\right)$ in $[\mathrm{Bmim}] \mathrm{HSO}_{4}, \mathbf{1 1 a}, \mathbf{b}, \mathbf{t}-\mathbf{v}$ (Scheme 6) were prepared in 80-92\% yields within 35-47 min, ${ }^{49}$ while Chaskar et al. applied $\mathrm{H}_{3} \mathrm{PMo}_{12} \mathrm{O}_{40}$ as catalyst in $\mathrm{CCl}_{4}$ under reflux conditions to afford 11a,c,e,h,j,k,w. ${ }^{59}$ The team of Cai and Almahy achieved the $\mathrm{KHSO}_{4}$-catalysed syntheses of 11a-c,e,l,x (Scheme 6) in good yields. ${ }^{42-44}$

Aryl aldehydes containing both electron-withdrawing and electron-donating groups, and also propionaldehyde, gave high yields of the desired products $(\mathbf{1 1 a}, \mathbf{b}, \mathbf{e}, \mathbf{f}, \mathbf{i}, \mathbf{k}, \mathbf{l}, \mathbf{o}, \mathbf{s}, \mathbf{y})$ in the presence of $N, N, N,{ }^{\prime} N$ '-tetrabromobenzene-1,3-disulfonamide under neat conditions at r.t. (Scheme 6). ${ }^{107}$

The syntheses of derivatives 11a,b,e,f,q,r through the use of $\mathrm{H}_{3} \mathrm{PW}_{12} \mathrm{O}_{40}$ in a molten salt (Et $\left.{ }_{4} \mathrm{NCl}\right)$ were described by Saidi et al. ${ }^{46}$ while $\mathrm{InCl}_{3}$ was found to be an efficient catalyst in furnishing $\mathbf{1 1 b}, \mathbf{h}, \mathbf{k}, \mathbf{l}, \mathbf{o}, \mathbf{z}$ under solvent-free microwave conditions ( $800 \mathrm{~W}$; Scheme 6$){ }^{48}$

Khavasi et al. carried out the synthesis of 13a (Scheme 7) in the presence of $p$-TSA at $100{ }^{\circ} \mathrm{C}$ under solvent-free conditions, with a yield of $54 \%$ in $3 \mathrm{~h}$, and studied the intermolecular and intramolecular hydrogen-bonds in the stabilization of the crystal structure. ${ }^{108}$

Zali et al. produced 11a,b,e,g,j,l,r in yields of 83-93\% within 30-90 min by applying nanosulfated $\mathrm{ZrO}_{2}$ under thermal $\left(120{ }^{\circ} \mathrm{C}\right)$ conditions. ${ }^{40}$ The preparations of 11a-c,e,j and 13a-e (Schemes 6 and 7) were achieved with excellent yields in DCE at r.t. and under solvent-free conditions at $125^{\circ} \mathrm{C}$ in the presence of $p$-TSA. ${ }^{80}$

The ultrasound-promoted $\mathrm{H}_{3} \mathrm{NSO}_{3}$-catalysed three-component condensations of $\mathbf{1}$, ureas and aldehydes gave 11a-c,e and 13a-g in good yields (82-94\%; Schemes 6 and 7). ${ }^{82}$ In the presence of Indion- 130 as catalyst at $110{ }^{\circ} \mathrm{C}$, these compounds were prepared within shorter reaction times, and in somewhat higher yields. ${ }^{83}$ 
The group of Shinde also investigated the catalytic effect of $\mathrm{H}_{3} \mathrm{NSO}_{3}$, but applied it in DCE at r.t., which led to the formation of 11a,b,e,f,k,x and 13b in yields of 55-86\% within 7-23 h (Schemes 6 and 7). ${ }^{56}$ They carried out the syntheses of these compounds in the presence of $\mathrm{ZrOCl}_{2}$ in DCE at r.t. too, which afforded the products in higher yields, but in longer reaction times. ${ }^{55}$ When $\mathrm{I}_{2}$ was applied under the same conditions, the yields of all the above-mentioned compounds were improved. ${ }^{57}$ From propionaldehyde, 11s was isolated in yields of only 23-30\%, and longer reaction times were needed in comparison with aromatic aldehydes.

$\mathrm{PPA} / \mathrm{SiO}_{2}$ was demonstrated to be an efficient catalyst for the synthesis of 11a,b,e and 13a-c,e in $\mathrm{CHCl}_{3}$ at $50{ }^{\circ} \mathrm{C}$ (Schemes 6 and 7). The products were formed in high yields within 4-10 min. ${ }^{62}$ Jiang et al. carried out the synthesis of $\mathbf{1 3 h}$-j in the presence of $\mathrm{H}_{3} \mathrm{PMo}_{12} \mathrm{O}_{40}$ in EtOAc at $65{ }^{\circ} \mathrm{C}^{84}$ and of polymer-supported sulfonic acid $\mathrm{NKC}-9$ in $\mathrm{CHCl}_{3}$ under reflux conditions (Scheme 7). ${ }^{85}$

Efficient methodology was developed for the preparation of 2-naphthol-condensed 1,3-oxazinone derivatives, involving a one-pot condensation in the presence of $\mathrm{K}_{2} \mathrm{CO}_{3}$ and $\mathrm{Cu}$ nanoparticles in PEG-400. With this method, 1,3-oxazinones 12a,b,d-g, $, \mathbf{y}, \mathbf{y}, \mathbf{z}$ were formed in yields of $74-93 \%$ within 45-60 min (Scheme 6). ${ }^{109}$<smiles>[R]NC(=O)NC(c1ccc([X])cc1)c1c(O)ccc2ccccc12</smiles>

$13 a-j$

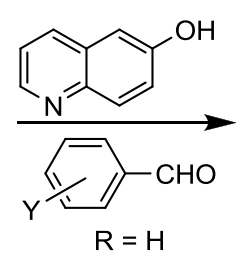

$\mathrm{Y}=\mathrm{H}: \mathbf{a} ; 4-\mathrm{Cl}: \mathbf{b} ; 4-\mathrm{F}: \mathbf{c} ; 4-\mathrm{Br}: \mathbf{d} ; 2-\mathrm{Cl}: \mathbf{e}$; 3-Br: f; 2-OMe: g; 4-OMe: $\mathbf{h}$; 4-Me: i

\section{Scheme 7}

The team of Bazgir isolated 1,2-dihydro-1-arylnaphth[1,2-e][1,3]oxazin-3-ones (12a-g, Scheme 6) in moderate to high yields by using $p$-TSA under microwave-assisted ( $900 \mathrm{~W}$ ) and thermal $\left(160{ }^{\circ} \mathrm{C}\right)$ solvent-free conditions. ${ }^{110}$ They also extended this reaction to 6-quinolinol as starting compound, and prepared oxazino[5,6-f]quinolin-3-ones (14a-i, Scheme 7). ${ }^{111}$

The syntheses of naphthoxazinones 12a-g,aa were achieved with good yields in the presence of $\mathrm{Zn}(\mathrm{OTf})_{2}$ in $\mathrm{MeCN}$ at reflux temperature. This method was additionally utilized for the preparation of 4-aryl-3,4-dihydronaphth[2,1-e][1,3]oxazin-2-ones from 1-naphthol, which afforded 15a-c in yields of $64-69 \%$ (Scheme 8). ${ }^{112}$ 
<smiles>Oc1cccc2ccccc12</smiles>

8<smiles>O=C1NC(Br)c2ccc3ccccc3c2O1</smiles>

15a-c

$\mathrm{Ar}=\mathrm{Ph}: \mathbf{a} ; 4-\mathrm{Me}-\mathrm{Ph}: \mathbf{b} ; 3,4,5-(\mathrm{OMe})_{3}-\mathrm{Ph}: \mathbf{c}$

\section{Scheme 8}

A further procedure for condensation of 2-naphthol, aldehydes and urea as nitrogen source involves the application of semicarbazide. When 2-naphthol (1) or 6-bromo-2-naphthol (16), aldehydes and semicarbazide hydrochloride were reacted in tetrahydrofuran (THF) at r.t. or under solvent-free conditions at $80^{\circ} \mathrm{C}$, catalysed by the $p$-TSA/NaOAc system, 17a-u were isolated in moderate to good yields, as presented in Scheme 9. The reaction was carried out with 2 equivalents of aldehyde, since the carbamidoalkylnaphthol formed immediately reacts with a second equivalent of aldehyde to form the isolated products. ${ }^{113}$

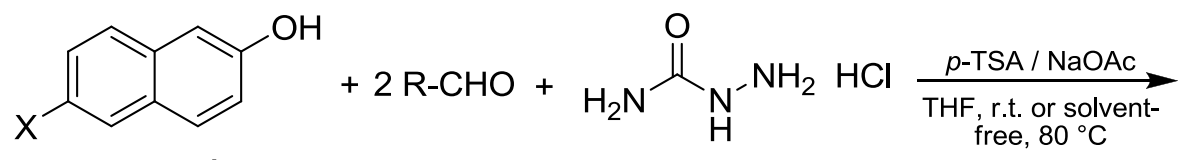

$\mathrm{X}=\mathrm{H}: 1$

$\mathrm{X}=\mathrm{Br}: 16$

$$
\mathrm{X}=\mathrm{H}: \mathbf{a - k} ; \mathbf{r}-\mathbf{t} ; \mathrm{Br}: \mathbf{l}-\mathbf{q} ; \mathbf{u}
$$<smiles>[R]C=NNC(=O)NC([R])c1c(O)ccc2cc([X])ccc12</smiles>

$17 a-u$

$\mathrm{R}=\mathrm{Ph}: \mathbf{a} ; 4-\mathrm{Cl}-\mathrm{Ph}: \mathbf{b} ; 2-\mathrm{Cl}-\mathrm{Ph}: \mathbf{c} ; 4-\mathrm{NO}_{2}-\mathrm{Ph}: \mathbf{d} ; 3-\mathrm{NO}_{2}-\mathrm{Ph}: \mathbf{e}$; 4-Me-Ph: f; 4-OMe-Ph: g; 3-OMe-Ph: h; 2-F,6-Cl-Ph: i; 2-furyl: j; 5-Me-2-thienyl: $\mathbf{k} ; \mathrm{Ph}$ : I; 4-NO $-\mathrm{Ph}: \mathbf{m}$; 4-Cl-Ph: $\mathbf{n}$; 4-Me-Ph: o; 3-OMe-Ph: p; 5-Me-2-thienyl: q; iPr: r; Et: s; $n$ Pr: t; Et: u

\section{Scheme 9}




\subsection{Syntheses of thioamido- and thiocarbamidoalkylnaphthols}

In consequence of the lower reactivity of the thio analogues of acetamide and urea, comparatively few publications have appeared on this field.

\subsubsection{Syntheses of thioamidoalkylnaphthols}

The research group of Murthy synthetized thioamidoalkylnaphthols from thioacetamide, benzaldehyde/pyridine-4-carbaldehyde and 2-naphthol in the presence of $\mathrm{H}_{2} \mathrm{SO}_{4} / \mathrm{SiO}_{2}$, obtaining 18a and $\mathbf{1 8 b}$ in yields of $79 \%$ and $82 \%$, respectively, within 2.2 and $2.5 \mathrm{~h}$ (Scheme 10). ${ }^{92}$

Derivatives 18a,c-h were prepared in yields of $78-88 \%$ in the presence of $\mathrm{Fe}\left(\mathrm{HSO}_{4}\right)_{3}$ in DCE at $60{ }^{\circ} \mathrm{C}\left(\right.$ Scheme 10). ${ }^{106}$

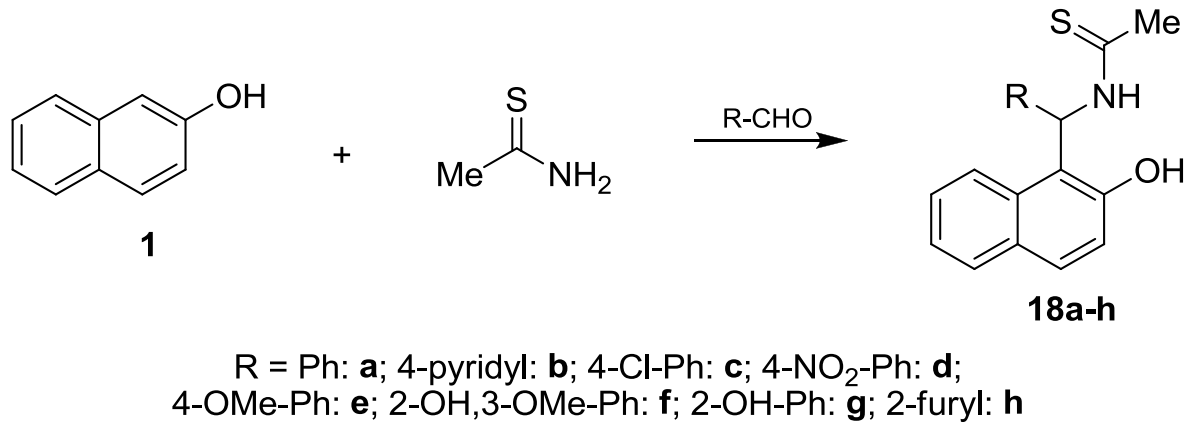

\section{Scheme 10}

\subsubsection{Syntheses of thiocarbamidoalkylnaphthols}

$\mathrm{H}_{2} \mathrm{SO}_{4} / \mathrm{SiO}_{2}$ was successfully applied under solvent-free conditions at r.t. in the three-component condensation of $\mathbf{1}$, aldehydes and thiourea. The expected products (19a-f) were formed in yields of 80$85 \%$ within $1.5-2.5 \mathrm{~h}$ (Scheme 11$).{ }^{92}$ It is worthy of note that this reaction did not lead to the desired thiocarbamidoalkylnaphthols from 1, thiocarbamide and the appropriate aldehyde in the presence of $\mathrm{K}_{2} \mathrm{CO}_{3}$ and $\mathrm{Cu}$ nanoparticles in PEG-400. ${ }^{109}$

Hossein et al. prepared thiocarbamidoalkylnaphthols $19 \mathrm{~g}-\mathbf{m}$ by using $\mathrm{Fe}\left(\mathrm{HSO}_{4}\right)_{3}$ at $60{ }^{\circ} \mathrm{C}$ in DCE (Scheme 11). The desired products were formed in yields of $75-91 \%$ within 5-8 h, whereas with furfural as starting compound, $\mathbf{1 9 m}$ was obtained in a yield of only $35 \%{ }^{106}$

A series of 1-thiocarbamidoalkyl-2-naphthols were prepared by Zhang et al. from aromatic aldehydes, 2-naphthol and $N$-phenylthiourea or thiourea in the presence of $p$-TSA at r.t. This inexpensive and mild method furnished the corresponding products in high yields. ${ }^{114}$ 


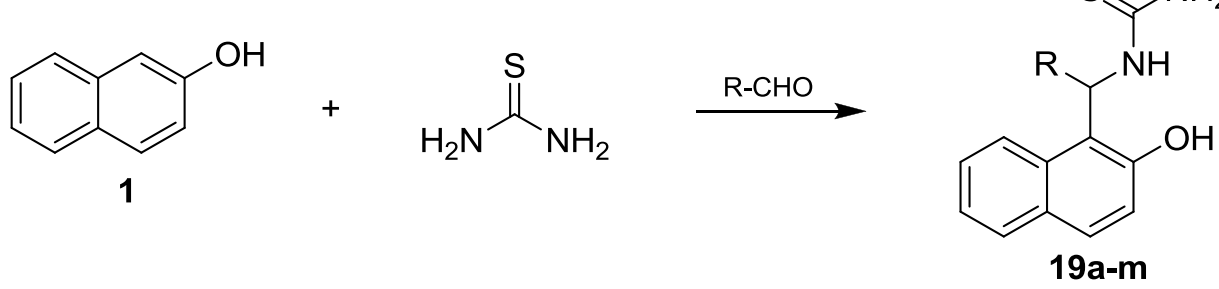

$\mathrm{R}=\mathrm{Et}: \mathbf{a} ; \mathrm{Pr}: \mathbf{b} ; \mathrm{CH}=\mathrm{CH}-\mathrm{Ph}$ : c; pentyl: d; cyclohexyl: e; 4-pyridyl: f; Ph: $\mathbf{g}$; 4-Cl-Ph: h; 4-NO ${ }_{2}-\mathrm{Ph}$ : i; 4-OMe-Ph: j; 2-OH,3-OMe-Ph: k; 2-Nph: I; 2-furyl: m

\section{Scheme 11}

It is of interest that 4-substituted 1-acylthiosemicarbazides 20a-r (Scheme 12) could be prepared in moderate to good yields in the presence of $p$-TSA via the three-component condensation of 2-naphthol, aldehydes and 1-acylthiosemicarbazides. ${ }^{115}$<smiles>O=C[O+]</smiles>

1<smiles>[X]c1ccc(C(=O)NNC(N)=S)cc1</smiles>

$$
\mathrm{X}=\mathrm{H}: \mathbf{a - j} ; 4-\mathrm{NO}_{2}: \mathbf{k - r}
$$<smiles>[X]c1ccc(C(=O)NNC(=S)NC([R])c2c(O)ccc3ccccc23)cc1</smiles>

20a-r

$\mathrm{R}=\mathrm{Ph}$ : a; 4-Me-Ph: b; 4-NO2-Ph: c; 4-OMe-Ph: d; 4-Cl-Ph: e; 2-Cl-Ph: f; 2-furyl: g; 2-pyridyl: $\mathbf{h}$; Et: i; $n$ Pr: j; Ph: k; 4-OMe-Ph: I; 3-NO2-Ph: m; 4-Cl-Ph: n; 4-Me-Ph: o; 2-pyridyl: p; Et: q; $n$ Pr: $\mathbf{r}$

\section{Scheme 12}

\subsection{Syntheses of carbamatoalkylnaphthols}

In the presence of a catalytic amount of $p$-TSA in a $[\mathrm{Bmim}] \mathrm{Br}$ medium at $60{ }^{\circ} \mathrm{C}$, 22a-f were synthetized in yields of $75-88 \%$ within a reaction time of $35-60$ min. It emerged that 22a-f can be converted into 1,2-dihydro-1-arylnaphth[1,2-e][1,3]oxazin-3-ones (12a,b,f-i) by heating in [Bmim]Br in the absence of catalyst at $160^{\circ} \mathrm{C}$ for $30 \mathrm{~min}$ (Schemes 6 and 13). Naphthoxazinone derivatives were obtained in yields of $58-79 \% .^{116}$

Carbamatoalkylnaphthols 22a,b,g-I were also prepared in high yields when $\mathrm{SiO}_{2}$-supported Preyssler nanoparticles were used as catalyst at $90{ }^{\circ} \mathrm{C}$ under solvent-free conditions (Scheme 13). ${ }^{117}$

Methyl (2-hydroxynaphthalen-1-yl)(phenyl)methylcarbamate (22a, Scheme 13) was prepared in a yield of $85 \%$ in the presence of $\left[\mathrm{MeC}(\mathrm{OH})_{2}\right]^{+} \mathrm{ClO}_{4}^{-}$, either at $80{ }^{\circ} \mathrm{C}$ under solvent-free conditions or in EtOAc at r.t. ${ }^{30}$ 


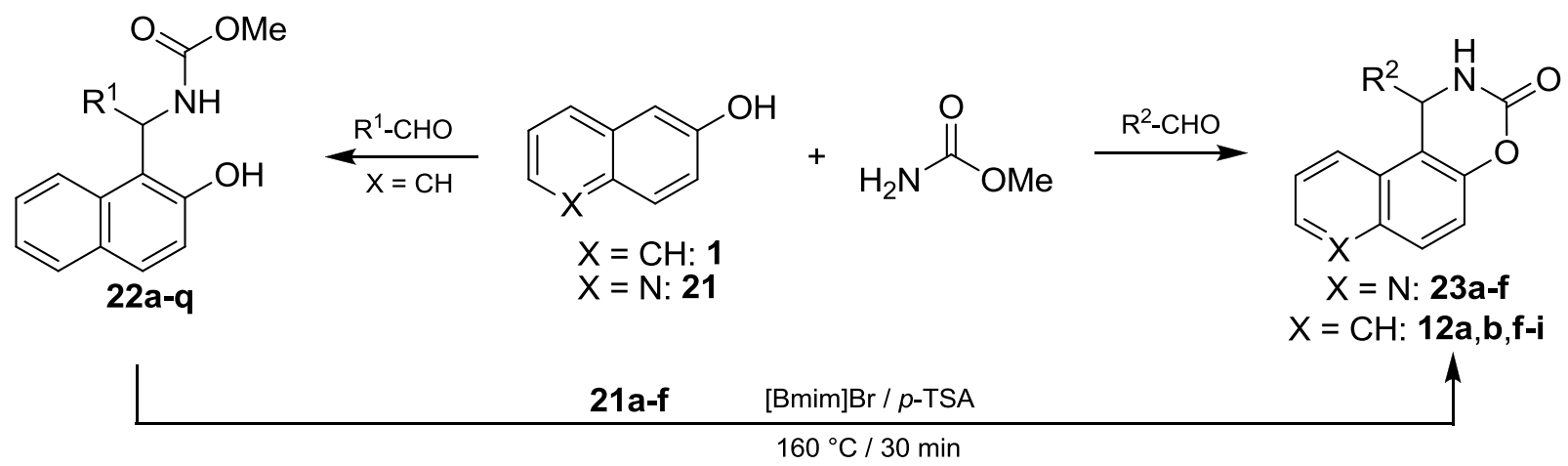

$\mathrm{R}^{1}=\mathrm{Ph}: \mathbf{a} ; 4-\mathrm{Cl}-\mathrm{Ph}: \mathbf{b} ; 4-\mathrm{F}-\mathrm{Ph}: \mathbf{c} ; 4-\mathrm{Br}-\mathrm{Ph}: \mathbf{d}$;

$\mathrm{R}^{2}=\mathrm{Ph}: \mathbf{a} ; 4-\mathrm{Cl}-\mathrm{Ph}: \mathbf{b} ; 4-\mathrm{F}-\mathrm{Ph}: \mathbf{c}$;

2-Cl-Ph: e; 3-Br-Ph: f; 3-Cl-Ph: g; 2-Me-Ph: $\mathbf{h}$; 4-Br-Ph: d; 4-OMe-Ph: e; 4-Me-Ph: f

2-NO $-\mathrm{Ph}: \mathrm{i} ; 3-\mathrm{NO}_{2}-\mathrm{Ph}: \mathbf{j} ; 4-\mathrm{NO}_{2}-\mathrm{Ph}: \mathbf{k} ; 2,4-\mathrm{Cl}_{2}-\mathrm{Ph}: \mathrm{I}$;

2,5-(OMe) ${ }_{2}-\mathrm{Ph}: \mathbf{m}$; Et: $\mathbf{n}$; $n$ Pr: o; iPr: $\mathbf{p}$; cyclohexyl: $\mathbf{q}$

\section{Scheme 13}

Efficient syntheses of 1,2-dihydro-1-arylnaphth[1,2-e][1,3]oxazin-3-ones (12a-d,f,g) and 1,2-dihydro-1-aryl[1,3] oxazino[5,6-f]quinolin-3-ones (23a-f) were accomplished in good yields (78-85\%) via reactions between 2-naphthol (1) or 6-quinolinol (21), aryl aldehydes and methyl carbamate in aqueous medium, catalysed by triethylbenzylammonium chloride (Schemes 6 and 13). ${ }^{118}$

Shaterian et al. achieved the $\mathrm{NaHSO}_{4} / \mathrm{SiO}_{2}{ }^{119}$ and $\mathrm{PPA} / \mathrm{SiO}_{2}$-catalysed ${ }^{120}$ syntheses of $\mathbf{2 2 a}, \mathbf{b}, \mathbf{g}, \mathbf{j}$ m and 24a-e at $100{ }^{\circ} \mathrm{C}$. In the presence of $\mathrm{HClO}_{4} / \mathrm{SiO}_{2}$ at $85^{\circ} \mathrm{C}$, carbamatoalkylnaphthols $22 \mathbf{a}, \mathbf{b}, \mathbf{g}, \mathbf{j}-\mathbf{m}$ and 24a-e were obtained in good yields (78-93\%) within 2.5-8.5 min (Schemes 13 and 14). ${ }^{121}$ The methods examined led to the formation of the desired compounds in good yields in the case of substituted benzaldehydes.

The research team of Hajra used a zwitterionic salt at $80^{\circ} \mathrm{C}$, this method furnishing $\mathbf{2 2 a}, \mathbf{b}, \mathbf{j}, \mathbf{k}, \mathbf{n}-\mathbf{q}$ and 24a,b in yields of $72-88 \%$ (Schemes 13 and 14). With aliphatic aldehydes, the reactions were complete within shorter reaction times. ${ }^{98}$

Brønsted acidic ILs ( $\mathrm{IL}_{1}$ and $\mathrm{IL}_{2}$ ) were revealed to be efficient catalysts for the preparation of 22a,b,f-I and 24a,e-g at $90{ }^{\circ} \mathrm{C}$ under neat conditions (Schemes 13 and 14). In both cases, high yields were attained, but no product could be detected when aliphatic aldehydes were used. ${ }^{122}$

Multicomponent condensation of aldehydes, 2-naphthol and methyl/benzyl carbamate was accomplished by using $\mathrm{Mg}\left(\mathrm{OCOCF}_{3}\right)_{2}$ as an efficient catalyst. This method resulted in the formation of a variety of methyl(2-hydroxynaphthalen-1-yl)(aryl)methyl/benzyl-carbamate derivatives in high yields. $^{123}$

The IL $[\mathrm{NMP}]^{+} \mathrm{HSO}_{4}^{-}$was applied as catalyst at $125{ }^{\circ} \mathrm{C}$ for the preparation of $\mathbf{2 4 d}, \mathbf{g}, \mathbf{h}, \mathbf{j}-\mathbf{l}$ in moderate to good yields (Scheme 14). ${ }^{74}$ 
The three-component aza-Friedel-Crafts reactions of 2-naphthol, 4-chlorobenzaldehyde and benzyl or tert-butyl carbamate in the presence of $\mathrm{I}_{2}$ as catalyst in toluene at r.t. led to the formation of carbamatoalkylnaphthols $\mathbf{2 4 i , \mathbf { m }}$ in yields of $74 \%$ and $62 \%$, respectively (Schemes 14). ${ }^{124}$<smiles>Oc1ccc2ccccc2c1</smiles>

1<smiles>[R]OC(N)=O</smiles>

$\mathrm{R}=\mathrm{Bn}: \mathbf{a - i} ; \mathrm{Et}: \mathbf{j}-\mathbf{l} ; \mathrm{tBu}: \mathbf{m}$

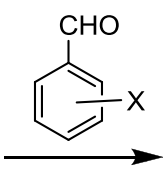<smiles>[R]OC(=O)NC(c1ccc([X])cc1)c1c(O)ccc2ccccc12</smiles>

24a-m

$\mathrm{X}=\mathrm{H}$ : $\mathbf{a}$; 2-Cl: b; 3-Cl: c; 3-OMe: d; 4-F: e; 3-Br: f; 3-NO $: \mathbf{~ g}$;

4-COOH: h; 4-Cl: i; $\mathrm{H}: \mathbf{j}$; 4-OMe: k; 3-NO 2 I; 4-Cl: m

\section{Scheme 14}

The high number of publications that have appeared on the synthesis of amido-, carbamido- and carbamatoalkylnaphthol derivatives reflect the importance of this area of organic chemistry. It is clear that the synthetic procedures generally demand the application of a heterogenous catalyst, and the reactions can usually be accelerated by applying additional irradiation techniques such as microwave irradiation or ultrasound. It may be concluded that the reactivity of 2-naphthol is higher than those of 1-naphthol or $N$-containing naphthol analogues. Benzaldehyde or substituted benzaldehydes generally react smoothly, and lower reactivity is observed for heteroaryl aldehydes. With aliphatic aldehydes as starting compounds, the desired products are not formed or can be isolated only in trace amounts. 


\section{RESULTS AND DISCUSSION}

\subsection{Syntheses of hydroxynaphthyl-substituted $\alpha$-amino acid derivatives}

When the synthesis of the desired hydroxynaphthyl-substituted glycine derivatives was designed, a rather cumbersome synthesis of 2-amino-2-(2'-hydroxynaphthalen-1'-yl)acetic acid was found. ${ }^{125}$ The intermediate 5-(2-methoxynaphthalen-1-yl)hydantoin was prepared from 2-hydroxy-1naphthaldehyde in two steps, and then treated with aq. $\mathrm{NaOH}$ solution under reflux for 1 day. The resulting product (2-amino-2-(2-methoxynaphthalen-1-yl)acetic acid) in THF was treated with $\mathrm{Et}_{3} \mathrm{~N}$ and di-tert-butyl dicarbonate at r.t. for 1 day to give 2-amino-2-(2'-hydroxynaphthalen-1'-yl)acetic acid hydrochloride.

In our first experiment, we attempted to prepare our target compound through the aminoalkylation of 2-naphthol with 2 equivalents of ethyl glyoxalate in the presence of $\mathrm{NH}_{3}$, followed by hydrolysis of the intermediate naphthoxazine. However, the basicity of the medium due to the $\mathrm{NH}_{3}{ }^{126}$ led to the formation of ethyl 2-hydroxy-2-(2'-hydroxynaphthalen-1'-yl)acetate by the direct addition of 2-naphthol to ethyl glyoxalate. To decrease the basic character of the reaction mixture, the $\mathrm{NH}_{3}$ was replaced by tert-butyl carbamate, ${ }^{127}$ but even on the use of different reaction conditions (solvent-free or $\mathrm{MeOH}, 60-100{ }^{\circ} \mathrm{C}$; microwave irradiation, solvent-free or $\mathrm{MeOH}, 60-130{ }^{\circ} \mathrm{C}$ ), the target compound could not be isolated, e.g. at low temperature there was no conversion, while higher temperature resulted in the formation of a multi-spot reaction mixture.

At this point, our attention was drawn to benzyl carbamate as another protected $\mathrm{NH}_{3}$ source. ${ }^{128} \mathrm{~A}$ mixture of 2-naphthol, glyoxylic acid monohydrate and benzyl carbamate was refluxed in $\mathrm{MeOH}$ for $70 \mathrm{~h}$, and the product was then isolated by column chromatographic purification ( $n$-hexane-EtOAc 2/1), in a yield of $13 \%$. The NMR data supported the structure of methyl 2-(benzyloxycarbonylamino)2-(2'-hydroxynaphthalen-1'-yl)acetate (25a, Scheme 15). It is interesting to note that in this reaction $\mathrm{MeOH}$ simultaneously played roles both as a solvent and as an esterification reagent. Since $p$-TSA is frequently applied as a catalyst in the $\mathrm{mMR},{ }^{80,129}$ its effect was examined in this reaction. In the presence of $10 \mathrm{~mol} \%$ p-TSA, the reaction yield rose to $21 \%$. In an effort to achieve a higher conversion, the amount of $p$-TSA was systematically increased, as presented in Table 1.

With 1 equivalent of $p$-TSA under reflux conditions, the product started to separate out as white crystals from the reaction mixture after a few hours; further refluxing for 24 h gave the product in $69 \%$ yield. The benzyloxycarbonyl group was then removed by catalytic $(\mathrm{Pd} / \mathrm{C})$ hydrogenation to afford compound 26a (Scheme 15). For the hydrolysis of 26a, different concentrations of aq. $\mathrm{HCl}$ solution 
were tested; refluxing for $2 \mathrm{~h}$ in $5 \%$ aq. $\mathrm{HCl}$ solution was found to be optimum for the formation of $\mathbf{2 7}$ (Scheme 15).

Table 1. Effect of the amount of $p$-TSA on the isolated yield of 25a by using benzyl carbamate in $\mathrm{MeOH}$ under reflux conditions

\begin{tabular}{ccc}
\hline Catalyst $(\mathrm{mol} \%)$ & Time $(\mathrm{h})$ & ${\text { Yield }(\%)^{\mathrm{a}}}^{\mathrm{a}}$ \\
\hline 0 & 70 & 13 \\
10 & 62 & 21 \\
20 & 51 & 44 \\
30 & 37 & 50 \\
100 & 26 & 69 \\
\hline
\end{tabular}

${ }^{\mathrm{a}}$ Isolated yields.

The optimized reaction conditions were then extended to 1-naphthol. Its reactions with glyoxylic acid monohydrate, benzyl carbamate and $p$-TSA in $\mathrm{MeOH}$ at reflux temperature led to the formation of 28a as white crystals that started to separate out from the reaction mixture after a few hours; further refluxing for $31 \mathrm{~h}$ gave the product $\mathbf{2 8 a}$ in $53 \%$ yield. The protecting group of $\mathbf{2 8 a}$ was removed by catalytic $(\mathrm{Pd} / \mathrm{C})$ hydrogenation to yield $\mathbf{2 9 a}$, which was then hydrolysed with $10 \%$ aq. $\mathrm{HCl}$ solution to furnish 30 in $88 \%$ yield (Scheme 15).<smiles>O=C(NC(C(=O)OCc1ccccc1)c1c(O)ccc2ccccc12)OCc1ccccc1</smiles>

25a,b

$$
\text { iii or iv }
$$<smiles>NC(C(=O)O)C(N)c1c(O)ccc2ccc(I)c(C(=O)O)c12</smiles>

26a,b<smiles>Cc1ccc2cc(O)ccc2c1</smiles><smiles>NC(=O)Cc1ccccc1</smiles><smiles>Oc1cccc2ccccc12</smiles><smiles>[R]OC(=O)C(NC(=O)OCc1ccccc1)c1ccc2ccccc2c1O</smiles>
$\downarrow$ viii or ix<smiles>[R]C(=O)C(N)c1ccc2ccccc2c1O</smiles>

30
$29 a, b$

$$
\mathrm{R}=\mathrm{Me}: \mathbf{a} ; \mathrm{Et}: \mathbf{b}
$$

Reagent, conditions and yields: (i) p-TSA, MeOH, reflux, $26 \mathrm{~h}, 69 \%$; (ii) p-TSA, EtOH, reflux, $94 \mathrm{~h}$, 34\%; (iii) $\mathrm{Pd} / \mathrm{C}, \mathrm{H}_{2}$, MeOH, r.t., 1 h, HCl-EtOH, 75\%; (iv) Pd/C, $\mathrm{H}_{2}$, EtOH, r.t., 1.5 h, HCl-EtOH, 72\%; (v) $\mathrm{R}=\mathrm{Me}, 5 \%$ aq. $\mathrm{HCl}$, reflux, $2 \mathrm{~h}, 82 \%$; (vi) $\mathrm{MeOH}$, reflux, $36 \mathrm{~h}, 53 \%$; (vii) EtOH, reflux, $97 \mathrm{~h}, 27 \%$; (viii) $\mathrm{Pd} / \mathrm{C}, \mathrm{H}_{2}, \mathrm{MeOH}$, r.t., 1 h, $\mathrm{HCl}-\mathrm{EtOH}, 84 \%$; (ix) $\mathrm{Pd} / \mathrm{C}, \mathrm{H}_{2}$, EtOH, r.t., 1.5 h, HCl-EtOH, 69\%; (x) $\mathrm{R}=\mathrm{Me}, 10 \%$ aq. $\mathrm{HCl}$, reflux, $4 \mathrm{~h}, 88 \%$. 
As a new extension of the synthetic protocol, $\mathrm{MeOH}$ was successfully replaced by $\mathrm{EtOH}$, starting either from 2-naphthol or from 1-naphthol (Scheme 15). It should be mentioned that longer reaction times were needed for the formation of the protected ethyl ester derivatives (25b and $\mathbf{2 8 b}$ ), and the products were isolated in lower yields. Removal of the benzyloxycarbonyl group furnished $\mathbf{2 6} \mathbf{b}$ and 29b, respectively (Scheme 15).

Our attention next focused on the application of other carbamates, such as tert-butyl carbamate. In the reaction of 2-naphthol, glyoxylic acid and tert-butyl carbamate in the presence of 1 equivalent of $p$-TSA, the desired protected ester derivative was not formed. The NMR spectra of the isolated product adequately supported the structure of 31, which is a known product of the reaction between 2-naphthol and glyoxylic acid, followed by reflux in $\mathrm{MeOH}$ in acidic media. ${ }^{126}$ The previous reaction was tested by starting from 1-naphthol, glyoxylic acid and tert-butyl carbamate, which led to the formation of methyl 2-(1'-hydroxynaphthalen-2'-yl)-2-methoxyacetate (32), in a yield of 39\% (Scheme 16).<smiles>COC(OC)C(C(C)=O)c1c(O)ccc2ccccc12</smiles>

31
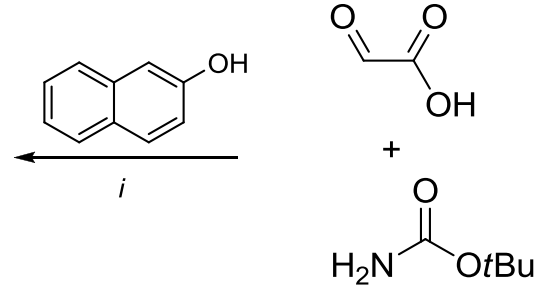

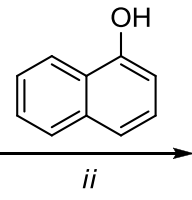<smiles>COC(C(C)=O)c1ccc2ccccc2c1O</smiles>

32

Reagent, conditions and yields: (i) p-TSA, $\mathrm{MeOH}$, reflux, 93 h, 38\%, (ii) p-TSA, MeOH, reflux, $98 \mathrm{~h}, 39 \%$.

\section{Scheme 16}

HPLC enantioseparation of aminonaphthol derivatives is frequently carried out on a cellulose tris(3,5-dimethylphenylcarbamate)-based chiral stationary phase (Chiralcel OD-H), with $n$-hexane2-PrOH as mobile phase. ${ }^{130} 1.1$ equivalents of $\mathrm{Et}_{3} \mathrm{~N}$ were used for the liberation of compounds $\mathbf{2 6}$ a and 29a, and the enantioseparation of their substituted glycine esters was then started with this column. Different mobile phase compositions were tested and the best resolution for 26a and 29a was found under the conditions described in Figure 1.

The enantioseparation was scaled up to milligram quantities by using a Lux $^{\mathrm{TM}}$ Cellulose- 1 semipreparative column. The chromatographic conditions applied were: $n$-hexane-2-PrOH (80/20 (v/v) for 26a, and 85/15 (v/v) for 29a) with a flow rate of $2 \mathrm{~mL} / \mathrm{min}$.

For the configurational assignment of the separated enantiomers of 26a and 29a, their CD analysis was performed. An MMFF conformational search for the second-eluting enantiomer of 26a followed by B3LYP/6-31G(d) optimization afforded the lowest-energy conformer with high population $(96.5 \%)$ and its torsional angle $\omega_{2 \mathrm{H}, \mathrm{C} 2, \mathrm{Cl}{ }^{\prime}, \mathrm{C} 10^{\prime}}$ was found to be $-12.04^{\circ}$. The $\mathrm{CD}$ spectra were 
then calculated for the lowest-energy conformer of 26a with various functionals (B3LYP, BH\&HLYP and CAM-B3LYP) and the TZVP basis set.

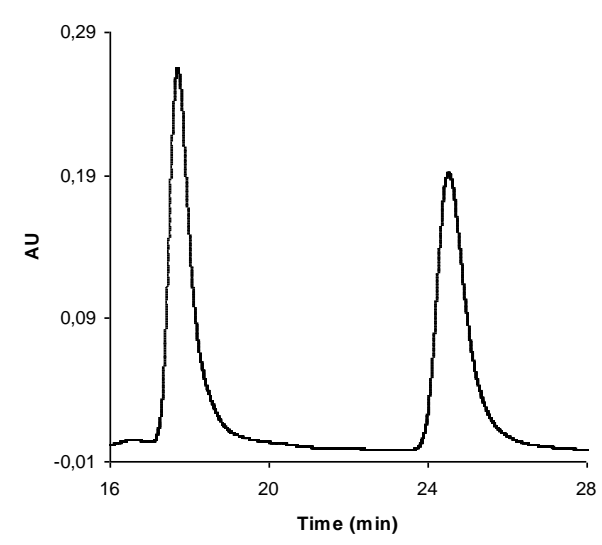

$\mathbf{a}$

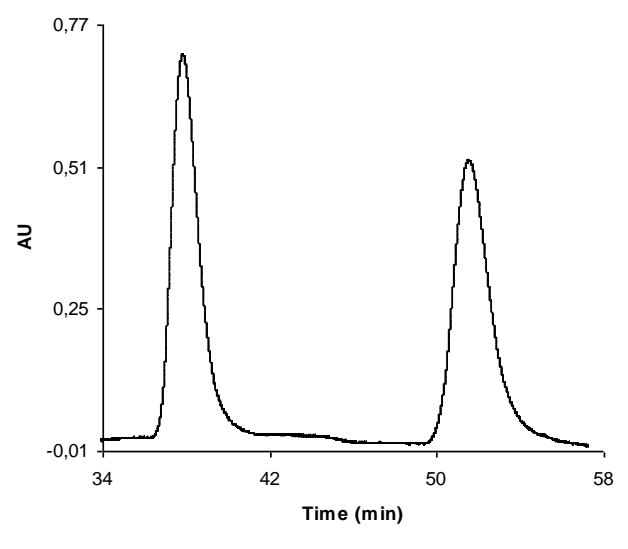

b

Figure 1. a) Chromatogram of 26a. Conditions: Chiralcel OD-H; $n$-hexane-2-PrOH $=70 / 30(\mathrm{v} / \mathrm{v})$; detection at $230 \mathrm{~nm}$; flow rate $0.5 \mathrm{~mL} / \mathrm{min}$.

b) Chromatogram of 29a. Conditions: Chiralcel OD-H; $n$-hexane-2-PrOH = $85 / 15(\mathrm{v} / \mathrm{v})$; detection at $230 \mathrm{~nm}$; flow rate $0.5 \mathrm{~mL} / \mathrm{min}$.

All the calculated CD spectra reproduced the experimental CD of the second-eluting enantiomer of 26a well, with BH\&HLYP/TZVP giving the best agreement. Thus, the absolute configuration of the second-eluting enantiomer was determined unambiguously as $S$. A similar CD calculation protocol was carried out on the first-eluting enantiomer of 29a to determine its absolute configuration. The lowestenergy calculated conformer had a population of $96.2 \%$ and its torsional angle $\omega_{2 \mathrm{H}, \mathrm{C} 2, \mathrm{C} 2}$, $\mathrm{C} 3$, was found to be $-10.91^{\circ}$. All three computed CD spectra of 29a reproduced the experimental CD of the firsteluting enantiomer well with the CAM-B3LYP/TZVP method, which showed negative CEs in the ${ }^{1} \mathrm{~L}_{\mathrm{b}}$ and ${ }^{1} \mathrm{~L}_{\mathrm{a}}$ regions and a negative couplet centred around $221 \mathrm{~nm}$. Thus, the absolute configuration of the first-eluting enantiomer of 29a was determined as $S$. 


\subsection{Syntheses and conformational analyses of naphthoxazine-fused quinazoline derivatives}

\subsubsection{Syntheses of naphthoxazinoquinazoline derivatives}

For the synthesis of the proposed naphthoxazinoquinazoline derivatives, the preparation of 1-(amino(2-aminophenyl)methyl)-2-naphthol (35) as starting material was planned. In our initial experiment, we attempted the aminoalkylation of 2-naphthol with 2 equivalents of 2-nitrobenzaldehyde in the presence of $\mathrm{NH}_{3}$, followed by hydrolysis of the intermediate naphthoxazine. This reaction resulted in the formation of a multi-spot reaction mixture (based on the TLC). In the following experiment, $\mathrm{NH}_{3}$ was replaced by tert-butyl carbamate as a protected $\mathrm{NH}_{3}$ source, and a mixture of 2-naphthol, 2-nitrobenzaldehyde and tert-butyl carbamate was therefore heated under solvent-free conditions for $55 \mathrm{~h}$ at $60{ }^{\circ} \mathrm{C}$. This furnished nitro derivative 33 in a yield of $46 \%$. When the reaction was repeated at $80{ }^{\circ} \mathrm{C}, \mathbf{3 3}$ was isolated in $53 \%$ yield after $47 \mathrm{~h}$. The tert-butoxycarbonyl group was removed with TFA, resulting in 34. This step was followed by reduction of the $\mathrm{NO}_{2}$ group by means of catalytic ( $\mathrm{Pd} / \mathrm{C})$ hydrogenation, yielding 35 (Scheme 17).<smiles>CCCOC(=O)NC(c1ccccc1[N+](=O)[O-])c1c(O)ccc2ccccc12</smiles>

33

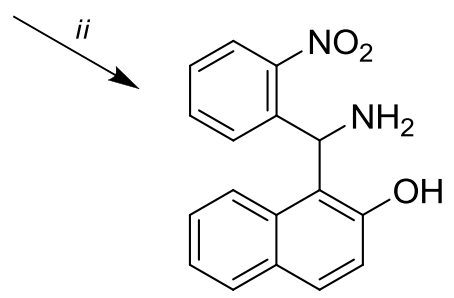

34<smiles>O=Cc1ccccc1[N+](=O)[O-]</smiles>

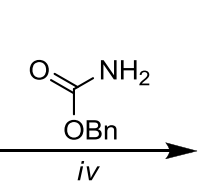<smiles>O=C(NC(c1ccccc1[N+](=O)[O-])c1c(O)ccc2ccccc12)OCc1ccccc1</smiles>

36

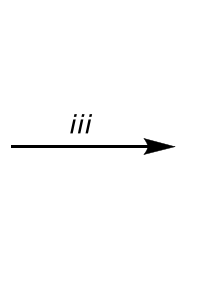<smiles>Nc1ccccc1C(N)c1c(O)ccc2ccccc12</smiles>

35

Reagents, conditions and yields: (i) $80{ }^{\circ} \mathrm{C}, 47 \mathrm{~h}, 53 \%$; (ii) $99 \%$ TFA, r.t., $10 \mathrm{~min}, 10 \% \mathrm{Na}_{2} \mathrm{CO}_{3}, 90 \%$; (iii) $\mathrm{Pd} / \mathrm{C}, \mathrm{H}_{2}$, $\mathrm{MeOH}$, r.t., 1.5 h, 68\%; (iv) $80{ }^{\circ} \mathrm{C}, 32$ h, $76 \%$; (v) $\mathrm{Pd} / \mathrm{C}, \mathrm{H}_{2}$, $\mathrm{MeOH}$, r.t., 2 h, $69 \%$.

\section{Scheme 17}

Since 33 was formed in only 53\% yield on starting from tert-butyl carbamate, our attention focused on another protected $\mathrm{NH}_{3}$ source, benzyl carbamate. From 2-naphthol, 2-nitrobenzaldehyde and benzyl carbamate under solvent-free conditions, 36 was synthetized in $71 \%$ yield at $60{ }^{\circ} \mathrm{C}$ after 
$46 \mathrm{~h}$, whereas at $80{ }^{\circ} \mathrm{C}$, in a shorter reaction time (32 h), the yield was $76 \%$. Removal of the protecting group and reduction of the $\mathrm{NO}_{2}$ group were accomplished in one step by catalytic $(\mathrm{Pd} / \mathrm{C})$ hydrogenation, yielding 35 (Scheme 17).

In the first stage of the transformations of $\mathbf{3 5}$ to heterocyclic derivatives, an $s p^{3}$ carbon was inserted between the $\mathrm{OH}$ and $\mathrm{NH}_{2}$ groups (in position $\mathrm{C}-8$ or C-10). Compound 35 was stirred with 2 equivalents of aqueous formaldehyde in $\mathrm{CHCl}_{3}$ at r.t. After $1.5 \mathrm{~h}$, when TLC showed no presence of the starting material, the reaction was stopped and 10,11-dihydro- $8 H, 15 \mathrm{~b} H$-naphth[1,2-e][1,3] oxazino[3,4-c]quinazoline (37) was isolated by column chromatographic purification (Scheme 18). Since 37 was formed from aqueous formaldehyde in $\mathrm{CHCl}_{3}$ in a yield of only $40 \%$, another solvent $(\mathrm{MeOH})$ and the use of paraformaldehyde were also examined, but these reactions were found by TLC to result in the formation of a multi-spot reaction mixture.

In order to extend the number of aldehyde reagents, we set out to examine the reactions of diamine 35 with benzaldehyde. Aminonaphthol derivative 35 was dissolved in $\mathrm{MeOH}, 1.1$ equivalents of benzaldehyde was added and the mixture was left to stand at r.t. for 1 day. After a few hours, the product 38d $(\mathrm{X}=\mathrm{H})$ started to separate out from the reaction mixture. Due to the presence of two $\mathrm{NH}_{2}$ and one phenolic $\mathrm{OH}$ group in the starting diamine 35, two different ring systems can be formed via its condensation with benzaldehyde. In solution at $300 \mathrm{~K}$, compound $\mathbf{3 8 d}$ is potentially present as a fivecomponent tautomeric mixture of the chain tautomer (A), two epimers of quinazoline (38B and $\mathbf{3 8 C}$ ) and two epimers of naphthoxazine (38D and 38E) derivatives (Scheme 18).

In the NMR spectra of $\mathbf{3 8 d}$ in $\mathrm{CD}_{2} \mathrm{Cl}_{2}$ at $300 \mathrm{~K}$, only three tautomeric forms were detected and identified. The major ring form was found to be 2-phenyl-4-(2-hydroxynaphthalen-1-yl)-1,2,3,4tetrahydroquinazoline (38dB or $\mathbf{3 8 d C}$ ); the NOESY spectrum proved that the major ring-closed tautomer in the equilibria contains $\mathrm{H}-2$ and H-4 in the trans position (38dB). Formation of the quinazoline derivative as the major product can be explained by the stabilization caused by the strong intramolecular hydrogen-bonds between the lone pair of the $\mathrm{N}$ atom and the $\mathrm{OH}$ group, and the higher nucleophilic character of $\mathrm{NH}_{2}$ than that of $\mathrm{OH}$. The minor ring forms were found to be 8-phenyl-10-(2aminophenyl)-8,9-dihydro-7H-naphth[1,2-e][1,3]oxazine (38dD and 38dE). The NOE interaction observed between $\mathrm{H}-8$ and $\mathrm{H}-10$ showed that the relative configuration of the major naphthoxazine epimer attains the cis arrangement (38dE), while for the minor epimer the lack of the cross-peak for H-8 and H-10 proves their trans arrangement (38dD). The chain tautomer $(\mathbf{A})$ and the cis quinazoline (C) were not detected in the NMR spectra. 


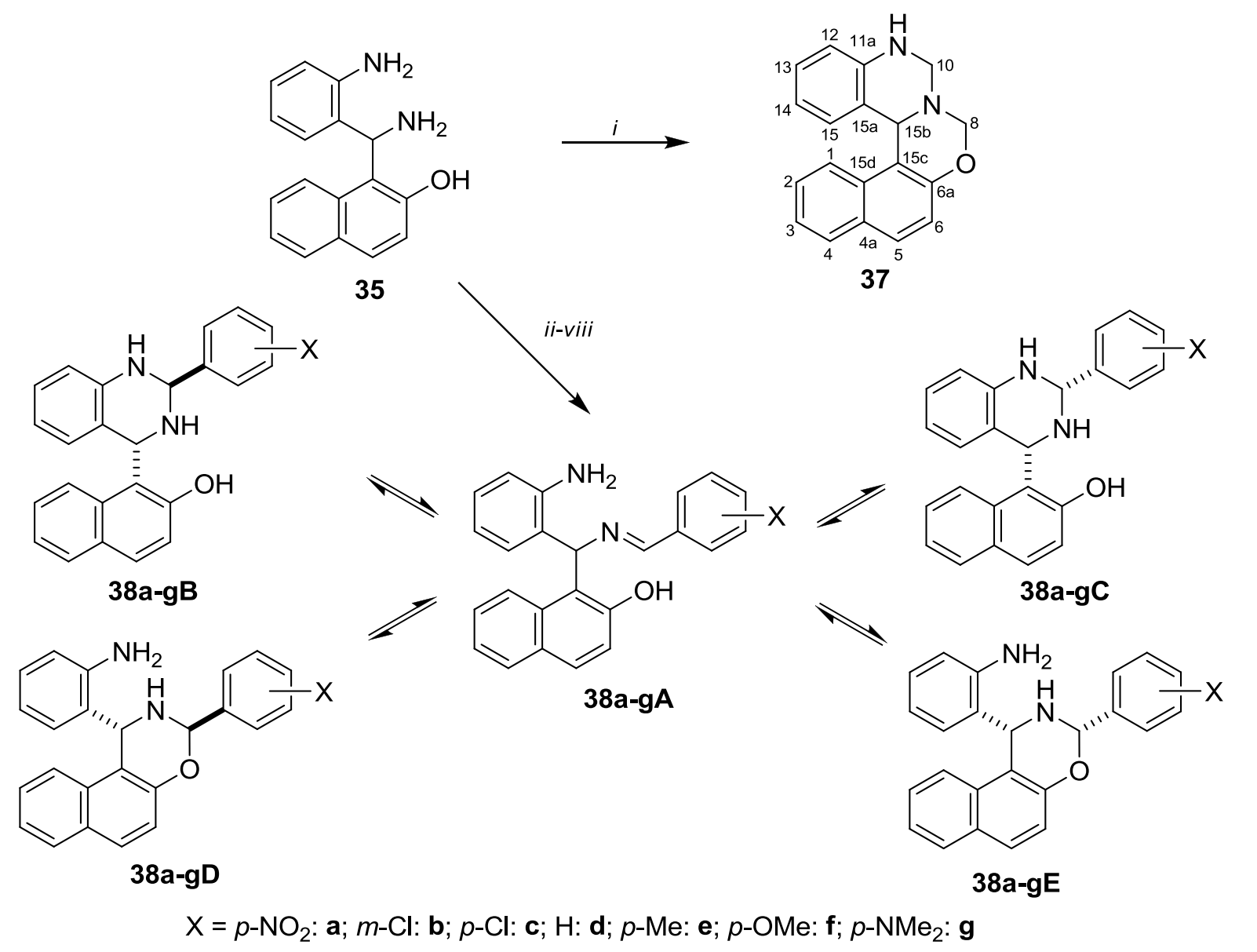

Reagents, conditions and yields: (i) 2 equiv. $30 \%$ aq. $\mathrm{CH}_{2} \mathrm{O}, \mathrm{CHCl}_{3}$, r.t., $1.5 \mathrm{~h}, 40 \%$; (ii) $p$ - $\mathrm{NO}_{2}-\mathrm{PhCHO}, \mathrm{MeOH}$, r.t., 24 h, 38a: 77\%; (iii) $m$-Cl-PhCHO, $\mathrm{MeOH}$, r.t., 24 h, 38b: 52\%; (iv) p-Cl-PhCHO, $\mathrm{MeOH}$, r.t., 24 h, 38c: 63\%; (v) $\mathrm{PhCHO}, \mathrm{MeOH}$, r.t., 24 h, 38d: 88\%; (vi) p-Me-PhCHO, $\mathrm{MeOH,} \mathrm{r.t.,} 24$ h, 38e: 66\%; (vii) $p$-OMe-PhCHO, $\mathrm{MeOH}$, r.t., 24 h, 38f: 90\%; (viii) $p$ - $\mathrm{NMe}_{2}-\mathrm{PhCHO}, \mathrm{MeOH}$, r.t., 24 h, 38g: $57 \%$.

\section{Scheme 18}

To characterize the effects of the aryl substituents on the tautomeric equilibria of this ring system, 2-(aryl-substituted)-4-(2-hydroxynaphthalen-1-yl)-1,2,3,4-tetrahydroquinazolines (38a-c and 38e-g) were also prepared (Scheme 18). The proportions of the ring tautomers ( $\mathbf{B}, \mathbf{D}$ and $\mathbf{E}$ ) in the tautomeric equilibria of 38a-g (Table 2) were determined by integration of the quinazoline and naphthoxazine proton singlets or doublets in the ${ }^{1} \mathrm{H}$ NMR spectra.

The tautomeric composition (e.g. the proportions of the ring-closed forms) demonstrated a small, but systematic dependence on the Hammett-Brown parameter ${ }^{131,132}\left(\sigma^{+}\right)$of the aryl substituent, which characterizes the electronic character of the substituent in question (Table 2).

The plots of the proportions of the tautomeric forms (B, D and $\mathbf{E}$ ) for 41a-g $v s . \sigma^{+}$(Figure 2) gave good correlations for all three forms ( 0.951 for $\mathbf{B}, 0.938$ for $\mathbf{D}$ and 0.978 for $\mathbf{E})$. It can be concluded that electron-donating substituents increase the proportions of the quinazoline form $(\mathbf{B})$, while electronwithdrawing substituents prefer the naphthoxazine forms (D and E). As concerns the slopes, the 
dependence for $\mathbf{B}$ seems to be the most characteristic; for $\mathbf{E}$, only small changes were observed for the various substitutions (Figure 2).

Table 2. Proportions (\%) of the tautomeric forms (A, B, C, D and $\mathbf{E})$ in tautomeric equilibrium for compounds 38a-g $\left(\mathrm{CD}_{2} \mathrm{Cl}_{2}, 300 \mathrm{~K}\right)$

\begin{tabular}{ccccccc}
\hline $\mathrm{X}$ & $\sigma^{+}$ & $\mathbf{A}(\%)$ & $\mathbf{B}(\%)$ & $\mathbf{C}(\%)$ & $\mathbf{D}(\%)$ & $\mathbf{E}(\%)$ \\
\hline$p-\mathrm{NO}_{2}$ & 0.79 & - & 79.1 & - & 5.8 & 15.1 \\
$m-\mathrm{Cl}$ & 0.40 & - & 80.6 & - & 5.5 & 13.9 \\
$p-\mathrm{Cl}$ & 0.11 & - & 82.0 & - & 5.3 & 12.7 \\
$\mathrm{H}$ & 0.00 & - & 84.5 & - & 4.8 & 10.7 \\
$p-\mathrm{Me}$ & -0.31 & - & 85.2 & - & 4.5 & 10.3 \\
$p-\mathrm{OMe}$ & -0.78 & - & 87.0 & - & 4.1 & 8.9 \\
$p-\mathrm{NMe}_{2}$ & -1.70 & - & 88.6 & - & 3.5 & 7.9 \\
\hline
\end{tabular}

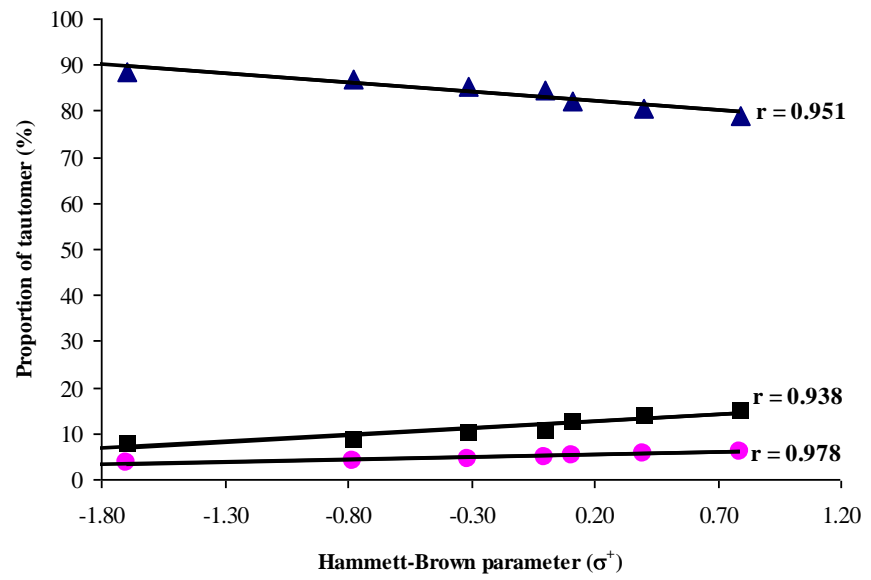

Figure 2. Plots of proportions of the tautomers (in $\left.\mathrm{CD}_{2} \mathrm{Cl}_{2}\right), \mathbf{B}(\mathbf{\Delta}), \mathbf{D}(\mathbf{\square}), \mathbf{E}(\bullet)$ for 38a-g vs. Hammett-Brown parameter $\left(\sigma^{+}\right)$

A further aim was the insertion of an $s p^{2}$ carbon in position C-8 or C-10 or both. For the direct ring closure reaction of diamine 35 with phosgene, it was stirred with 0.5 equivalents of triphosgene in toluene in the presence of $\mathrm{Na}_{2} \mathrm{CO}_{3}$ (Scheme 19). The appearance of two new TLC spots was observed. The products formed were separated by column chromatography and the mass spectra confirmed that one was the oxo compound 39 and the other was the corresponding 8,10-dione (40). The 2D NMR measurements on the single ring-closed compound supported the structure of the quinazolin-2-one derivative (39). For its preparation, a reaction time of $45 \mathrm{~h}$ was found to be optimum, but it should be mentioned that 39 was separated in only $40 \%$ yield, which can be explained in terms of the parallel formation of 10,11 -dihydro- $8 H, 15 \mathrm{~b} H$-naphth[1,2-e][1,3]oxazino[3,4-c]quinazolin-8,10-dione (40). 
To isolate $\mathbf{4 0}$ in higher yield, and to avoid the formation of $\mathbf{3 9}$, the reaction of $\mathbf{3 5}$ was repeated but with 4 equivalents of triphosgene. After a reaction time of $8.5 \mathrm{~h}, \mathbf{4 0}$ was isolated in $67 \%$ yield (Scheme 19).

To examine the ring closure ability of $\mathbf{3 9}$, it was reacted with benzaldehyde. In consequence of the decreased nucleophilic character of the carbamide $\mathrm{NH}(\mathrm{PhCHNH})$, despite a long reaction time (refluxing in toluene for $51 \mathrm{~h}$ ), the presumed oxo derivative $\mathbf{4 1}$ was not formed.

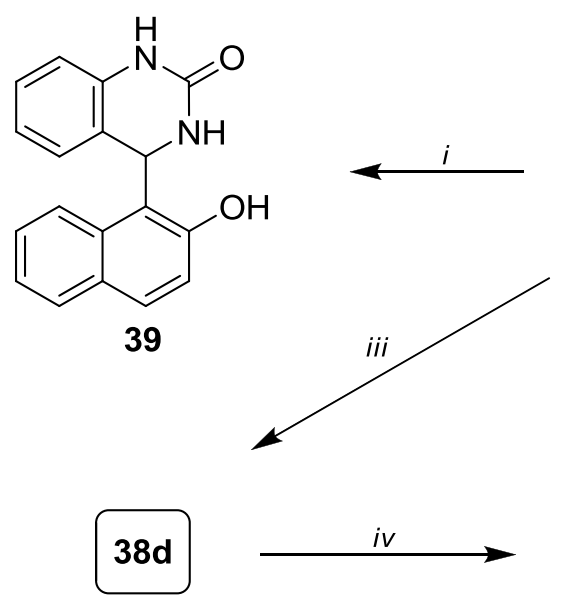<smiles>Nc1ccccc1C(N)c1c(O)ccc2ccccc12</smiles>

35

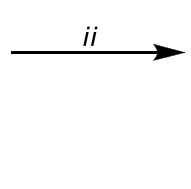<smiles></smiles>

41<smiles>Cc1ccc2c(c1)OC(=O)N1C(=O)Nc3ccccc3C21</smiles><smiles>O=C1CC2(Nc3ccccc3[C@H]2c2ccccc2)c2c(ccc3ccccc23)O1</smiles>

42

Reagents, conditions and yields: (i) 0.5 equiv. $\left(\mathrm{COCl}_{2}\right)_{3}, 5$ equiv. $\mathrm{Na}_{2} \mathrm{CO}_{3}$, toluene, r.t., $45 \mathrm{~h}, 40 \%$; (ii) 4 equiv. $\left(\mathrm{COCl}_{2}\right)_{3}, 10$ equiv. $\mathrm{Na}_{2} \mathrm{CO}_{3}$, toluene, r.t., $6.5 \mathrm{~h}, 31 \%$; (iii) 1.1 equiv. $\mathrm{PhCHO}, \mathrm{MeOH}$, r.t., $24 \mathrm{~h}, 88 \%$; (iv) 4 equiv. $\left(\mathrm{COCl}_{2}\right)_{3}, 10$ equiv. $\mathrm{Na}_{2} \mathrm{CO}_{3}$, toluene, r.t., $8.5 \mathrm{~h}, 67 \%$.

\section{Scheme 19}

The ability of $\mathbf{3 8 d}$ to undergo transformation was further tested by its reaction with phosgene. When 38d was reacted with 4 equivalents of triphosgene in the presence of $\mathrm{Na}_{2} \mathrm{CO}_{3}$ in toluene for $6.5 \mathrm{~h}$ at r.t., the product (41 or $\mathbf{4 2}$ ) was isolated after column chromatographic purification in a yield of $31 \%$. Full assignment of the NMR signals in DMSO supported the formation of the quinazolinone derivative (41). The two possible ring systems have very similar chemical environments; the cross-peak between C-6a (150.5 ppm) and H-8 (7.04 ppm) in the HMBC spectrum should be the only difference supporting the presence of 8-phenyl-10,11-dihydro- $8 H, 15 \mathrm{~b} H$-naphth[1,2-e][1,3] oxazino[3,4-c]quinazolin-10-one (41) instead of 10-phenyl-10,11-dihydro- $8 H, 15 \mathrm{~b} H$-naphth[1,2-e][1,3] oxazino[3,4-c]quinazolin-8-one (42). To support the structure found by NMR measurement, crystalline product $\mathbf{4 1}$ was examined with electron impact ionization in $\mathrm{MeOH}$. The electron ionization (EI) mass spectrum of naphthoxazinoquinazolinone $\mathbf{4 1}$ is characterized by the fragment ion $[\mathrm{M}-\mathrm{CONH}]^{+}$at $m / z, 335$. This ion is probably formed by direct loss of this fragment from the molecular ion at $m / z$, 378, which proves that the newly inserted oxo group is at position 10. This unexpected structure can be explained through the 
tautomeric equilibrium present for $\mathbf{3 8 d}$ in solution and, probably because of the stronger nucleophilic character of $\mathrm{NH}_{2}(\mathbf{3 8 d D}$, Scheme 18) than that of $\mathrm{OH}(\mathbf{3 8 d B}$, Scheme 18), this minor tautomeric form reacts with triphosgene to give 41. During the reaction, the formation of two diastereomers is possible; the diastereomeric ratio was therefore checked by NMR spectroscopy on the crude product. It was found that only one diastereomer is present. The NOE measurements on purified $\mathbf{4 1}$ indirectly proved the trans arrangement of $\mathrm{H}-8$ and $\mathrm{H}-15 \mathrm{~b}$ (Scheme 19).

In order to investigate the influence of the anellation on the conformation of naphth[1,2-e][1,3]oxazinoquinazolines, our aims were to synthetize new naphth[1,2-e][1,3]oxazino[3,2-c]quinazoline derivatives, and to achieve the conformational analyses of these polycyclic compounds by NMR spectroscopy and accompanying molecular modelling.

For the synthesis of the proposed naphthoxazinoquinazolines, the preparations of 2-(2,3-dihydro$1 H$-naphth[1,2-e][1,3]oxazin-3-yl)aniline and 2-(1-phenyl-2,3-dihydro-1 $H$-naphth[1,2-e][1,3]oxazin-3yl)aniline as starting materials were planned. In our initial experiments, we attempted to prepare the target compounds through the condensations of 1-aminomethyl-2-naphthol or 1-aminobenzyl-2naphthol with 1.1 equivalents of 2-aminobenzaldehyde. ${ }^{133}$ However, because of the low reactivity of 2-aminobenzaldehyde (which can be explained by the presence of its imino mesomer structure), ${ }^{134}$ there was no conversion. An attempt was made to shift the equilibrium towards the aldehyde function by using 1.5 equivalents of $\mathrm{Et}_{3} \mathrm{~N}$ or $\mathrm{HCl}-\mathrm{EtOH}$, but even on the use of different reaction conditions (in $\mathrm{EtOH}$ at r.t., or the application of microwave irradiation in $\mathrm{EtOH}$ at $60-90{ }^{\circ} \mathrm{C}$ ), the target compounds could not be isolated, e.g. at r.t. there was no conversion, while the higher temperatures led to decomposition of the starting aminonaphthol.

In further experiments, the condensations of 1-aminomethyl-2-naphthol or 1-aminobenzyl-2naphthol with 1.1 equivalents of 2-nitrobenzaldehyde were attempted in $\mathrm{MeOH}$ in order to synthetize 2-(2,3-dihydro- $1 H$-naphth[1,2-e][1,3]oxazin-3-yl)aniline and 2-(1-phenyl-2,3-dihydro- $1 H$ naphth[1,2-e][1,3]oxazin-3-yl)aniline. These reactions did lead to the formation of the expected $\mathrm{NO}_{2}$ derivatives. However, although the transformation of the $\mathrm{NO}_{2}$ function to an $\mathrm{NH}_{2}$ group should have been achieved for the syntheses of 2-aminophenyl-substituted naphthoxazines, neither catalytic $(\mathrm{Pd} / \mathrm{C})$ hydrogenation nor reduction with $\mathrm{Fe}$ powder in the presence of concentrated $\mathrm{HCl}$ resulted in isolation of the desired amino derivatives, and after even a short reaction time decomposition of the starting naphthoxazines was observed on TLC.

As a new synthetic strategy, aminonaphthols 43a and 43c were reacted with benzyl $N$-(2-formylphenyl)carbamate ${ }^{135}$ to afford the corresponding benzyloxycarbonyl-protected intermediates (44a and 
44c, Scheme 20). The mixtures were stirred for 2-4 days at r.t., during which white crystals separated out. The crystalline products (44a and $\mathbf{4 4 c}$ ) were filtered off and washed with cold EtOH.<smiles>[R]C(N)c1c(O)ccc2ccccc12</smiles>

43a-f
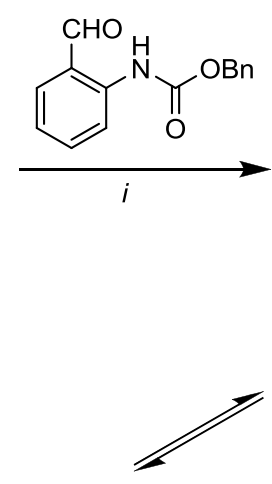<smiles>[R]C1N[C@@H](c2ccccc2NC(=O)OCc2ccccc2)Oc2ccc3ccccc3c21</smiles>

44a-fB<smiles>[R]C(N=Cc1ccccc1NC(=O)OCc1ccccc1)c1c(O)ccc2ccccc12</smiles>

44a-fA 1

1<smiles>O=CO[Bi]Br</smiles><smiles>[R]C(=NCc1ccccc1NC)c1c(O)ccc2ccccc12</smiles>

44a-fA ${ }^{2}$

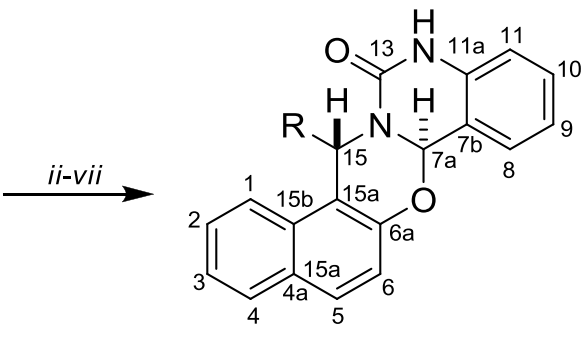

45a-f<smiles>[R]C1NC(c2ccccc2NC(=O)OCc2ccccc2)Oc2ccc3ccccc3c21</smiles>

$\mathrm{R}=\mathrm{H}: \mathbf{a} ; p-\mathrm{Cl}-\mathrm{Ph}: \mathbf{b} ; \mathrm{Ph}: \mathbf{c} ; p-\mathrm{OMe}-\mathrm{Ph}: \mathbf{d} ; 1-\mathrm{Nph}: \mathbf{e} ; 2-\mathrm{Nph}: \mathbf{f}$

Reagents, conditions and yields: (i) $\mathrm{Et}_{3} \mathrm{~N}$, EtOH, r.t., 2-4 days; (ii) $\mathrm{MeONa}, 174{ }^{\circ} \mathrm{C}, 10 \mathrm{~min}, 45 \mathrm{a}$ : $70 \%$; (iii) $\mathrm{MeONa}, 179^{\circ} \mathrm{C}, 20 \mathrm{~min}, 45 \mathrm{~b}$ : 61\%; (iv) MeONa, $152{ }^{\circ} \mathrm{C}, 30 \mathrm{~min}, 45 \mathrm{c}: 54 \%$; (v) MeONa, $154{ }^{\circ} \mathrm{C}, 40 \mathrm{~min}$, 45d: 60\%; (vi) $\mathrm{MeONa}, 203{ }^{\circ} \mathrm{C}, 15 \mathrm{~min}, 45 \mathrm{e}: 74 \%$; (vii) $\mathrm{MeONa}, 165^{\circ} \mathrm{C}, 20 \mathrm{~min}$, 45f: 51\%;

\section{Scheme 20}

Our efforts to remove the protecting group, either by catalytic $(\mathrm{Pd} / \mathrm{C})$ hydrogenation at atmospheric pressure or with $33 \% \mathrm{HBr}-\mathrm{AcOH}$ at r.t., led to the decomposition of $\mathbf{4 4 a}$ and $\mathbf{4 4 c}$ instead of the formation of the desired amino derivatives. In additional experiments, the benzyloxycarbonyl-protected intermediates (44a and 44c) were heated with $\mathrm{MeONa}(30 \mathrm{~mol} \%)$ under solvent-free conditions at their melting temperatures. After reaction times of 10-65 min, when TLC showed no presence of the starting materials, the reaction mixtures were cooled down and the products $(\mathbf{4 5 a}$ and $\mathbf{4 5 c}$ ) were isolated by treatment with EtOH. This synthetic pathway was extended to the preparation of naphthoxazinoquinazolinones containing different aryl substituents at position 15 ( $p$-Cl-Ph: 45b, p-OMe-Ph: 45d, 1-Nph: 45e, and 2-Nph: 45f) (Scheme 20). It should be mentioned that in the cases of $\mathbf{4 5 d}$ and $\mathbf{4 5 f}$ a doubled amount of MeONa (60 mol\%) increased the yields (from $31 \%$ to $60 \%$ for $\mathbf{4 5 d}$, and from $37 \%$ to $51 \%$ for 45f). For 45f, a different work-up procedure was applied; the solid residue was extracted with 
EtOAc and dried $\left(\mathrm{Na}_{2} \mathrm{SO}_{4}\right)$, and after evaporation of the solvent the residue was crystallized from a mixture of $n$-hexane-EtOAc.

During the ring closure reaction of $\mathbf{4 4 b - f}$ with $\mathrm{MeONa}$, the formation of two diastereomers is possible; the diastereomeric ratio was therefore checked by NMR spectroscopy on the crude products. It was found that only one diastereomer was present in all five cases. The preliminary NOE check on purified 45b-f adequately proved the trans arrangement of $\mathrm{H}-15$ and $\mathrm{H}-7 \mathrm{a}$ (Scheme 20), similarly to the ring-anellation analogue phenyl-10,11-dihydro- $8 H, 15 \mathrm{bH}$ naphth[1,2-e][1,3]oxazino[3,4-c]quinazolin-10-one (41; Scheme 19).

In solvent at $300 \mathrm{~K}, \mathbf{4 4 a - f}$ can be present in three-component tautomeric mixtures containing diastereomeric ring forms (B and $\mathbf{C}$ ) besides the chain form (A). Because of the low solubility of intermediates 44a-f in $\mathrm{CDCl}_{3}$, the NMR spectra were recorded in DMSO. The total assignment of $\mathbf{4 4 c}$ revealed the presence of a new tautomeric chain form $\left(\mathbf{A}^{2}\right)$ besides the trans ring form $\mathbf{B}$ and chain form $\mathbf{A}^{\mathbf{1}}$. Through the use of 2D NMR techniques, the structure of $\mathbf{A}^{\mathbf{2}}$ was identified as a new chain form, in which the imine double bond is in an $\alpha$ position relative to the naphthyl ring, as depicted in Scheme 20. To establish whether this unexpected rearrangement is influenced by the nature of substituent R, the NMR spectra of 44a,b and 44d-f (Table 3, entries 1, 4, 14, 19 and 24) were recorded on solutions of $15 \mathrm{mg}$ of crystals in $700 \mu \mathrm{L}$ of deuterated DMSO. The ratio of $\mathbf{A}^{\mathbf{1}}$ to $\mathbf{A}^{\mathbf{2}}$ did differ, but

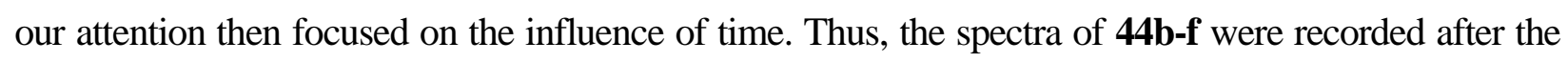
solutions had been allowed to stand for $4 \mathrm{~h}$ or 3,4 or 7 days. In the case of $\mathbf{4 4 a}$, form $\mathbf{A}^{\mathbf{2}}$ could not be detected even after 12 days (Table 3, entry 3). The reason for this is that, in the lack of an aromatic ring system, there is no possibility of conjugation with the $\mathrm{C}=\mathrm{N}$ double bond in $\mathbf{A}^{\mathbf{2}}$. Further proof of the presence of conjugation in form $\mathbf{A}^{2}$ is that, in the case of $\mathbf{4 4 e}$, containing a 1-naphthyl (1-Nph) ring, the newly formed $\mathbf{A}^{2}$ could not be detected even after 7 days. This can be explained by the hindered rotation of the naphthyl ring, which restricts conjugation of the aromatic system with the $\mathrm{C}=\mathrm{N}$ double bond.

Table 3 demonstrates that the standing time has a characteristic influence on the tautomeric ratios. In all cases (44b-d,f), the amount of $\mathbf{A}^{\mathbf{2}}$ increases, while those of $\mathbf{B}$ and $\mathbf{A}^{\mathbf{1}}$ decrease as time passes. It can also be concluded from Table 3 that the formation of $\mathbf{A}^{\mathbf{2}}$ (after standing for 7 days) is the highest for the electron-donating substituent $p$-OMe.

To prove the reversibility of the process in DMSO (the presence of a tautomeric equilibrium), $40 \mathrm{mg}$ of $\mathbf{4 4 c}$ was dissolved in DMSO (2 $\mathrm{mL}$, corresponding to the concentration used for the NMR measurements) and the solution was left to stand at r.t. for 7 days. A sample from this mixture was then evaporated to dryness, and dissolved again in deuterated DMSO, after which its NMR spectrum was run. The tautomeric composition observed was similar to that after the dissolution of crystalline $\mathbf{4 4 c}$. 
Table 3. Tautomeric ratios for 44a-f in DMSO at $300 \mathrm{~K}$

\begin{tabular}{|c|c|c|c|c|c|}
\hline Entries & $\mathrm{R}$ & Time $^{a}$ & $\mathrm{~A}^{1}(\%)$ & $\mathrm{A}^{2}(\%)$ & $\mathrm{B}(\%)$ \\
\hline 1 & \multirow{3}{*}{$\begin{array}{c}\mathrm{H} \\
\mathbf{4 4 a}\end{array}$} & 0 & 100 & - & - \\
\hline 2 & & 7 days & 82.2 & - & 17.8 \\
\hline 3 & & 12 days & 76.9 & - & 23.1 \\
\hline 4 & \multirow{5}{*}{$\begin{array}{c}p-\mathrm{Cl}-\mathrm{Ph} \\
\mathbf{4 4 b}\end{array}$} & 0 & 91.7 & - & 8.3 \\
\hline 5 & & $4 \mathrm{~h}$ & 81.1 & 11.1 & 7.8 \\
\hline 6 & & 3 days & 40.5 & 54.1 & 5.4 \\
\hline 7 & & 4 days & 30.4 & 67.2 & 2.4 \\
\hline 8 & & 7 days & 18.6 & 80.1 & 1.3 \\
\hline 9 & \multirow{5}{*}{$\begin{array}{l}\mathrm{Ph} \\
\mathbf{4 4 c}\end{array}$} & 0 & 82.6 & 10.5 & 6.9 \\
\hline 10 & & $4 \mathrm{~h}$ & 65.3 & 28.8 & 5.9 \\
\hline 11 & & 3 days & 38.3 & 57.7 & 4.0 \\
\hline 12 & & 4 days & 34.2 & 63.2 & 2.6 \\
\hline 13 & & 7 days & 27.6 & 70.2 & 2.2 \\
\hline 14 & \multirow{5}{*}{$\begin{array}{c}p-\mathrm{OMe}-\mathrm{Ph} \\
\mathbf{4 4 d}\end{array}$} & 0 & 89.4 & - & 10.6 \\
\hline 15 & & $4 \mathrm{~h}$ & 76.7 & 14.0 & 9.3 \\
\hline 16 & & 3 days & 12.4 & 86.3 & 1.3 \\
\hline 17 & & 4 days & 5.9 & 93.1 & 1.0 \\
\hline 18 & & 7 days & 2.8 & 97.2 & - \\
\hline 19 & \multirow{5}{*}{$\begin{array}{c}\text { 1-Nph } \\
\mathbf{4 4 e}\end{array}$} & 0 & 66.7 & - & 33.3 \\
\hline 20 & & $4 \mathrm{~h}$ & 67.4 & - & 32.6 \\
\hline 21 & & 3 days & 66.4 & - & 33.6 \\
\hline 22 & & 4 days & 67.4 & - & 32.6 \\
\hline 23 & & 7 days & 67.0 & - & 33.0 \\
\hline 24 & \multirow{5}{*}{$\begin{array}{c}\text { 2-Nph } \\
\mathbf{4 4 f}\end{array}$} & 0 & 90.9 & 0.5 & 8.6 \\
\hline 25 & & $4 \mathrm{~h}$ & 53.9 & 38.9 & 7.2 \\
\hline 26 & & 3 days & 19.4 & 76.2 & 4.4 \\
\hline 27 & & 4 days & 16.3 & 83.7 & - \\
\hline 28 & & 7 days & 14.8 & 85.2 & - \\
\hline
\end{tabular}

${ }^{\mathrm{a}}$ The duration of standing after dissolution of the samples.

The mMR was successfully applied for the synthesis of highly functionalized aminonaphthols such as 1-(amino(2-aminophenyl)methyl)-2-naphthol (35) and 1-(amino(2-hydroxyphenyl)methyl)-2naphthol (46). ${ }^{9}$

In order to capitalize on all three functional groups in compounds 35 and 47 at the same time, our aim was to investigate their reactions with dialdehydes, with a view to obtaining new hetero- and polycyclic compounds (Scheme 21).

The synthesis of piperidine-fused quinazolinonaphthoxazine derivative 46 was planned from 1-(amino(2-aminophenyl)methyl)-2-naphthol (35). A mixture of diamine 35 and 1.1 equivalents of aqueous glutardialdehyde solution was dissolved in $\mathrm{EtOH}$ and the solution was stirred at r.t. After $3 \mathrm{~h}$, when TLC indicated no more starting material, the reaction mixture was concentrated to dryness and 
the product was isolated by column chromatography and crystallized from $n$-hexane. The 2D NMR spectra of the isolated compound proved the structure of $\mathbf{4 6 .}$

The starting aminodiol (47) was synthetized according to the literature procedure ${ }^{9}$ by the aminoalkylation of 2-naphthol with 2 equivalents of salicylaldehyde in the presence of $\mathrm{NH}_{3}$, followed by acidic hydrolysis of the intermediate napthoxazine with TFA.

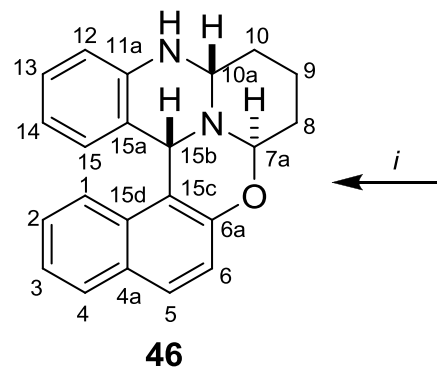<smiles>Nc1ccccc1C(N)c1c(O)ccc2ccccc12</smiles>

35<smiles>NC(c1ccccc1O)c1c(O)ccc2ccccc12</smiles>

47

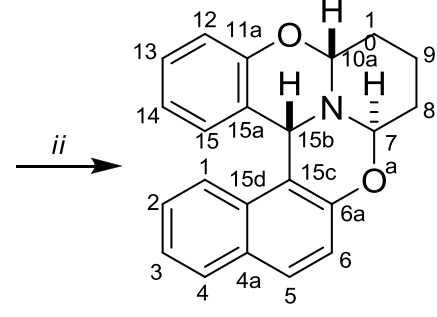

48

Reagents, conditions and yields: (i) $25 \%$ aq. $\mathrm{OHC}\left(\mathrm{CH}_{2}\right)_{3} \mathrm{CHO}, \mathrm{EtOH}$, r.t., 3 h, 43\%; (ii) $\mathrm{Et}_{3} \mathrm{~N}$, $25 \%$ aq. $\mathrm{OHC}\left(\mathrm{CH}_{2}\right)_{3} \mathrm{CHO}$, EtOH, r.t., 24 h, $81 \%$.

\section{Scheme 21}

For the synthesis of the analogous piperidine-fused benzoxazinonaphthoxazine derivative $\mathbf{4 8}$, aminodiol 47 was dissolved in $\mathrm{EtOH}$ and 1.1 equivalents of aqueous glutardialdehyde solution was added. The mixture was stirred for 1 day at r.t., during which white crystals separated out. Preliminary 2D NMR measurements on the precipitated crystals supported the expected structure of 48 (Scheme 21).

In the course of the ring closure reactions of $\mathbf{3 5}$ and $\mathbf{4 7}$ with glutardialdehyde, two new asymmetric centres are introduced, and the formation of four diastereomers is therefore theoretically possible. However, the NMR spectra of the crude products indicated that only a single diastereomer was formed. In the NOESY spectra of the purified $\mathbf{4 6}$ and $\mathbf{4 8}$, the weak interactions between $\mathrm{H}-7 \mathrm{a}$ and $\mathrm{H}-15 \mathrm{~b}$ and between $\mathrm{H}-7 \mathrm{a}$ and $\mathrm{H}-10 \mathrm{a}$ proved their trans arrangement, while the presence of a strong cross-peak between $\mathrm{H}-10 \mathrm{a}$ and $\mathrm{H}-15 \mathrm{~b}$ demonstrated their cis arrangement.

In order to extend the series of newly synthetized hexacyclic ring systems, e.g. to the syntheses of pyrrollidine- and azepane-fused naphthoxazine derivatives, our attention focused on the reactions of diamine 35 and aminodiol $\mathbf{4 7}$ with succindialdehyde and adipic dialdehyde. However, these reactions did not result in the desired polycyclic compounds either at r.t. or at higher temperature $\left(80-90{ }^{\circ} \mathrm{C}\right.$, classical heating or $\mathrm{MW}$ ), e.g. at r.t. there was no conversion, while the higher temperature led to decomposition of the starting $\mathbf{3 5}$ and $\mathbf{4 7 .}$ 


\subsubsection{Conformational study of naphthoxazinoquinazoline derivatives}

\subsubsection{Conformational analysis of naphth $[1,2-e][1,3]$ oxazino $[3,4-c]$ quinazolines}

In the case of the naphth[1,2-e][1,3]oxazino[3,4-c]quinazoline ring system, theoretical calculations were performed on compounds $\mathbf{3 7}, \mathbf{4 1}$ and $\mathbf{4 2}$, and their global minimum-energy structures were determined.

While 37 can be accepted as the basic ring system (unsubstituted 10,11-dihydro- $8 H, 15 b H$ naphth[1,2-e][1,3]oxazino[3,4-c]quinazoline), full geometry optimization was performed by using DFT calculations. The unsaturated ring system 37 contains invertible $\mathrm{N}$ atoms. Both the $R$ and the $S$ configurations of the $\mathrm{N}$ atoms and of $\mathrm{C}-15 \mathrm{~b}$ must be considered. All isomers/enantiomers were studied by means of DFT calculations with regard to the conformational equilibria. The preferred conformers thus obtained, together with other proximate conformers with similar energy, were collected and studied with respect to ring puckering as the second variable beside the $N$-interconversion. The energy difference values $(\Delta E)$ obtained for the lowest-energy conformers for each configuration are listed in Table 4.

Table 4. Calculated energy differences for 37

\begin{tabular}{cccccc}
\hline $\begin{array}{c}\text { Optimized } \\
\text { geometry }\end{array}$ & C-15b & N-9 & N-11 & $\begin{array}{c}\Delta E^{\mathrm{a}} \\
(\mathrm{kcal} / \mathrm{mol})\end{array}$ & $\begin{array}{c}\Delta E^{\mathrm{b}} \\
(\mathrm{kcal} / \mathrm{mol})\end{array}$ \\
\hline$G \_\mathrm{I}$ & $S^{*}$ & $R^{*}$ & $R^{*}$ & 0 & 0 \\
$G_{-} \mathrm{II}$ & $S^{*}$ & $R^{*}$ & $S^{*}$ & 0.41 & 0.26 \\
$G \_$III & $S^{*}$ & $S^{*}$ & $R^{*}$ & 13.12 & 12.66 \\
$G \_$IV & $S^{*}$ & $S^{*}$ & $S^{*}$ & 13.27 & 13.80 \\
\hline
\end{tabular}

\footnotetext{
${ }^{\mathrm{a}}$ In the gas phase.

${ }^{\mathrm{b}}$ In $\mathrm{CH}_{2} \mathrm{Cl}_{2}$ as solvent.
}

It can be concluded that the relative configurations of C-15b and N-9 exert characteristic effects on the $\Delta E$ values (Table 4, geometries $G_{-}$I, $G \_$II $v s$. $G \_$III, $G \_$IV). As the NMR measurements were recorded in $\mathrm{CD}_{2} \mathrm{Cl}_{2}$, the energies of the participating conformers were calculated with consideration of the effect of the solvent too $\left(\mathrm{CH}_{2} \mathrm{Cl}_{2}\right)$. Table 4 shows the same tendency for the $\Delta E$ values. Unfortunately, the conformations obtained are not characteristic in a stereochemical frame, especially because of the nearly planar -NH- structures. Thus, general conclusions concerning the conformers of compound 37 could not be drawn.

To distinguish between structures $G \_$I and $G \_$II (Figure 3), low-temperature NMR measurements were recorded. The dynamic process in which conformers $G \_$I and $G \_$II are equilibrated, $N$-inversion, 
is still fast on the NMR time-scale, even at the lowest temperatures. Thus, it was not possible experimentally to differentiate between the two conformers.

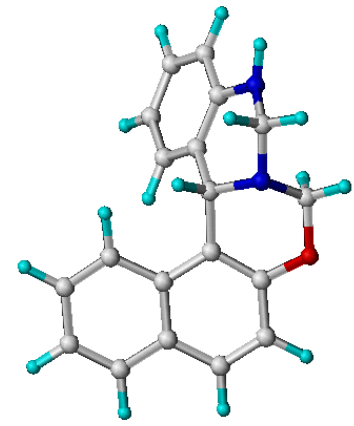

$G_{-} \mathrm{I}$

$\Delta E=0 \mathrm{kcal} / \mathrm{mol}$

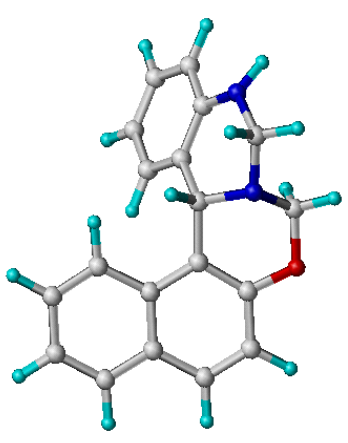

G_I I

$\Delta E=0.26 \mathrm{kcal} / \mathrm{mol}$

Figure 3. Minimum-energy conformers of $\mathbf{3 7}$

Since the formation of $\mathbf{4 1} v s . \mathbf{4 2}$ was experimentally proved, our further aim was to support this finding by using DFT calculations. For the studied compounds (41 and $\mathbf{4 2}$ ), theoretical calculations were performed for all of the stereoisomers as regards the inversion possibilities for $\mathbf{4 1}(\mathrm{C}-15 \mathrm{~b}$ and C-8) and for 42 (C-15b, N-11 and C-10). It was found that the geometry of the $\mathrm{N}$ atoms (N-9 and N-11 for 41 and N-9 for 42) are parts of planar amide bonds. Calculations were performed for all cis and trans isomers of $\mathbf{4 1}$ and $\mathbf{4 2}$. The results of the optimization are given in Table 5 for $\mathbf{4 1}$ and in Table 6 for 42.

Table 5. Calculated energy differences for $\mathbf{4 1}$

\begin{tabular}{cccc}
\hline Optimized geometry & $\mathrm{C}-15 \mathrm{~b}$ & $\mathrm{C}-8$ & $\Delta E(\mathrm{kcal} / \mathrm{mol})$ \\
\hline$G_{\mathrm{t}}^{\mathrm{a}}$ & $S^{*}$ & $R^{*}$ & 0 \\
$G_{\mathrm{c}}{ }^{\mathrm{b}}$ & $S^{*}$ & $S^{*}$ & 1.33 \\
\hline${ }^{\mathrm{a}} G_{\mathrm{t}}=$ trans isomer. & & & \\
${ }^{\mathrm{b}} G_{\mathrm{c}}=$ cis isomer. & & &
\end{tabular}

It can be concluded that the trans arrangement of $\mathrm{H}-15 \mathrm{~b}$ and $\mathrm{H}-8$ is favourable for $\mathbf{4 1}$, while for 42, the trans orientation of $\mathrm{H}-15 \mathrm{~b}$ and $\mathrm{H}-10$ is favourable (Tables 5 and 6). 
Table 6. Calculated energy differences for $\mathbf{4 2}$

\begin{tabular}{ccccc}
\hline Optimized geometry & $\mathrm{C}-15 \mathrm{~b}$ & $\mathrm{~N}-11$ & $\mathrm{C}-10$ & $\Delta E(\mathrm{kcal} / \mathrm{mol})$ \\
\hline$G_{\llcorner} \mathrm{I}^{\mathrm{a}}$ & $S^{*}$ & $S^{*}$ & $R^{*}$ & 0 \\
$G_{\mathrm{L} \_} \mathrm{II}$ & $S^{*}$ & $R^{*}$ & $R^{*}$ & 0.48 \\
$G_{\mathrm{c} \_} \mathrm{I}^{\mathrm{b}}$ & $S^{*}$ & $S^{*}$ & $S^{*}$ & 3.81 \\
$G_{\mathrm{c} \_\mathrm{II}}$ & $S^{*}$ & $R^{*}$ & $S^{*}$ & 5.45 \\
\hline${ }^{\mathrm{a}} G_{\mathrm{t}}=$ trans isomer. & & & & \\
${ }^{\mathrm{b}} G_{\mathrm{c}}=$ cis isomer. & & & &
\end{tabular}

Figure 4 depicts the global minimum-energy structures of $\mathbf{4 1}$ and $\mathbf{4 2}$. Since our original aim was to explain the formation of $\mathbf{4 1}$ instead of $\mathbf{4 2}$, we calculated the energy difference between the global minimum-energy structures, $G_{\mathrm{t}}$ geometry for $\mathbf{4 1}$ and $G_{\llcorner} \mathrm{I}$ for $\mathbf{4 2}$. It was found to be $0.74 \mathrm{kcal} / \mathrm{mol}$, which clearly supports our experimental results, i.e. $\mathbf{4 1}$ is the preferred product, corresponding to the MS results.

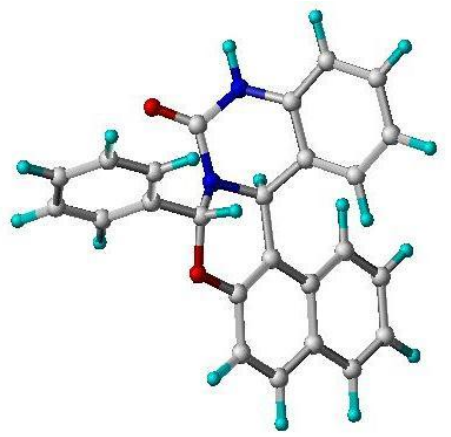

$G_{\mathrm{t}}$ for 41

$\Delta E=0 \mathrm{kcal} / \mathrm{mol}$

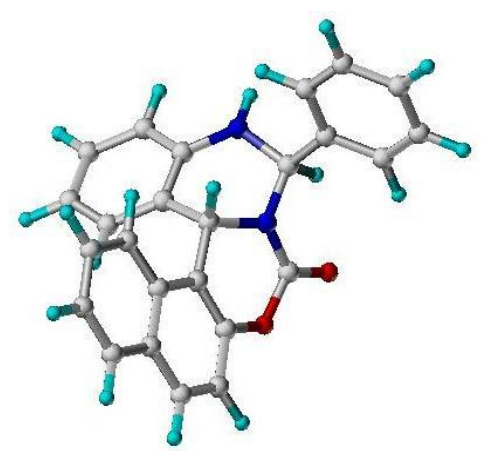

$G_{\llcorner}$I for $\mathbf{4 2}$

$\Delta E=0.74 \mathrm{kcal} / \mathrm{mol}$

Figure 4. Global minimum-energy structures of $\mathbf{4 1}$ and $\mathbf{4 2}$

\subsubsection{Conformational analysis of naphth $[1,2-e][1,3]$ oxazino[3,2-c]quinazolinones}

As the NMR measurements on naphth[1,2-e][1,3] oxazino[3,2-c]quinazolin-13-one derivatives were recorded in DMSO, the energies of the participating conformers were calculated with consideration of the effect of the solvent via the dielectric constant $\varepsilon=46.7$. All configurations of 45a-f were studied at the DFT level of theory with respect to the preferred conformers or conformational equilibria. In 7aH,12H,15bH-naphth[1,2-e][1,3] oxazino[3,2-c]quinazolin-13-one (45a), only one chiral centre is present. Figure 5 shows the global minimum-energy structure of 45a. 


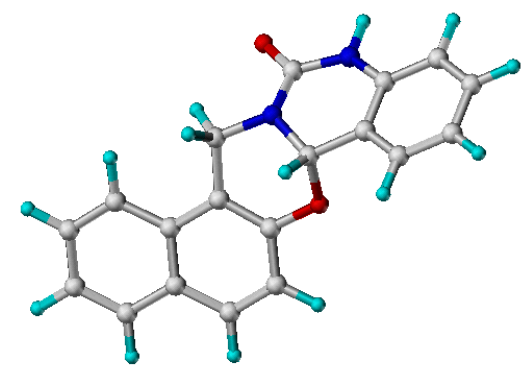

Figure 5. Global minimum-energy structure of $\mathbf{4 5 a}$

In consequence of the presence of the aryl substituents at position 15, the other five compounds (45b-f) contain two chiral centres. Theoretical calculations were performed for all of the stereoisomers as regards both the configurations of C-15 and C-7a and the ring interconversions of the two nonaromatic ring moieties. The results of optimization for $\mathbf{4 5 b} \mathbf{d} \mathbf{d}$ are listed in Table 7. It can be concluded from the relative energy values that the trans arrangement of $\mathrm{H}-15$ and $\mathrm{H}-7 \mathrm{a}$ is favourable for $\mathbf{4 5} \mathbf{b}-\mathbf{d}$ (Table 7).

Table 7. Calculated energy differences for $\mathbf{4 5 b}-\mathbf{d}$

\begin{tabular}{cccccc}
\hline & Optimized geometry & $\mathrm{C}-15$ & $\mathrm{C}-7 \mathrm{a}$ & $\Delta E^{a}(\mathrm{kcal} / \mathrm{mol})$ & $\Delta E^{b}(\mathrm{kcal} / \mathrm{mol})$ \\
\hline \multirow{2}{*}{$48 b$} & $G_{\mathrm{t}}{ }^{\mathrm{c}}$ & $S^{*}$ & $R^{*}$ & 0 & 0 \\
& $G_{\mathrm{c}}{ }^{\mathrm{d}}$ & $S^{*}$ & $S^{*}$ & 5.27 & 5.10 \\
\hline \multirow{2}{*}{$\mathbf{4 8 c}$} & $G_{\mathrm{t}}$ & $S^{*}$ & $R^{*}$ & 0 & 0 \\
& $G_{\mathrm{c}}{ }^{\mathrm{d}}$ & $S^{*}$ & $S^{*}$ & 5.56 & 5.32 \\
\multirow{2}{*}{$\mathbf{4 8 d}$} & $G_{\mathrm{t}}^{\mathrm{c}}$ & $S^{*}$ & $R^{*}$ & 0 & 0 \\
& $G_{\mathrm{c}}{ }^{\mathrm{d}}$ & $S^{*}$ & $S^{*}$ & 5.79 & 5.57 \\
\hline
\end{tabular}

${ }^{\mathrm{a}}$ In the gas phase. ${ }^{\mathrm{b}}$ In DMSO as solvent.

${ }^{\mathrm{c}} G_{\mathrm{t}}=$ trans isomer. ${ }^{\mathrm{d}} G_{\mathrm{c}}=$ cis isomer.

The lack of NOESY interaction between H-15 and H-7a indirectly proved the trans arrangement, which is indicated by the theoretical calculations at the DFT level. Figure 6 depicts the global minimum-energy structures $\left(G_{\mathrm{t}}\right)$ of $\mathbf{4 5 b} \mathbf{b}$.
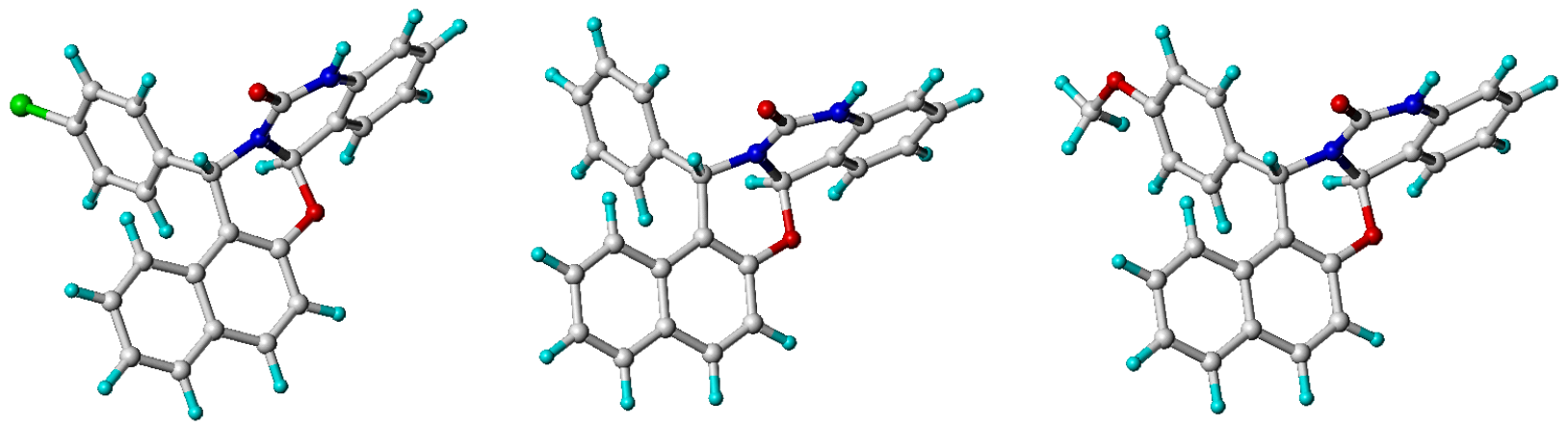

Figure 6. Global minimum-energy structures of $\mathbf{4 5 b}-\mathbf{d}$ 
As a result of the restricted rotation of the Nph substituents at position 15 around the C-15-C-1' bond in $\mathbf{4 5 e}$, and around the C-15-C-2' bond in $\mathbf{4 5 f}$, four conformers were obtained after the geometry optimization, i.e. structures with syn and anti positions of $\mathrm{H}-15$ and C-2' in 45e and of $\mathrm{H}-15$ and C-1' in $45 f$ (Table 8).

The theoretical results in Table 8 demonstrate that the trans arrangement of $\mathrm{H}-15$ and $\mathrm{H}-7 \mathrm{a}$ is favourable for both $\mathbf{4 5 e}$ and $\mathbf{4 5 f}$. This is the case in both the trans and the cis diastereomers of $\mathbf{4 5 e}$ (anti position of $\mathrm{H}-15$ and C-2'). In the $G_{\mathrm{L}}$ I and $G_{\mathrm{c} \_}$II geometries of $\mathbf{4 5 e}, \mathrm{N}-14$ is not planar and its relative configuration is $R^{*}$, while in both the $G_{\llcorner}$II and the $G_{\mathrm{c} \_}$I geometries of $45 \mathbf{e}, \mathrm{N}-14$ was found to be planar, as in the cases of 45a-d and $\mathbf{4 8 f}$.

Table 8. Calculated energy differences for $\mathbf{4 5 e}$ and $\mathbf{4 5 f}$

\begin{tabular}{|c|c|c|c|c|c|c|}
\hline & $\begin{array}{l}\text { H-15-C-2'/ } \\
\text { H-15-C-1' }\end{array}$ & $\begin{array}{l}\text { Optimized } \\
\text { geometry }\end{array}$ & C-15 & C-7a & $\Delta E^{a}(\mathrm{kcal} / \mathrm{mol})$ & $\Delta E^{b}(\mathrm{kcal} / \mathrm{mol})$ \\
\hline \multirow{4}{*}{$45 e$} & anti $^{c}$ & $G_{\mathrm{t}} \mathrm{I}^{\mathrm{d}}$ & $S^{*}$ & $R^{*}$ & 0 & 0 \\
\hline & syn & $G_{\mathrm{七}} \mathrm{II}$ & $S^{*}$ & $R^{*}$ & 4.88 & 4.92 \\
\hline & anti & $G_{\mathrm{c} \_} \mathrm{I}^{\mathrm{e}}$ & $S^{*}$ & $S^{*}$ & 8.27 & 8.09 \\
\hline & $\operatorname{syn}^{c}$ & $G_{\text {c_III }}$ & $S^{*}$ & $S^{*}$ & 9.21 & 8.78 \\
\hline \multirow{4}{*}{$45 f$} & anti & $G_{\llcorner} \mathrm{I}^{\mathrm{d}}$ & $S^{*}$ & $R^{*}$ & 0 & 0 \\
\hline & syn & $G_{\mathrm{t}}$ II & $S^{*}$ & $R^{*}$ & 0.79 & 0.78 \\
\hline & syn & $G_{\mathrm{c} \_} \mathrm{I}^{\mathrm{e}}$ & $S^{*}$ & $S^{*}$ & 5.66 & 5.40 \\
\hline & anti & $G_{\text {c_II }}$ & $S^{*}$ & $S^{*}$ & 6.25 & 5.98 \\
\hline
\end{tabular}

${ }^{\mathrm{a}}$ In the gas phase. ${ }^{\mathrm{b}}$ In DMSO as solvent.

${ }^{\mathrm{c}}$ In these structures, N-14 was found to be not planar and its relative configuration was $R^{*}$.

${ }^{\mathrm{d}} G_{\mathrm{t}}=$ trans isomer. ${ }^{\mathrm{e}} G_{\mathrm{c}}=$ cis isomer.

The sterically hindered rotation of the 1-Nph substituent around the C-15-C-1' bond led to the energy difference between the $G_{\llcorner}$I and $G_{\llcorner}$II geometries of 45e being relatively high: $4.92 \mathrm{kcal} / \mathrm{mol}$ (Table 8). Figure 7 illustrates the global minimum-energy structures $\left(G_{\llcorner} \mathrm{I}\right)$ of $\mathbf{4 5 e}$ and $\mathbf{4 5 f}$.
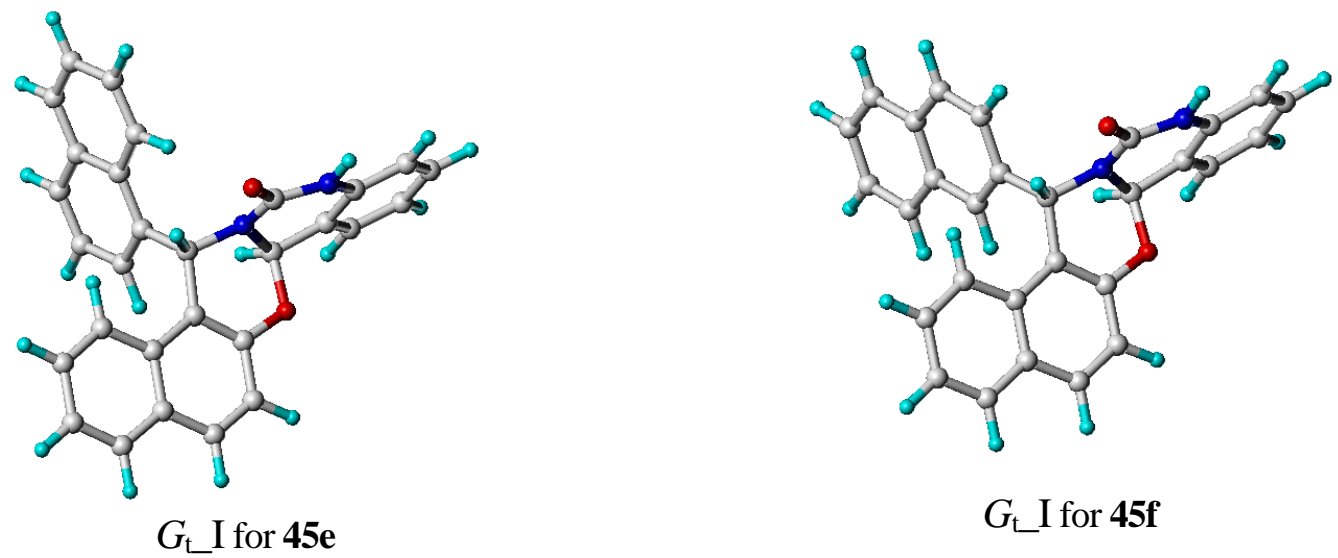

Figure 7. Global minimum-energy structures of $\mathbf{4 5 e}$ and $\mathbf{4 5 f}$ 
In order to demonstrate the stereochemistry of the naphth[1,2-e][1,3]oxazino[3,2-c]quinazolinone derivatives (obtained by means of DFT calculations and proved only indirectly through the lack of NOE (H-7a-H-15) information), the ring current effects of the 15-aryl substituents on $\mathrm{H}-1$ in 45c,e and 45f were computed. For this purpose, the spatial NICS approach ${ }^{136}$ was employed. The through-space NMR shieldings (TSNMRSs) can be visualized ${ }^{136}$ as iso-chemical-shielding surfaces (ICSSs) and employed to quantify the anisotropic effects of functional groups on proton chemical shifts (to determine the stereochemistry of nuclei proximal to the functional group), ${ }^{137}$ in order to separate the anisotropic effects of functional groups from the influence of steric hindrance on the same proton chemical shifts, ${ }^{138}$ and to visualize and quantify planar or spherical (anti)aromaticity and chelatoaromaticity.

From the optimized geometries of $\mathbf{4 5 c}, \mathbf{e}$ and $\mathbf{4 5 f}$, the TSNMRSs of the aryl moieties on C-15 were calculated, visualized by ICCSs of various sizes and directions (Figure 8 for $\mathbf{4 5 c}(\mathrm{Ph}$ ) and $\mathbf{4 5 e}$ (Nph ring system), respectively) and finally the corresponding anisotropic effect of the 15-aryl moiety on H-1 was computed quantitatively. The corresponding values (as shielding values, negative for deshielding and positive for the shielding of $\mathrm{H}-1$ ) are given in Table 9, together with the $\mathrm{H}-1$ chemical shift in $\mathbf{4 5} \mathbf{a}$ as reference.

Table 9. Experimental differences in the chemical shifts $\delta / \mathrm{ppm}$ of $\mathrm{H}-1$ and the anisotropic effects of 15-aryl in $\mathbf{4 5 c , e , f} \sigma / \mathrm{ppm}$

\begin{tabular}{cccc}
\hline Compound & $\delta_{\exp }(\mathrm{H}-1)$ & $\Delta \delta_{\exp } / \mathrm{ppm}$ & $\sigma_{\text {cald }} / \mathrm{ppm}$ \\
\hline $\mathbf{4 5 a}$ & 7.84 & 0 & - \\
$\mathbf{4 5 c}$ & 7.39 & 0.45 & 0.56 \\
$\mathbf{4 5 e}$ & 7.22 & 0.62 & 0.55 \\
$\mathbf{4 5 f}$ & 7.45 & 0.39 & 0.49 \\
\hline
\end{tabular}

The coincidence is very good: the anisotropic effect of the 15 -aryl moiety proves to be $\sim 0.5 \mathrm{ppm}$, in complete agreement with the experiment, and proves the stereochemistry of the naphth[1,2-e][1,3] oxazino[3,2-c] quinazolinone derivatives 45c,e and $45 f$. 

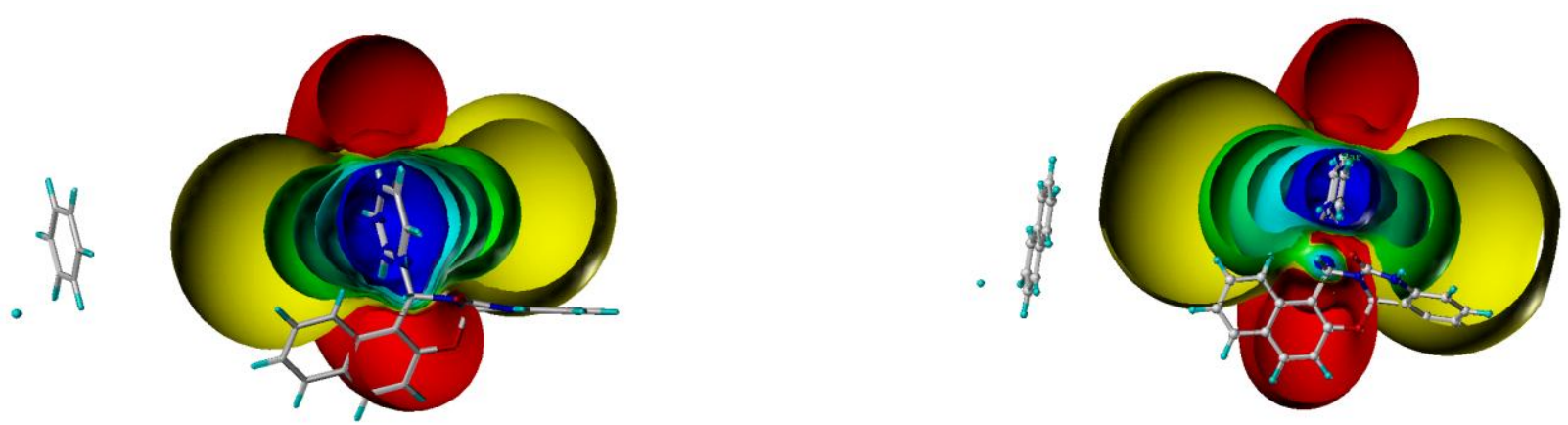

Figure 8. Ring current effects of the $\mathrm{Ph}$ ring in $\mathbf{4 5 c}$ and the 1-Nph ring in 45e on $\mathrm{H}-1$

The conformational study of phenyl-10,11-dihydro- $8 H, 15 \mathrm{~b} H$-naphth[1,2-e][1,3]oxazino[3,4-c]quinazolin-10-one (41, Figure 4) revealed that the oxazine ring proved to prefer an envelope, and the quinazolone ring a twisted boat conformation; while in naphth[1,2-e][1,3]oxazino[3,2-c]quinazolin-13-ones (45a-f) the oxazine ring prefers a twisted chair conformation and the quinazolone ring is almost planar (Figures 5, 6 and 7).

\subsubsection{Conformational analysis of piperidine-fused quinazolino- and benzoxazino- naphthoxazines}

As the NMR measurements of piperidine-fused quinazolino- and benzoxazinonaphthoxazines were recorded in $\mathrm{CD}_{2} \mathrm{Cl}_{2}$, the energies of the participating conformers were calculated with consideration of the effect of the solvent too $\left(\mathrm{CH}_{2} \mathrm{Cl}_{2}\right)$. Compounds 46 and 48 were studied in all the configurations at the DFT level of theory with respect to the preferred conformers and conformational equilibria. Theoretical calculations were performed for all of the stereoisomers of $\mathbf{4 6}$ and $\mathbf{4 8}$ as regards the $R / S$ stereochemistry of the involved chiral centres $\mathrm{C}-7 \mathrm{a}, \mathrm{C}-10 \mathrm{a} \mathrm{C}-15 \mathrm{~b}$ and $\mathrm{N}-16$. The results of the optimization are given in Table 10 for $\mathbf{4 6}$ and in Table 11 for $\mathbf{4 8}$. 
Table 10. Calculated energy differences for 46

\begin{tabular}{|c|c|c|c|c|c|}
\hline $\begin{array}{l}\text { Optimized } \\
\text { geometry }\end{array}$ & $\mathrm{H}-7 \mathrm{a}-\mathrm{H}-15 \mathrm{~b}$ & $\mathrm{H}-10 \mathrm{a}-\mathrm{H}-15 \mathrm{~b}$ & H-7a-H-10a & $\begin{array}{c}\Delta E(\mathrm{kcal} / \mathrm{mol}) \\
\text { (in the gas phase) }\end{array}$ & $\begin{array}{c}\Delta E(\mathrm{kcal} / \mathrm{mol}) \\
\left(\text { in } \mathrm{CH}_{2} \mathrm{Cl}_{2}\right)\end{array}$ \\
\hline$G_{\mathrm{tc} \_} \mathrm{I}^{\mathrm{a}}$ & trans & cis & trans & 0 & 0 \\
\hline$G_{\text {ccc } \_} \mathrm{I}^{\mathrm{b}}$ & cis & $c i s$ & cis & 4.13 & 3.77 \\
\hline$G_{\mathrm{ctt}\llcorner} \mathrm{I}^{\mathrm{c}}$ & cis & trans & trans & 5.61 & 5.46 \\
\hline$G_{\text {ttc } \_} I^{d}$ & trans & trans & cis & 8.19 & 7.67 \\
\hline$G_{\text {ccc__ II }}{ }^{\mathrm{e}}$ & cis & $c i s$ & cis & 8.20 & 7.99 \\
\hline$G_{\text {cttL }}$ II $^{\mathrm{f}}$ & cis & trans & trans & 10.22 & 9.88 \\
\hline$G_{\text {ttc_II }}{ }^{\mathrm{g}}$ & trans & trans & cis & 10.48 & 10.73 \\
\hline$G_{\text {tcŁ_II }}$ I $^{\mathrm{h}}$ & trans & cis & trans & 17.61 & 17.32 \\
\hline
\end{tabular}

The numbers correspond to the following relative configurations:

${ }^{\mathrm{a}} \mathrm{C}-15 \mathrm{~b}\left(S^{*}\right), \mathrm{N}-16\left(R^{*}\right), \mathrm{C}-7 \mathrm{a}\left(R^{*}\right), \mathrm{C}-10\left(S^{*}\right) . \quad{ }^{\mathrm{e}} \mathrm{C}-15 \mathrm{~b}\left(S^{*}\right), \mathrm{N}-16\left(R^{*}\right), \mathrm{C}-7 \mathrm{a}\left(S^{*}\right), \mathrm{C}-10\left(S^{*}\right)$

${ }^{\mathrm{b}} \mathrm{C}-15 \mathrm{~b}\left(S^{*}\right), \mathrm{N}-16\left(S^{*}\right), \mathrm{C}-7 \mathrm{a}\left(S^{*}\right), \mathrm{C}-10\left(S^{*}\right) . \quad{ }^{\mathrm{f}} \mathrm{C}-15 \mathrm{~b}\left(S^{*}\right), \mathrm{N}-16\left(S^{*}\right), \mathrm{C}-7 \mathrm{a}\left(S^{*}\right), \mathrm{C}-10\left(R^{*}\right)$.

${ }^{\mathrm{c}} \mathrm{C}-15 \mathrm{~b}\left(S^{*}\right), \mathrm{N}-16\left(R^{*}\right), \mathrm{C}-7 \mathrm{a}\left(S^{*}\right), \mathrm{C}-10\left(R^{*}\right) . \quad{ }^{\mathrm{g}} \mathrm{C}-15 \mathrm{~b}\left(S^{*}\right), \mathrm{N}-16\left(R^{*}\right), \mathrm{C}-7 \mathrm{a}\left(R^{*}\right), \mathrm{C} 10\left(R^{*}\right)$.

${ }^{\mathrm{d}} \mathrm{C}-15 \mathrm{~b}\left(S^{*}\right), \mathrm{N}-16\left(S^{*}\right), \mathrm{C}-7 \mathrm{a}\left(R^{*}\right), \mathrm{C}-10\left(R^{*}\right) . \quad{ }^{\mathrm{h}} \mathrm{C}-15 \mathrm{~b}\left(S^{*}\right), \mathrm{N}-16\left(S^{*}\right), \mathrm{C}-7 \mathrm{a}\left(R^{*}\right), \mathrm{C}-10\left(S^{*}\right)$.

It can be concluded from the relative energies of the stereoisomers that the trans arrangement of $\mathrm{H}-7 \mathrm{a}$ and $\mathrm{H}-15 \mathrm{~b}$, the cis arrangement of $\mathrm{H}-10 \mathrm{a}$ and $\mathrm{H}-15 \mathrm{~b}$ and the trans arrangement of $\mathrm{H}-7 \mathrm{a}$ and $\mathrm{H}-10 \mathrm{a}$ were preferred for both $\mathbf{4 6}$ and 48 (Tables 10 and 11); on the energy hypersurface, the cis/cis/cis and cis/trans/trans isomers display energies of $6.1 \mathrm{kcal} / \mathrm{mol}$ and $3.8 \mathrm{kcal} / \mathrm{mol}$, respectively. These computational results were corroborated by the NOE measurements on $\mathbf{4 6}$ and $\mathbf{4 8}$ (vide supra).

Table 11. Calculated energy differences for $\mathbf{4 8}$

\begin{tabular}{|c|c|c|c|c|c|}
\hline $\begin{array}{l}\text { Optimized } \\
\text { geometry }\end{array}$ & $\mathrm{H}-7 \mathrm{a}-\mathrm{H}-15 \mathrm{~b}$ & $\mathrm{H}-10 \mathrm{a}-\mathrm{H}-15 \mathrm{~b}$ & $\mathrm{H}-7 \mathrm{a}-\mathrm{H}-10 \mathrm{a}$ & $\begin{array}{c}\Delta E(\mathrm{kcal} / \mathrm{mol}) \\
\text { (in the gas phase) }\end{array}$ & $\begin{array}{c}\Delta E(\mathrm{kcal} / \mathrm{mol}) \\
\left(\text { in } \mathrm{CH}_{2} \mathrm{Cl}_{2}\right)\end{array}$ \\
\hline$G_{\mathrm{tc}\llcorner} \mathrm{I}^{\mathrm{a}}$ & trans & cis & trans & 0 & 0 \\
\hline$G_{\text {ccc__ }} \mathrm{I}^{\mathrm{b}}$ & cis & $c i s$ & $c i s$ & 6.39 & 6.10 \\
\hline$G_{\text {ccc__II }}{ }^{\mathrm{c}}$ & cis & $c i s$ & cis & 6.44 & 5.97 \\
\hline$G_{\mathrm{ctt}} \mathrm{I}^{\mathrm{d}}$ & cis & trans & trans & 7.62 & 7.63 \\
\hline$G_{\mathrm{ttc} \_} \mathrm{I}^{\mathrm{e}}$ & trans & trans & cis & 11.24 & 11.38 \\
\hline$G_{\mathrm{ttc} \_} \mathrm{II}^{\mathrm{f}}$ & trans & trans & cis & 11.34 & 10.84 \\
\hline$G_{\text {ctt_II }}{ }^{\mathrm{g}}$ & cis & trans & trans & 13.15 & 12.89 \\
\hline$G_{\mathrm{tcL}} \mathrm{II}^{\mathrm{h}}$ & trans & cis & trans & 18.33 & 18.08 \\
\hline
\end{tabular}

The numbers correspond to the following relative configurations:

${ }^{\mathrm{a}} \mathrm{C}-15 \mathrm{~b}\left(S^{*}\right), \mathrm{N}-16\left(R^{*}\right), \mathrm{C}-7 \mathrm{a}\left(R^{*}\right), \mathrm{C}-10\left(R^{*}\right) . \quad{ }^{\mathrm{e}} \mathrm{C}-15 \mathrm{~b}\left(S^{*}\right), \mathrm{N}-16\left(R^{*}\right), \mathrm{C}-7 \mathrm{a}\left(R^{*}\right), \mathrm{C}-10\left(S^{*}\right)$

${ }^{\mathrm{b}} \mathrm{C}-15 \mathrm{~b}\left(S^{*}\right), \mathrm{N}-16\left(R^{*}\right), \mathrm{C}-7 \mathrm{a}\left(S^{*}\right), \mathrm{C}-10\left(R^{*}\right) . \quad{ }^{\mathrm{f}} \mathrm{C}-15 \mathrm{~b}\left(S^{*}\right), \mathrm{N}-16\left(S^{*}\right), \mathrm{C}-7 \mathrm{a}\left(R^{*}\right), \mathrm{C}-10\left(S^{*}\right)$.

${ }^{\mathrm{c}} \mathrm{C}-15 \mathrm{~b}\left(S^{*}\right), \mathrm{N}-16\left(S^{*}\right), \mathrm{C}-7 \mathrm{a}\left(S^{*}\right), \mathrm{C}-10\left(R^{*}\right) . \quad{ }^{\mathrm{g}} \mathrm{C}-15 \mathrm{~b}\left(S^{*}\right), \mathrm{N}-16\left(S^{*}\right), \mathrm{C}-7 \mathrm{a}\left(S^{*}\right), \mathrm{C}-10\left(S^{*}\right)$.

${ }^{\mathrm{d}} \mathrm{C}-15 \mathrm{~b}\left(S^{*}\right), \mathrm{N}-16\left(R^{*}\right), \mathrm{C}-7 \mathrm{a}\left(S^{*}\right), \mathrm{C}-10\left(S^{*}\right) . \quad{ }^{\mathrm{h}} \mathrm{C}-15 \mathrm{~b}\left(S^{*}\right), \mathrm{N}-16\left(S^{*}\right), \mathrm{C}-7 \mathrm{a}\left(R^{*}\right), \mathrm{C}-10\left(R^{*}\right)$. 
No really preferred conformation of the three flexible saturated/partly saturated heterocyclic ring moieties (benzoxazine bo and quinazoline $q$, respectively, naphthoxazine no and piperidine $p$ ) was found. The lowest-energy conformers, $G_{\mathrm{tc} \_} \mathrm{I}$ for $\mathbf{4 6}$ and $G_{\mathrm{tct}} \mathrm{I}$ for $\mathbf{4 8}$, of the two trans/cis/trans isomers are conformationally identical: bo, $q$ (half-chair), no (twist) and $p$ (chair). The chair conformation of the piperidine moiety was proved by proton spectrum simulation/iteration of the frozen $-\mathrm{C}_{10 a} \mathrm{H}-\mathrm{C}_{10} \mathrm{H}_{2}-$ $\mathrm{C}_{9} \mathrm{H}_{2}-\mathrm{C}_{8} \mathrm{H}_{2}-\mathrm{C}_{7 a} \mathrm{H}-$ unit delivering the expected large coupling constants ${ }^{3} J(\mathrm{ax}$, ax $)$ and ${ }^{2} J(\mathrm{ax}, \mathrm{eq})$ and the much smaller ${ }^{3} J(\mathrm{ax}, \mathrm{eq})$ and ${ }^{3} J(\mathrm{eq}, \mathrm{eq})$. As the two $G_{\mathrm{tc} \_}$I minimum-energy conformers of $\mathbf{4 6}$ and 48 are the experimentally available ones, the congruence of the experimental NMR and the computational study can be concluded. For the same reasons, experimental information concerning the energetically next-lowest conformers is not available: $G_{\text {ccc_I }}$ of $\mathbf{4 6}$ occurs as the $q$ (twisted boat), no (half-chair), $p$ (chair) conformers and $G_{\mathrm{ctt}} \mathrm{I}$ of $\mathbf{4 6}$ as the $q$ (half-chair), no (boat), $p$ (twisted chair) conformers, and the $O$-analogue $G_{\text {ccc_I }}$ of $\mathbf{4 8}$ occurs as the bo (twist), no (boat), $p$ (twist-boat) conformer and $G_{\text {ccc_II of }}$ 48 as the bo (half-chair), no (twisted boat), $p$ (chair) conformers (Figure 9).

The most stable stereoisomers, $G_{\mathrm{tc}\llcorner}$ I for $\mathbf{4 6}$ and $G_{\mathrm{tc}\llcorner}$ I for $\mathbf{4 8}$, were identified by theoretical calculations at the DFT level of theory, considering the solvent, corroborated by spatial NOE information between $\mathrm{H}-7 \mathrm{a} / \mathrm{H}-10 \mathrm{a} / \mathrm{H}-15 \mathrm{~b}$ and the $\mathrm{H}, \mathrm{H}$ coupling pattern of the protons in the flexible part of the piperidine ring moiety.

The fragmentations of $\mathbf{4 6}$ and $\mathbf{4 8}$ were investigated by positive ESI. The corresponding ions $[\mathrm{M}+\mathrm{H}]^{+}$and the fragment ions resulting from "in source CID" experiments were used as precursor ions and their CID fragmentations were studied. The similar intensities of the typical fragment ions, together with the NMR results (vide supra), corroborate the conformations of the two heterocyclic ring systems in 46 and 48: the twisted chair and the $G_{\mathrm{tct} \_}$I configuration, as obtained from DFT calculations and depicted in Figure 9. 

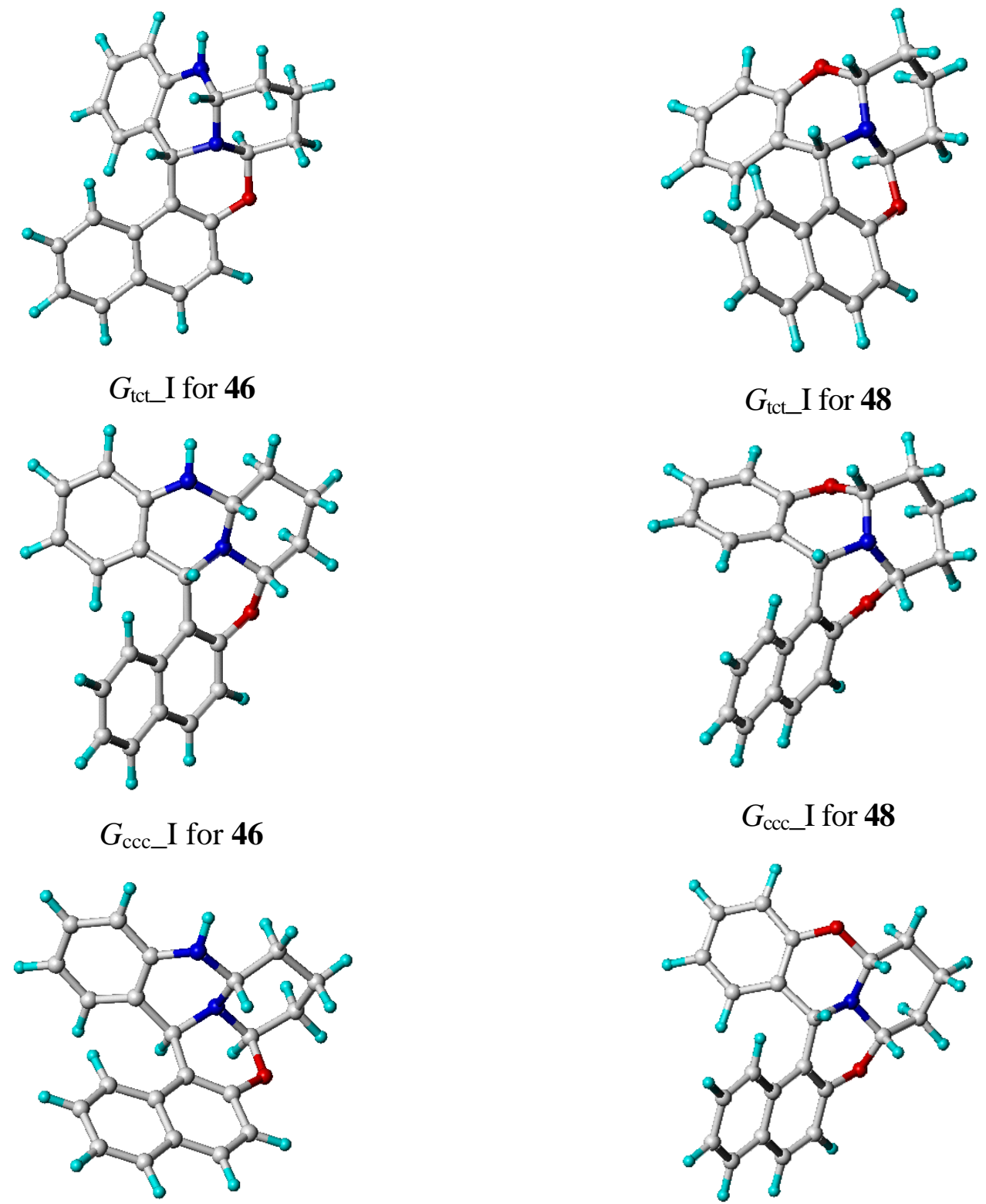

$G_{\text {ctt_I for } 46}$

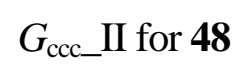

Figure 9. Minimum-energy conformers of 46 and 48 


\subsection{Methods}

\section{Melting points and elemental analysis:}

For compounds 25-31 and 33-41, melting points were determined on a Kofler micro melting point apparatus and are uncorrected. Elemental analyses were performed with a Perkin-Elmer 2400 CHNS elemental analyser.

For compounds 44-46 and 48, melting points were determined on a Hinotek X-4 melting point apparatus and are uncorrected. The HRMS EI spectra were recorded with a GC/MS instrument with a time-of-flight mass analyser (Micromass/Waters, Manchester, UK) in positive ion mode. The elemental compositions of the ions were determined by accurate mass measurements with standard deviation $<5$ ppm. Perfluorokerosene was used as reference compound and the mass resolution was 5000.

\section{NMR measurements:}

For compounds 25-31, the ${ }^{1} \mathrm{H}$ and ${ }^{13} \mathrm{C}$ NMR spectra were recorded in DMSO solution in $5 \mathrm{~mm}$ tubes, at r.t., on a Bruker Avance DRX400 spectrometer at $400.13\left({ }^{1} \mathrm{H}\right)$ and $100.61\left({ }^{13} \mathrm{C}\right) \mathrm{MHz}$, with the deuterium signal of the solvent as the lock and TMS as internal standard.

For compounds 33-36, 39-41, 44 and 45 , the ${ }^{1} \mathrm{H}$ and ${ }^{13} \mathrm{C}$ NMR spectra were recorded in DMSO solution, and for compounds 37, 38, 46 and 48 in $\mathrm{CD}_{2} \mathrm{Cl}_{2}$ solution, in $5 \mathrm{~mm}$ tubes, at r.t., on a Bruker Avance III spectrometer at $600.13\left({ }^{1} \mathrm{H}\right)$ and $150.61\left({ }^{13} \mathrm{C}\right) \mathrm{MHz}$, with the deuterium signal of the solvent as the lock and TMS as internal standard. All spectra $\left({ }^{1} \mathrm{H},{ }^{13} \mathrm{C}\right.$, gs-H, H-COSY, gs-HMQC, gs-1D-HMQC, gs-HMBC and NOESY) were acquired and processed with the standard BRUKER software. For the equilibria to be established in tautomeric mixtures (38a-g), the samples were dissolved in $\mathrm{CD}_{2} \mathrm{Cl}_{2}$ and the solutions were allowed to stand at ambient temperature for 1 day before the ${ }^{1} \mathrm{H}$ NMR spectra were run. The number of scans was usually 24.

\section{Quantum chemical calculations:}

Conformational searches for 26a and 29a were carried out by means of the Macromodel 9.7.211 ${ }^{139}$ software, using the Merck Molecular Force Field (MMFF) with the implicit solvent model for $\mathrm{H}_{2} \mathrm{O}$. In each conformational search, the maximum number of steps was set to 30000 . Geometry reoptimizations at the B3LYP/6-31G(d) level of theory, followed by TDDFT calculations using various functionals (B3LYP, BH\&HLYP and CAM-B3LYP) and the TZVP basis set, were performed with the Gaussian $03^{140}$ and the Gaussian $09^{141}$ packages. Boltzman distributions were estimated from the ZPVE corrected B3LYP/6-31G(d) energies. CD spectra were generated as the sum of Gaussians ${ }^{142}$ with $3000 \mathrm{~cm}^{-1}$ half-height width (corresponding to $c a .15 \mathrm{~nm}$ at $225 \mathrm{~nm}$ ), using dipole-velocity computed rotational strengths. The MOLEKEL ${ }^{143}$ software package was used for visualization of the 
results.

Geometry optimizations for compounds 37, 41, 42, 45a-f, 46 and 48 were performed without restrictions, using the Gaussian $09^{141}$ program package. Different conformations and configurations of all studied compounds were preoptimized by using the PM3 Hamiltonian ${ }^{144,145}$ Density functional theory calculations were carried out at the B3LYP/6-31G***146,147 level of theory. Different starting conformations were created and the results were analysed and displayed by using the molecular modelling program SYBYL $7.3^{148}$ and the program GaussView 2.0. ${ }^{149}$ The self-consistent reaction field method and the integral equation formalism variant of the polarizable continuum model were applied to take solvent effects $\left(\mathrm{CD}_{2} \mathrm{Cl}_{2}\right.$ and DMSO) into account. ${ }^{150}$ Different local minimum-energy conformations were selected to analyse the relative stability and the geometrical parameter.

Mass spectrometric measurements:

The low-resolution EI mass spectra for compounds 37, 41, 44-46 and 48 were obtained by using a GC-MS TRACE DSQ II mass spectrometer (Thermo Fisher Scientific Dreieich, Germany), with an electron energy of $70 \mathrm{eV}$ and a source temperature of $180^{\circ} \mathrm{C}$, using a direct insertion probe with a DEP (Direct Desorption Probe) filament in positive ion mode.

The ESI mass spectra for compounds 39 and $\mathbf{4 0}$ were recorded (in the interval 200-2200 a.m.u.) by using the AGILENT 1100 LC/MSD TRAP instrument in positive ion mode. 


\section{SUMMARY}

1. Hydroxynaphthyl-substituted glycine derivatives 26a and 29a were successfully prepared from 2or 1-naphthol, glyoxylic acid and benzyl carbamate in $\mathrm{MeOH}$ via a mMR in the presence of p-TSA, followed by removal of the protecting group. Acidic hydrolysis of 26a and 29a resulted in the expected $\alpha$-amino acids 27 and $\mathbf{3 0}$. The optimized reaction conditions were extended by starting from EtOH. Benzyloxycarbonyl-protected ethyl esters $\mathbf{2 5 b}$ and $\mathbf{2 8 b}$ were isolated in lower yields as compared with those of methyl esters 25a and 28a.

2. The enantiomers of 26a and 29a were successfully separated on analytical and semi-preparative HPLC columns. Their absolute configurations were determined by CD analysis supported by TDDFT CD calculations, which revealed that the absolute configuration of the second-eluting enantiomer of 26a was $S$, and that of the first-eluting enantiomer of 29a was $S$.

3. A new, highly functionalized aminonaphthol derivative, 1-(amino(2-aminophenyl)methyl)-2naphthol (35), was synthetized by the reaction of 2-naphthol, 2-nitrobenzaldehyde and tert-butyl carbamate or benzyl carbamate, followed by reduction and/or removal of the protecting group. The aminonaphthol derivative thus obtained was converted in a ring closure reaction with formaldehyde to 10,11-dihydro- $8 H, 15 \mathrm{~b} H$-naphth[1,2-e][1,3]oxazino[3,4-c]quinazoline (37). The ring closure reaction of the starting diamine with phosgene and/or benzaldehyde led to the formation of new naphthoxazinoquinazolinone derivatives (39-41).

4. Products 38a-g obtained via the condensation of $\mathbf{3 5}$ with substituted benzaldehydes can potentially furnish five-component tautomeric mixtures in $\mathrm{CD}_{2} \mathrm{Cl}_{2}$ at $300 \mathrm{~K}$. We succeeded in detecting three of the five components: one epimeric quinazoline $(\mathbf{B})$ and two epimeric naphthoxazines $(\mathbf{D}$ and $\mathbf{E})$. The influence of aryl substituents on the tautomeric composition could be described in terms of the Hammett-Brown parameter $\left(\sigma^{+}\right)$. It can be concluded that electron-donating substituents increase the proportion of the quinazoline form $(\mathbf{B})$, while electron-withdrawing substituents prefer the naphthoxazine forms ( $\mathbf{D}$ and $\mathbf{E})$.

5. The syntheses of naphth[1,2-e][1,3] oxazino[3,2-c]quinazolin-13-one derivatives (45a and 45c) were achieved by the solvent-free heating of benzyloxycarbonyl-protected intermediates $(\mathbf{4 4 a}$ and 44c) with MeONa. Compounds $\mathbf{4 4 a}$ and $\mathbf{4 4 c}$ were synthetized by the reactions of substituted aminonaphthol derivatives (43a and 43c) with benzyl $N$-(2-formylphenyl)carbamate. This synthetic pathway was extended to the preparation of naphthoxazinoquinazolinones containing different aryl substituents at position 15 ( $p$-Cl-Ph: 45b, p-OMe-Ph: 45d, 
1-Nph: 45e, and 2-Nph: 45f). The lack of a cross-peak between H-15 and H-7a in the NOESY NMR spectra of $\mathbf{4 5 b}-\mathbf{f}$ indirectly proved their trans arrangement.

6. In solution at $300 \mathrm{~K}$, 44a-f can furnish three-component tautomeric mixtures containing diastereomeric ring forms (B and $\mathbf{C}$ ) besides the chain form (A). When the NMR spectra of 44a-f were recorded in DMSO, the spectra of $\mathbf{4 4 b - d , f}$ revealed the presence of a new tautomeric chain form $\left(\mathbf{A}^{\mathbf{2}}\right)$ besides the trans ring form $\mathbf{B}$ and the chain form $\mathbf{A}^{\mathbf{1}}$. The reason for the formation of $\mathbf{A}^{\mathbf{2}}$ may be the possibility of conjugation of substituent $\mathrm{R}$ (aryl) with the $\mathrm{C}=\mathrm{N}$ double bond, which is supported by the lack of $\mathbf{A}^{\mathbf{2}}$ in $\mathbf{4 4 a}$ and $\mathbf{4 4 e}$. In $\mathbf{4 4 a}$ there is no aromatic ring, while for $4 \mathbf{4 e}$ the hindered rotation of the 1-Nph ring restricts the conjugation. The amount of $\mathbf{A}^{\mathbf{2}}$ increases, while those of $\mathbf{B}$ and $\mathbf{A}^{\mathbf{1}}$ decrease as the duration of standing in DMSO becomes longer.

7. Compounds $\mathbf{3 7}, \mathbf{4 1}$ and $\mathbf{4 2}$ were studied in all the configurations at the DFT level of theory with respect to the preferred conformers and conformational equilibria. The experimental NMR parameters obtained were in general agreement with the theoretical findings. The conformational study of phenyl-10,11-dihydro- $8 H, 15 \mathrm{~b} H$-naphth[1,2-e][1,3]oxazino[3,4-c] quinazolin-10-one (41) revealed that the oxazine ring proved to prefer an envelope, and the quinazolone ring a twisted boat conformation; while in naphth[1,2-e][1,3]oxazino[3,2-c]quinazolin-13-ones (45a-f) the oxazine ring prefers a twisted chair conformation and the quinazolone ring is almost planar.

8. The anisotropic effect of the 15-aryl ring on H-1 was calculated for 45b-f: the excellent agreement of the computational and experimental results proved the stereochemistry of the naphth[1,2-e][1,3]oxazino[3,2-c]quinazolin-13-one derivatives $\mathbf{( 4 5 b - f )}$ deduced from the theoretical calculations.

9. The reactions of 1-(amino(2-aminophenyl)methyl)-2-naphthol (35) and 1-(amino(2hydroxyphenyl)methyl)-2-naphthol (47) with glutardialdehyde resulted in the formation of piperidine-fused quinazolinonaphthoxazine $\mathbf{4 6}$ and benzoxazinonaphthoxazine $\mathbf{4 8}$, respectively, both in diastereopure form.

The NOESY measurements on $\mathbf{4 6}$ and $\mathbf{4 8}$ revealed the following relative arrangements of H-7a-H-15b-H-10a: $\quad H-7 a \stackrel{\text { trans }}{\longleftrightarrow} H-15 b ; \quad H-10 a \stackrel{\text { cis }}{\longleftrightarrow} H-15 b ; \quad H-7 a \stackrel{\text { trans }}{\longleftrightarrow} H-10 a$. The experimental results were supported by theoretical calculations at the DFT level of theory. These calculations and the $\mathrm{H}, \mathrm{H}$ coupling pattern of the protons in the flexible part of the piperidine ring moiety highlighted that the configuration with a twisted chair conformation is preferred for both $\mathbf{4 6}$ and $\mathbf{4 8 .}$ 


\section{ACKNOWLEDGEMENTS}

This work was carried out in the Institute of Pharmaceutical Chemistry, University of Szeged, during the years 2008-2012.

I would like to express my warmest thanks to my supervisor, Professor Ferenc Fülöp, head of the Institute, for his guidance of my work, his inspiring ideas, his useful advice and his constructive criticism.

My warmest thanks are due to Dr. István Szatmári, for his continuous support and interest in my activities. His advice and help have been invaluable during all stages of my work.

I am greatly indebted to Professor Erich Kleinpeter, Department of Chemistry, University of Potsdam, for providing me with the opportunity to work for 4 months in his research group.

I am grateful to Dr. Andreas Koch for his help relating to molecular modeling, and to Dr. Matthias Heydenreich for helpful discussions concerning the NMR assignments.

I would like to thank Dr. Tibor Kurtán for the CD-spectroscopic measurements and Dr. Ines Starke for the mass spectrometric measurements.

I would like to thank all members of Investigation Laboratory 3 at the Institute of Pharmaceutical Chemistry for their help and friendship. I feel very fortunate to have been able to work in such a collaborative environment.

Finally, I would like to give my special thanks to my family for their love and support during my Ph.D. studies. 


\section{REFERENCES}

1. Betti, M. Gazz. Chim. Ital. 1900, 30 II, 310.

2. Betti, M. Gazz. Chim. Ital. 1901, 31 II, 377.

3. Betti, M. Gazz. Chim. Ital. 1901, 31 II, 170.

4. Betti, M. Gazz. Chim. Ital. 1901, 31 II, 191.

5. Betti, M. Org. Synth. Coll. Vol. 1941, 1,381.

6. Szatmári, I.; Fülöp, F. Tetrahedron, submitted.

7. Szatmári, I.; Fülöp, F. Curr. Org. Synth. 2004, 1, 155.

8. Szatmári, I.; Hetényi, A.; Lázár, L.; Fülöp, F. J. Heterocycl. Chem. 2004, 41, 367.

9. Heydenreich, M.; Koch, A.; Klod, S.; Szatmári, I.; Fülöp, F.; Kleinpeter, E. Tetrahedron 2006, $62,11081$.

10. Heydenreich, M.; Koch, A.; Szatmári, I.; Fülöp, F.; Kleinpeter, E. Tetrahedron 2008, 64, 7378.

11. Szatmári, I.; Fülöp, F. Tetrahedron Lett. 2011, 52, 4440.

12. Möhrle, H.; Tröster, K. Arch. Pharm. 1982, 315, 222.

13. Möhrle, H.; Miller, C.; Wendisch D. Chem. Ber. 1974, 107, 2675.

14. Selvam, N. P.; Perumal, P. T. Tetrahedron Lett. 2006, 47, 7481.

15. Das, B.; Laxminarayana, K.; Thirupathi, P.; Ramarao, B. Synlett 2007, 3103.

16. Damodiran, M.; Selvam, N. P.; Perumal, P. T. Tetrahedron Lett. 2009, 50, 5474.

17. Shaterian, H. R.; Yarahmadi, H.; Ghashang, M. Bioorg. Med. Chem. Lett. 2008, 18, 788.

18. Green, W.; Wats, M. P. G. Protecting groups in organic synthesis; 2nd ed.; John Wiley and Sons: New York, 1999.

19. Shaterian, H. R.; Yarahmadi, H. Tetrahedron Lett. 2008, 49, 1297.

20. Shaterian, H. R.; Yarahmadi, H.; Ghashang, M. Tetrahedron 2008, 64, 1263.

21. Shaterian, H. R.; Yarahmadi, H. Arkivoc 2008, ii, 105.

22. Shaterian, H. R.; Yarahmadi, H.; Ghashang, M. Lett. Org. Chem. 2008, 5, 290.

23. Anary-Abbasinejad, M.; Hassanabadi, A.; Kamali-Gharamaleki, M.; Saidipoor, A.; Anaraki-Ardakani, H. J. Chem. Res. 2007, 644.

24. Heravi, M. M.; Tavakoli-Hoseini, N.; Bamoharram, F. F. Bulg. Chem. Commun. 2011, 3, 423.

25. She, T-T.; Liu, Z-L., Gong, K. Chin. J. Appl. Chem. 2010, 7, 778.

26. Khazaei, A.; Zolfigol, M. A. Moosavi-Zare, A. R.; Zare, A.; Parhami, A.; KhalafiNezhad, A. Appl. Catal. A: Gen. 2010, 386, 179. 
27. Anary-Abbasinejad, M.; Anaraki-Ardakani, H.; Hassanabadi, A. Synth. Commun. 2008, 38,3706 .

28. Selvam, N. P.; Perumal, P. T. Tetrahedron 2008, 64, 2972.

29. Tamaddon, F.; Tavakoli, F. J. Mol. Cat. A: Chem. 2011, 337, 52.

30. Tamaddon, F.; Bistgani, J. M. Synlett 2011, 2947.

31. Shaterian, H. R.; Yarahmadi, H.; Ghashang, M. Turk. J. Chem. 2009, 33, 449.

32. Su, W.; Tang, W.; Li, J. J. Chem. Res. 2008, 123.

33. Prasanna, T. S. R.; Raju, K. M. Org. Chem.: An Indian Journal 2011, 7, 332.

34. Jafari, H.; Moghanian, H. Lett. Org. Chem. 2012, 9, 273.

35. Habibzadeh, S.; Ghasemnejad-Bosra, H. J. Chin. Chem. Soc. 2011, 6, 1.

36. Heravi, M. M.; Tavakoli-Hoseini, N.; Bamoharram, F. F. Synth. Commun. 2011, 41, 298.

37. Forouzani, M.; Ghasemnejad-Bosra, H. Arab. J. Chem. 2011, http://dx.doi.org/10.1016/j.arabjc.2011.08.002.

38. Zare, A.; Hasaninejad, A.; Salimi Beni, A.; Moosavi-Zare, A. R.; Merajoddina, M.; Kamali, E.; Akbari-Seddigh, M.; Parsaee, Z. Scientia Iranica 2011, 18, 433.

39. Zare, A. Org. Prep. Proc. Int. 2012, 44, 82.

40. Zali, A.; Shokrolahi, A. Chin. Chem. Lett. 2012, 23, 269.

41. Montazeri, N.; Pourshamsian, K.; Ghorchibeigi, M.; Fouladi, M. Res. J. Pharm., Biol. Chem. Sci. 2012, 3, 867.

42. Cai, X-H.; Guo, H.; Xie, B. Jordan J. Chem. 2011, 6, 17.

43. Cai, X-H. Int. J. Chem. 2011, 3, 119.

44. Almahy, H. A. A. Res. J. Appl. Sci. 2011, 6, 464.

45. Bamoharram, F. F.; Heravi, M.; Roshani, M.; Mohammad, J.; Charkhi, S. Eur. J. Chem. 2011, 8, 523.

46. Dorehgiraee, A.; Khabazzadeh, H.; Saidi, K. Arkivoc 2009, vii, 303.

47. Mistry, S. R.; Joshi, R. S.; Maheria, K. C. J. Chem. Sci. 2011, 123, 427.

48. Chavan, N. L.; Naik, P. N.; Nayak, S. K.; Kusurkar, R. S. Synth. Commun. 2010, 40, 2941.

49. Sapkal, S. B.; Shelke, K. F.; Madje, B. R.; Shingate, B. B.; Shingare, M. S. Bull. Korean Chem. Soc. 2009, 30, 2887.

50. Niralwad, K. S.; Shingate, B. B.; Shingare, M. S. Chin. Chem. Lett. 2011, 22, 551.

51. Nagarapu, L.; Baseeruddin, M.; Apuri, S.; Kantevari, S. Catal. Commun. 2007, 8, 1729.

52. Kantevari, S.; Vuppalapati, S. V. N.; Nagarapu, L. Catal. Commun. 2007, 8, 1857.

53. Mahdavinia, G. H.; Bigdeli, M. A.; Heravi, M. M. Chin. Chem. Lett. 2008, 19, 1171. 
54. Mahdavinia, G. H.; Bigdeli, M. A. Chin. Chem. Lett. 2009, 20, 383.

55. Nagawade, R. R.; Shinde, D. B. Acta Chim. Slov. 2007, 54, 642.

56. Nagawade, R. R.; Shinde, D. B. Chin. J. Chem. 2007, 25, 1710.

57. Nagawade, R. R.; Shinde, D. B. Mendeleev Commun. 2007, 17, 299.

58. Ansari, S. A. M. K.; Sangshetti, J. N.; Kokare, N. D.; Wakte, P. S., Shinde, D. B. Indian J. Chem. Technol. 2010, 17, 71.

59. Gawand, P.; Deokar, H.; Langi, B.; Yadav, A.; Chaskar, A. Synth. Commun. 2009, 39, 4171 .

60. Shaterian, H. R.; Amirzadeh, A.; Khorami, F.; Ghashang, M. Synth. Commun. 2008, 38, 2983.

61. Shaterian, H. R.; Khorami, F.; Amirzadeh, A.; Ghashang, M. Chin. J. Chem. 2009, 27, 815.

62. Shaterian, H. R.; Hosseinian, A.; Ghashang, M. Synth. Commun. 2008, 38, 3375.

63. Khabazzadeh, H.; Saidi, K.; Seyedi, N. J. Chem. Sci. 2009, 121, 429.

64. Rashinkar, G.; Salunkhe, R. J. Mol. Cat. A: Chem. 2010, 316, 146.

65. Supale, A. R.; Gokavi, G. S. J. Chem. Sci. 2010, 122, 189.

66. Quan, Z-J., Ren, R-G.; Da, Y-X.; Zhang, Z.; Wang, X-C. Synth. Commun. 2011, 41, 3106.

67. Khazdooz, L.; Zarei, A.; Hajipour, A. R.; Sheikhan, N. Iranian J. Catal. 2011, 1, 1.

68. Datta, B.; Pasha, M. A. Ultrason. Sonochem. 2011, 18, 624.

69. Hong, M.; Cai, C.; Yi, W. B. Chin. Chem. Lett. 2011, 22, 322.

70. Puri, S.; Kaur, B.; Parmar, A.; Kumar, H. Org. Prep. Proced. Int. 2012, 44, 91.

71. Kore, R.; Srivastava, R. J. Mol. Cat. A: Chem. 2011, 345, 117.

72. Ravindran, A.; Srivastava, R. Chin. J. Catal. 2011, 32, 1597.

73. Deepali, A.; Kotadia, D. A.; Soni, S. S. J. Mol. Cat. A: Chem. 2012, 353-354, 44.

74. Deshmukh, K. M.; Qureshi, Z. S.; Patil, Y. P.; Bhanage, B. M. Synth. Commun. 2012, 42, 93.

75. Hajipour, A. R.; Ghayeb, Y.; Sheikhan, N.; Ruoho, A. E. Tetrahedron Lett. 2009, 50, 5649.

76. Samantaray, S.; Hota, G.; Mishra, B. G. Catal. Commun. 2011, 12, 1255.

77. Zolfigol, M. A.; Khazaei, A.; Moosavi-Zare, A. R.; Zare, A.; Khakyzadeh, V. Appl. Catal. A: Gen. 2011, 400, 70.

78. Zare, A.; Hasaninejad, A.; Rostami, E.; Moosavi-Zare, A. R.; Pishahang, N.; Roshankar, M.; Khedri, F.; Khedr, M. Eur. J. Chem. 2010, 7, 1162. 
79. Zhang, P.; Zhang, Z-H. Monatsh. Chem. 2009, 140, 199.

80. Khodaei, M. M.; Khosropour, A. R.; Moghanian, H. Synlett 2006, 916.

81. Das, B.; Laxminarayana, K.; Ravikanth, B.; Rao, B. R. J. Mol. Cat. A: Chem. 2007, 261, 180.

82. Patil, S. B.; Singh, P. R.; Surpur, M. P.; Samant, S. D. Ultrason. Sonochem. 2007, 14, 515.

83. Patil, S. B.; Singh, P. R.; Surpur, M. P.; Samant, S. D. Synth. Commun. 2007, 37, 1659.

84. Jiang, W-Q.; An, L-T.; Zou, J-P. Chin. J. Chem. 2008, 26, 1697.

85. An, L-T.; Lu, X-H.; Ding, F-Q.; Jiang, W-Q.; Zou, J-P. Chin. J. Chem. 2008, 26, 2117.

86. Nandi, G. C.; Samai, S.; Kumar, R.; Singh, M. S. Tetrahedron Lett. 2009, 50, 7220.

87. Das, B.; Kumar, D. N.; Laxminarayana, K.; Ravikanth, B. Helv. Chim. Acta 2007, 90, 1330.

88. Zandi, M.; Sardarian, A. R. C. R. Chimie 2012, 15, 365.

89. Zhang, Q.; Luo, J.; Wei, Y. Green Chem. 2010, 12, 2246.

90. Luo, J.; Zhang, Q. Monatsh. Chem. 2011, 142, 923.

91. Kumar, A.; Rao, M. S.; Ahmad, I.; Khungar, B. Can. J. Chem. 2009, 87, 714.

92. Srihari, G.; Nagaraju, M.; Murthy, M. M. Helv. Chim. Acta 2007, 90, 1497.

93. Rani, V. J.; Suresh, M.; Lavanya, P.; Vani, K. V.; Nagarjuna, B.; Rao, C. V. Pharma Chemica 2010, 2, 224.

94. Wang, M.; Liang, Y. Monatsh. Chem. 2011, 142, 153.

95. Song, Z.; Zhao, S.; Wan, X. Chin. J. Org. Chem. 2011, 31, 870.

96. Wang, M.; Liang, Y.; Zhang, T.; Gao, J. Chin. J. Chem. 2011, 29, 1656.

97. Wang, M.; Liang, Y.; Zhang, T. T.; Gao, J. J. Chin. Chem. Lett. 2012, 23, 65.

98. Kundu, D.; Majee, A.; Hajra, A. Catal. Commun. 2010, 11, 1157.

99. Lei, M.; Ma, L.; Hu, L. Tetrahedron Lett. 2009, 50, 6393.

100. Khavasi, H. R.; Bazgir, A.; Amani, V.; Rahimi, R. J. Chem. Res. 2008, 450.

101. Bahrami, M. J.; Hosseini, S. M. A.; Pilvar, P. Corros. Sci. 2010, 52, 2793.

102. Sabitha, G.; Arundhathi, K.; Sudhakar, K.; Sastry, B. S.; Yadav, J. S. J. Heterocycl. Chem. 2010, 47, 272.

103. Nizam, A.; Päsha, M. A. Synth. Commun. 2010, 40, 2864.

104. Chaskar, A.; Vyavhare, V.; Padalkar, V.; Phatangare, K.; Deokar, H. J. Serb. Chem. Soc. 2011, 76, 21.

105. Rao, G. B. D.; Kaushik, M. P.; Halve, A. K. Tetrahedron Lett. 2012, 53, 2741.

106. Eshghi, H.; Zohuri, G. H.; Damavandi, S. Synth. Commun. 2012, 42, 516. 
107. Ghorbani-Vaghei, R.; Malaekehpour, S. M. Cent. Eur. J. Chem. 2010, 8, 1086.

108. Bazgir, A.; Amani, V.; Khavasi, H. R. Acta Cryst. 2006, E62, 3875.

109. Kumar, A.; Saxena, A.; Dewan, M.; De, A.; Mozumdar, S. Tetrahedron Lett. 2011, 52, 4835 .

110. Dabiri, M.; Delbari, A. S., Bazgir, A. Synlett 2007, 821.

111. Shakibaei, G. I.; Khavasi, H. R.; Mirzaei, P.; Bazgir, A. J. Heterocycl. Chem. 2008, 45, 1481.

112. Hajra, A.; Kundu, D.; Majee, A. J. Heterocycl. Chem. 2009, 46, 1019.

113. Foroughifar, N.; Mobinikhaledi, A.; Moghanian, H.; Ebrahimi, S.; Fard, M. A. B. Synlett 2008, 821.

114. Zhang, Z-P.; Wen, J-M.; Li, J-H.; Hu, W-X. J. Chem. Res. 2009, 162.

115. Foroughifar, N.; Mobinikhaledi, A.; Moghanian, H. Synth. Commun. 2009, 39, 3668.

116. Dabiri, M.; Delbari, A. S.; Bazgir, A. Heterocycles 2007, 71, 543.

117. Heravi, M. M.; Tavakoli-Hoseini, N., Bamoharram, F. F. Green Chem. Lett. Rev. 2010, $3,263$.

118. Mosslemin, M. H.; Nateghi, M. R.; Mohebat, R. Monatsh. Chem. 2008, 139, 1247.

119. Shaterian, H. R.; Hosseinian, A.; Ghashang, M. Tetrahedron Lett. 2008, 49, 5804.

120. Shaterian, H. R.; Hosseinian, A.; Ghashang, M. Chin. J. Chem. 2009, 27, 821.

121. Shaterian, H. R.; Hosseinian, A.; Ghashang, M. Synth. Commun. 2009, 39, 2560.

122. Tavakoli-Hoseini, N.; Heravi, M. M.; Bamoharram, F. F.; Davoodnia, A. Bull. Korean Chem. Soc. 2011, 32, 787.

123. Shafiee, M. R. M.; Moloudi, R.; Ghashang, M. J. Chem. Res. 2011, 35, 622.

124. Jaratjaroonphong, J.; Krajangsri, S.; Reutrakul, V. Tetrahedron Lett. 2012, 53, 2476.

125. Sato, F.; Ikobe, A.; Koizumi, T.; Katsuno, K; Kobayashi, Y. Jpn. Kokai Tokkyo Koho JP $09059233,1997$.

126. Okano, H.; Motoyanagi, Y.; Cho, N.; Yoshinaga, T.; Tsuru, T.; Mukae, K. Synthesis 2004, 341.

127. Tsuzuki, Y.; Chiba, K.; Mizuno, K.; Tomita, K.; Suzuki, K. Tetrahedron: Asymmetry 2001, 12, 2989.

128. Carter, H. E.; Frank, R. L.; Johnston, H. W. Org. Synth. Coll. Vol. 1955, 3, 167.

129. Khosropour, A. R.; Khodaei, M. M.; Moghanian, H. Synlett 2005, 955.

130. Sztojkov-Ivanov, A.; Tóth, D.; Szatmári, I.; Fülöp, F.; Péter, A. Chirality 2007, 19, 374.

131. Taft, R. W.; Topsom, R. D. Prog. Phys. Org. Chem. 1987, 16, 1-83.

132. Hansch, C.; Leo, A.; Taft, R. W. Chem. Rev. 1991, 91, 165. 
133. Diedrich, C. L. Eur. J. Org. Chem. 2008, 10, 1811.

134. Sanz, P.; Mó, O.; Yáñez, M.; Elguero, J. J. Phys. Chem. A 2007, 111, 3585.

135. Waibel, M.; Hasserodt, J. Tetrahedron Lett. 2009, 50, 2767.

136. Klod, S.; Kleinpeter, E. J. Chem. Soc., Perkin Trans. 2 2002, 1893.

137. Klod, S.; Koch, A.; Kleinpeter, E. J. Chem. Soc., Perkin Trans. 2, 2002, 1506.

138. Kleinpeter, E.; Koch, A.; Seidl, P. R. J. Phys. Chem. A 2008, 112, 4989.

139. (a) Mohamadi, F.; Richard, N. G. J.; Guida, W. C.; Liskamp R.; Lipton, M.; Caufield, C.; Chang, G.; Hendrickson, T.; Still, W. C. J. Comput. Chem. 1990, 11, 440.; (b) MacroModel, Schrödinger LLC, 2009. http://www.schrodinger.com/Products/ macromodel html.

140. Frisch, M. J.; Trucks, G. W.; Schlegel, H. B.; Scuseria, G. E.; Robb, M. A.; Cheeseman, J. R.; Montgomery, Jr., J. A.; Vreven, T.; Kudin, K. N.; Burant, J. C.; Millam, J. M.; Iyengar, S. S.; Tomasi, J.; Barone, V.; Mennucci, B.; Cossi, M.; Scalmani, G.; Rega, N.; Petersson, G. A.; Nakatsuji, H.; Hada, M.; Ehara, M.; Toyota, K.; Fukuda, R.; Hasegawa, J.; Ishida, M.; Nakajima, T.; Honda, Y.; Kitao, O.; Nakai, H.; Klene, M.; Li, X.; Knox, J. E.; Hratchian, H. P.; Cross, J. B.; Bakken, V.; Adamo, C.; Jaramillo, J.; Gomperts, R.; Stratmann, R. E.; Yazyev, O.; Austin, A. J.; Cammi, R.; Pomelli, C.; Ochterski, J. W.; Ayala, P. Y.; Morokuma, K.; Voth, G. A.; Salvador, P.; Dannenberg, J. J.; Zakrzewski, V. G.; Dapprich, S.; Daniels, A. D.; Strain, M. C.; Farkas, O.; Malick, D. K.; Rabuck, A. D.; Raghavachari, K.; Foresman, J. B.; Ortiz, J. V.; Cui, Q.; Baboul, A. G.; Clifford, S.; Cioslowski, J.; Stefanov, B. B.; Liu, G.; Liashenko, A.; Piskorz, P.; Komaromi, I.; Martin, R. L.; Fox, D. J.; Keith, T.; Al-Laham, M. A.; Peng, C. Y.; Nanayakkara, A.; Challacombe, M.; Gill, P. M. W.; Johnson, B.; Chen, W.; Wong, M. W.; Gonzalez, C.; Pople, J. A. Gaussian 03, Revision C.02, 2004, Gaussian Inc., Wallingford CT.

141. Frisch, M. J.; Trucks, G. W.; Schlegel, H. B.; Scuseria, G. E.; Robb, M. A.; Cheeseman, J. R.; Scalmani, G.; Barone, V; Mennucci, B.; Petersson, G. A.; Nakatsuji, H.; Caricato, M.; Li, X.; Hratchian, H. P.; Izmaylov, A. F.; Bloino, J.; Zheng, G.; Sonnenberg, J. L.; Hada, M.; Ehara, M.; Toyota, K.; Fukuda, R.; Hasegawa, J.; Ishida, M.; Nakajima, T.; Honda, Y.; Kitao, O.; Nakai, H.; Vreven, T.; Montgomery, J. A.; Peralta, J. E. Jr.; Ogliaro, F.; Bearpark, M.; Heyd, J. J.; Brothers, E.; Kudin, K. N.; Staroverov, V. N.; Kobayashi, R.; Normand, J.; Raghavachari, K.; Rendell, A.; Burant, J. C.; Iyengar, S. S.; Tomasi, J.; Cossi, M.; Rega, N.; Millam, J. M.; Klene, M.; Knox, J. E.; Cross, J. B.; Bakken, V.; Adamo, C.; Jaramillo, J.; Gomperts, R.; Stratmann, R. E.; 
Yazyev, O.; Austin, A. J.; Cammi, R.; Pomelli, C.; Ochterski, J. W.; Martin, R. L.;

Morokuma, K.; Zakrzewski, V. G.; Voth, G. A.; Salvador, P.; Dannenberg, J. J.;

Dapprich, S.; Daniels, A. D.; Farkas, O.; Foresman, J. B.; Ortiz, J. V.; Cioslowski, J.;

Fox, D. J. Gaussian 09, Revision A.02, 2009, Gaussian, Inc., Wallingford CT.

142. Stephens, P. J.; Harada, N. Chirality 2010, 22, 229.

143. Flükiger, P.; Lüthi, H. P.; Portmann, S.; Weber, J. MOLEKEL 5.4., 2000-2002, Swiss Center for Scientific Computing, Manno, Switzerland.

144. Stewart, J. J. P. Comp. Chem. 1989, 10, 209.

145. Stewart, J. J. P. Comp. Chem. 1989, 10, 221.

146. Hehre, W. J.; Radom, L.; Schleyer P. v. R.; Pople, J. A. Ab Initio Molecular Orbital Theory Wiley, New York, 1986.

147. Becke, A. D. J. Chem. Phys. 1993, 98, 1372.

148. SYBYL 7.3, Tripos Inc., 1699 South Hanley Rd. St. Louis, MO 63144, USA 2006.

149. Gauss View 2.0, Gaussian Inc. Carnegie Office Park, Building 6, Pittsburgh, PA 15106, USA.

150. Tomasi, J.; Mennucci, B.; Cammi, R. Chem. Rev. 2005, 105, 2999. 


\section{ANNEX}

